University of St.Gallen

«THE ROLE OF LEVERAGED ETFS AND OPTION MARKET IMBALANCES ON END-OF-DAY PRICE DYNAMICS»

ANDREA BARBON

HEINER BECKMEYER

ANDREA BURASCHI

MATHIS MOERKE

WORKING PAPERS ON FINANCE NO. 2021/14

SWISS INSTITUTE OF BANKING AND FINANCE (S/BF - HSG)

SEPTEMBER, 2021 


\title{
The Role of Leveraged ETFs and Option Market Imbalances on End-of-Day Price Dynamics*
}

\author{
Andrea Barbon` Heiner Beckmeyer; Andrea Buraschi§ Mathis Moerke $\mathbb{I}^{\ddagger}$
}

\begin{abstract}
Leveraged ETFs and market makers who are active in option markets must adjust imbalances arising from market movements. Establishing delta-neutrality may cause either return momentum or reversal depending on the sign and size of the imbalance vis-a-vis market prevailing liquidity. We find that a large and negative (positive) aggregated gamma imbalance, relative to the average dollar volume, gives rise to an economically and statistically significant end-of-day momentum (reversal). We compare this channel to the rebalancing of leveraged ETFs and find that the effect generated by leveraged ETFs is economically larger. Consistent with the notion of temporary price pressure, the documented effects quickly revert at the next day's open. Information-based explanations are unlikely to cause the results, suggesting a non-informational channel through which leveraged ETFs and option markets affect underlying stocks towards the market close.
\end{abstract}

JEL classification: G12, G13, G14, G23

Keywords: Intraday Momentum, Cross-Sectional Momentum, Gamma Exposure, Option Market Maker, Leveraged ETF

*We thank Dmitriy Muravyev, Mahendrarajah Nimalendran (discussant) and Angelo Ranaldo, as well as participants at the 37th International Conference of the French Finance Association, the EFMA annual meeting 2021, the 5th SAFE Market Microstructure Conference and the Brown Bag Seminar of the University of St.Gallen for insightful and constructive comments. This paper has been previously circulated under the title End-of-Day Momentum and Option Hedging.

†Swiss Institute of Banking and Finance, University of St.Gallen, Unterer Graben 21, 9000 St.Gallen, Switzerland. Email: andrea.barbon@unisg.ch.

${ }^{\ddagger}$ School of Business and Economics, Finance Center Müunster, University of Münster, Universitätsstr. 14-16, 48143 Münster, Germany. E-mail: heiner.beckmeyer@wiwi.uni-muenster.de

IImperial College, 53 Prince's Gate, London SW7 2AZ, United Kingdom, Email: andrea.buraschi@impeiral.ac.uk

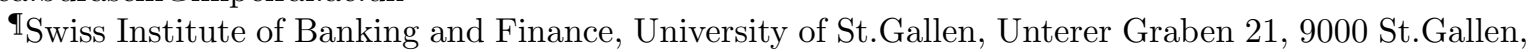
Switzerland. Email: mathis.moerke@unisg.ch. 


\section{Introduction}

We investigate the potential links between large portfolio rebalancing effects due to hedging strategies used by option market makers and leveraged ETFs, the intraday dynamics of stock prices (momentum and reversal), and abnormal changes in end-of-day volatility.

The role of options markets and leveraged ETFs on the dynamics on the underlying stock prices has recently garnered a lot of attention, attracting negative press coverage for potentially contributing to market volatility during already turbulent times. ${ }^{1}$ Just recently, the trading activities in options was blamed to increase the violent stock swings during the February-March 2020 Covid-19 selloff. The Wall Street Journal wrote:

"Investors searching for clues on what drove the back-to-back drops in the stock market are pointing to the options market as a contributor, saying hedging activity by traders may have exacerbated the decline."

Wall Street Journal, Feb. 27, 2020²

While it is widely accepted that options are non-redundant and may directly influence the price of the underlying (Black, 1975), we lack a clear quantification of these effects in individual stocks and how they relate to end-of-day price dynamics. We study the role of two distinct institutional channels.

The first channel relates to the activity of (option) market makers. Market makers and broker/dealers provide liquidity to clients who want to take positions in stock options. However, they have institutional incentives to avoid directional exposures and they usually delta-hedge their positions. Since the option delta changes when the value of the underlying changes, market makers need to regularly update their positions to maintain delta neutrality.

The direction of the price pressure exerted by the market maker depends on its initial gamma imbalance and the price movement of the underlying asset. Suppose, for instance, that the price of a stock has a positive jump, due to some positive unexpected fundamental news about future cash flows. If the gamma of the market maker positions is initially negative, maintaining delta-neutrality requires the purchase of additional shares in the underlying stock. On the contrary, an initial positive net gamma requires selling

\footnotetext{
${ }^{1}$ See for example Davies (2019).

${ }^{2}$ https://www.wsj.com/articles/the-invisible-forces-exacerbating-market-swings11582804802
} 
the underlying asset. Thus, if the aggregate gamma of market makers is significant negative, delta-hedging could give rise to significant net purchase contributing to end-of-day momentum. On the contrary, if the aggregate gamma imbalance of market makers were positive, delta-hedging would have a stabilizing effect in the form of end-of-day reversal.

Notice that derivative markets are by construction zero-sum games. For each option, there is a buyer and a seller. Therefore, the overall dollar value of aggregate gamma for each option is zero across all purchasers and sellers. However, certain market participants may have different incentives to hedge. Thus, in the cross-section one can observe a distribution of delta and gamma imbalances. Market makers are obliged to uphold liquidity in the options market and facilitate the efficiency of trades. They refrain from taking any directional bets on the underlying stocks and hence, hedge their option delta-exposure, for example to manage their risk exposure towards non-trading periods.

The second source of institutional frictions relates to the end-of-day mechanical rebalancing of leveraged ETFs. The mechanism is simple. For a normal ETF the payoff is equal to the value of the referenced portfolio. Thus, the required notional exposure is identical to the actual exposure. Leveraged ETFs are synthetic instruments created with total return swaps whose notional principal is a multiple of the value of a referenced portfolio. Thus, different than for a normal ETF, a price appreciation of the underlying asset portfolio has the compounded effect of increasing both the referenced portfolio and the required notional value of the swap. As a consequence, any price appreciation or drop gives rise to an imbalance between the required and effective notional amount of the swap. The swap counterparty has to manage her exposure to the underlying ETF, thus potentially inducing a large rebalancing of the portfolio of physical assets used to hedge the swap (see Section 2.3). Cheng and Madhavan (2010) argues that the portfolio rebalancing of leveraged ETFs may have an impact on intraday prices.

Figure 1 (top panel) illustrates the rebalancing effects caused by option market makers and leveraged ETFs towards the end of the trading day. The upper panel shows the intraday return path for Tesla stock on 13 December 2012. At the beginning of the day, the aggregate gamma was positive and economically significant. During the day, Tesla experienced a negative return equal to $-6.62 \%$ by until 15:30. Based on the information available, the gamma imbalanced implied that delta-hedgers needed to trade an amount equal to $102.11 \%$ of the average dollar trading volume of Tesla shares in the last halfhour. As Figure 1 illustrates, a strong price reversal emerged in the last 30 minutes of the trading day, which is consistent with the large initial positive gamma imbalance.

An interesting example that relates to the role of leveraged ETFs is provided by 
the dynamics of Apple stock on 24 October 2018, see Figure 1 (middle panel). Apple stocks are an important stock for leveraged ETFs. At the same time, at the beginning of the trading day the aggregate gamma of market makers was close to zero. By 15:30, Apple shares had dropped by $-2.24 \%$. As a consequence, leveraged ETF had to sell large quantities of Apple shares to rebalance their portfolio of leveraged swaps for an estimated dollar amount equal to $8.85 \%$ of the average dollar daily trading volume in Apple shares. Possibly as a result, the price dropped further by $-1.22 \%$.

The timing of delta-hedging by market makers and portfolio rebalancing by leveraged ETFs can be different. Figure 1 (bottom panel) illustrates this heterogeneity and the potential effect on the price dynamics. On 23 June 2016, the gamma imbalance of market makers on Amazon stock options was large and positive. At the opening, the price dropped by almost $4 \%$. The implied hedging demand by likely delta-hedgers required purchasing shares for approximately $50 \%$ of the average dollar volume in Amazon shares. Consistently, the share price started to mean revert, albeit not completely. At 15:30 the share price was $-3.27 \%$ lower than the previous day. Leveraged ETF had to rebalance, which caused further downward pressure as it emerged shortly before the market closing.

There are two important differences between these two channels. First, the direction of the price pressure from leveraged ETFs only depends on the return on the benchmark index which the leveraged ETF promises to track as a multiple. ${ }^{3}$ Hence, the price pressure can support dynamics consistent with intraday momentum. On the other hand, the price pressure exerted by the rebalancing of market makers depends on the sign of their gamma imbalance and the effect can be consistent with either a momentum or meanreversion effect. Second, while option market makers have discretion on the execution of their hedging strategies, leveraged ETF swap counterparties are required to establish the target exposure of the fund at the close. We thus expect larger effects of leveraged ETF rebalancing on end-of-day returns. ${ }^{4}$ Third, the demand pressure arising from leveraged ETFs is common effect across all stocks which are part of the index referenced by these ETFs. On the other hand, the market makers gamma imbalance is stock specific and

\footnotetext{
${ }^{3}$ There are generally two types of leveraged ETFs, bull funds that promise to deliver a multiple of the underlying ETF's return, and bear funds, which are designed to generate a multiple of the opposite return of the index.

${ }^{4}$ While market makers should hedge continuously, whenever a large intraday price movement emerges, the existence of frictions may create incentives for them to delay their hedging and distribute implied price pressure during the day (Clewlow and Hodges, 1997). Indeed, liquidity and volume patterns are attractive at the open and close, as previous studies have documented a U-shape end-of-day volume pattern (Andersen and Bollerslev, 1997). It is certainly unusual for market makers to remain unhedged when markets are closed due to the significant overnight gap risks and regulations such as BIS capital requirements that make it costly to hold overnight positions due to higher capital costs.
} 

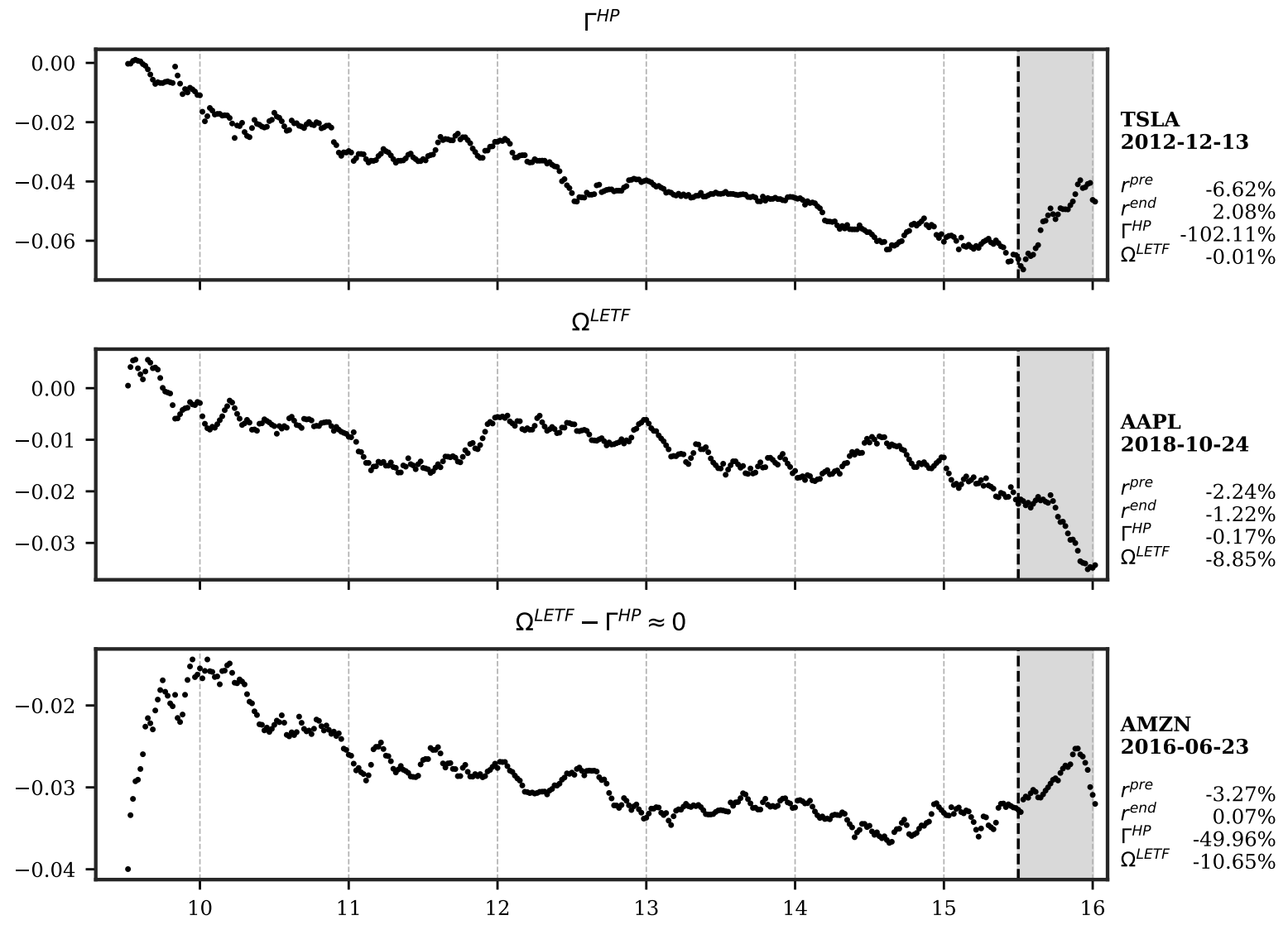

Fig. 1. Delta-Hedging and Leveraged ETF Rebalancing Effects

The figure depicts the effects of delta-hedging and leveraged ETF rebalancing on three days in our sample for Tesla (TSLA), Apple (AAPL), and Amazon (AMZN) stock, respectively. $r^{\text {pre }}$ denotes the return from previous day's close price until 15:30. $r^{\text {end }}$ denotes the return from 15:30 to close. $\Gamma^{H P}$ is defined in Equation 5 and is the product of $r^{\text {pre }}$ and the aggregate gamma imbalance, $\Gamma^{I B} \cdot \Omega^{L E T F}$ is the measure for leveraged ETF rebalancing, defined in Equation (6). $\Gamma^{H P}$ and $\Omega^{L E T F}$ are expressed in relative terms to the average dollar trading volume in the last half hour over the last quarter.

it can be, at the same time, positive for one stock and negative for another. This may generate mean-reversal for a set of stocks and intra-day momentum for others.

We build a unique dataset that merges data from several option exchanges providing the identity of all option counterparties and the portfolio composition of 72 leveraged ETFs for 24 underlying benchmark ETFs, which represents almost the whole universe of leveraged ETFs on U.S. equity indexes. After computing the gamma imbalance of market makers and the rebalancing demand of leveraged ETFs, we use intraday TAQ 
data to study the potential implications on intraday price dynamics. We ask three related questions: First, is there an empirical correlation between the required portfolio rebalancing of leveraged ETFs, the gamma imbalance of market makers, and end-of-day price dynamics? What is the relative importance of these two channels? Second, given the emergence of a price jump during the trading day, what is the extent to which the resulting portfolio imbalances are absorbed during the trading day versus at the market closure? Third, how does the effect hold up in different subsamples and over time? Is the effect more pronounced for small or large stocks? While large stocks are often more liquid, they are more often part of those indexes that are referenced by leveraged ETFs.

First, we investigate both effects in isolation. We find that end-of-day returns and orderflow measured by signed trading volume are correlated with a measure of deltahedging required by market makers to neutralize price changes that have occurred until 15:30. When this hedging-pressure is positive (negative), we observe abnormal selling (buying) pressure at the close, which directly translates into lower (higher) returns. This effect is robust to a series of control variables suggested in the literature, such as the trading volume in the option relative to the market (Roll, Schwartz, and Subrahmanyam, 2010), the put/call ratio (Blau, Nguyen, and Whitby, 2014), and properties of the implied volatility. Turning to the impact of rebalancing flows originating from leveraged ETF replication, we find large effects on both end-of-day orderflow and returns. The riskiness of the stock position does not drive our results.

Next, we compare the two effects on a joint dataset, comprising all stocks that are optionable and included in at least one leveraged ETF. First, the effect by leveraged ETFs on end-of-day returns is larger in terms of economic and statistical significance. A one standard-deviation increase in the $\Gamma$ hedging pressure depresses end-of-day returns by $-211 \%$ of the average return in the last thirty minutes of a trading day. A one standarddeviation increase in leveraged ETF rebalancing flows increases end-of-day returns by $403 \%$ of the average return in the last half hour. Moreover, we find that the impact of both rebalancing sources is amplified when controlling for the magnitude of the other. This is most evident when we condition on days where both sources agree to buy (sell) the underlying stock.

To assess the economic significance of the cross-sectional impact of these rebalancing flows, we design a long-short strategy that uses as conditional signal the estimated demand pressure. We find that the average annualized return of the strategy is positive, unexplained by traditional risk factors, and orthogonal to the market return at the close. The annualized Sharpe-ratio is about 3 (5), with a success rate of $58.13 \%$ (61.91\%), using 
a value-weighted (equal-weighted) portfolio.

A central question in our analysis regards the timing of the portfolio rebalancing. While theoretical arguments imply that hedging activity should be done instantaneously by market makers, the presence of frictions delay the hedging activity to the end-of-day when liquidity is deeper. We empirically address this question by varying the intraday hedging window at 30 minute intervals, between 10:00 and 16:00. We find supporting evidence that a significant component of the hedging activity of option market makers takes place toward the end of the trading day (an hour before the close); at the same time, leveraged ETFs unequivocally implement their portfolio rebalancing at the close.

Building on this insight, we also investigate how quickly option market makers actively hedge following a large price shock in the underlying. If the large movement has occurred early during the trading day, we find that the hedging activity is almost immediate. In contrast, the rebalancing activity of leveraged ETFs is unrelated to intraday jumps and takes place solely end-of-day.

Furthermore, we find that the estimated impact of option market maker is robust to the presence of absence of fundamental news about the underlying stock. We consider both earnings announcements and the release of material news as identified by RavenPack.

If portfolio rebalancing and hedging activities substantially distorts prices at the close, we expect other market participants to correct this mispricing at the next open. Indeed, we find that more than $80 \%$ of the impact of market makers and a third of the impact of leveraged ETFs is reversed at the next open, highlighting the transitory nature of the phenomenon.

Using rolling three-year subsamples, we provide evidence that the impact of both channels has been both economically and statistically significant in all subsamples between 2012 and 2019. Additionally, we find that the impact of delta-hedging has increased over time, whereas it remained constant for leveraged ETF rebalancing.

The effects of delta-hedging on the price of the underlying are more pronounced for large stocks. This is due to the larger dollar open interest of high market capitalization stocks, which skews the $\Gamma$-imbalance distribution towards them. On the other hand, the impact of leveraged ETF rebalancing is symmetric between large and small stocks.

We provide a battery of robustness checks, relating to the empirical setup, the assumption regarding who engages into delta-hedging, different ways to measure average and risk-adjusted returns, and confirm that our results are unaffected by the respective company's industry. Furthermore, we address concerns regarding the possibility that changes in the options inventory of market makers in response to private and/or public 
information on end-of-day returns explain our results (see Ni, Pearson, Poteshman, and White, 2020, for the effect of delta-hedging on stock return volatility).

\section{Related Literature}

Our work relates to four streams of the literature. The first stream studies the feedback effects of option markets on the underlying stock price dynamics. The literature generally distinguishes between two channels through which option trading may have an impact on the price of the underlying. $\mathrm{Hu}(2014)$ provides evidence that the information found in market makers' initial delta-hedges can significantly affect the price dynamics of the underlying. Other studies advocating an informational channel are Cremers and Weinbaum (2010) and Pan and Poteshman (2006). However, a non-informational channel may also be at work: Ni, Pearson, and Poteshman (2005) and Golez and Jackwerth (2012) document that rebalancing and unwinding of option market makers' delta hedges on or very close to expiration drive the prices of individual stocks and stock index futures towards option strike prices on option expiration dates. Lately, Ni et al. (2020) analyze the effects of $\Gamma$-imbalance on absolute returns and the autocorrelation of returns, based on theoretical models that predict a negative relation between stock volatility and $\Gamma$-imbalance. ${ }^{5}$ Whereas Ni et al. (2020) resort to daily data, Barbon and Buraschi (2020) concentrate on intraday price dynamics. They find that $\Gamma$-imbalance is negatively related to intraday volatility and document that $\Gamma$-imbalance can affect the frequency and magnitude of flash crashes. Finally, Baltussen, Da, Lammers, and Martens (2020) show that end-of-day momentum in many futures contracts concentrates on days with negative $\Gamma$-exposure of option market makers.

A different, but related stream of the literature studies the effects of market maker inventory. Gârleanu, Pedersen, and Poteshman (2009) have provided path-breaking work on how demand pressure affects option prices. A closely related study is by Fournier and Jacobs (2020). Johnson, Liang, and Liu (2016) investigate the forces behind the use of S\&P 500 index option and conclude that unspanned crash risk drives much of their demand. Related, Jacobs and Mai (2020) find a tight link between prices and demand in S\&P 500 and VIX options.

The third stream studies intraday return patterns. We find high-frequency return continuation in the cross-section of stock returns, consistent with evidence provided by

\footnotetext{
${ }^{5}$ For a theoretical foundation, see among others Frey and Stremme (1997), Frey (1998), Sircar and Papanicolaou (1998), Platen and Schweizer (1998), Wilmott and Schönbucher (2000).
} 
Gao, Han, Zhengzi Li, and Zhou (2018) and Baltussen et al. (2020). Both studies focus on aggregate investment vehicles, such as ETFs and index Futures. Gao et al. (2018) show that their effects are stronger on days with elevated volatility, which are typically also accompanied by higher trading volume. In the cross-section of stocks, we confirm the finding of Komarov (2017) that stocks performing best in the first half of the day will likely lose in the second half if controlled for market returns. Another study on shortterm return reversals is Heston, Korajczyk, and Sadka (2010). The authors show that the returns of a half-hour period have predictive power over the same half-hour periods for up to 40 days in the future, when controlling for the impact of the market. They relate this to the usage of trade mechanisms by institutional traders, designed to limit the relative price impact of their orders. More recently, studies link investor heterogeneity on the stock-level to cross-sectional intraday and overnight return variations. Lou, Polk, and Skouras (2019) hypothesize that different investor types trade predominately at different times throughout the trading day. Empirically, the authors document high persistence in overnight and intraday return components, which they find not on single-stock basis, but also for 14 equity strategies such as size, value or profitability. Bogousslavsky (2020) focuses only on intraday returns and finds that a mispricing factor earns positive returns up to the last half hour, consistent with the idea that arbitrageurs trading on mispricing reduce their positions at the end of the trading day.

Finally, the last streams focuses on the U.S. equity market closing auction. Bogousslavsky and Muravyev (2020) shows the share of daily volume in the closing auction has more than doubled from 2010 to 2018 . They attribute the increase in trading volume to the rise of indexing and ETFs.

\section{Data and Empirical Methodology}

To conduct our analysis we merge multiple databases.

\subsection{Data Sources}

Option Markets. The first dataset merges option data from five different exchanges: (a) the CBOE C1 exchange, (b) NASDAQ GEMX (GEMX), (c) NASDAQ International Security Exchange (ISE), (d) NASDAQ BX (NOBO), and (e) NASDAQ PHLX (PHLX). The dataset includes information on signed trading volume, the identity of the counterparties engaged in the trade. Since traders can execute the same order in different 
exchanges, we obtain this data. The sample starts in May 2005, when ISE data becomes available, then it adds PHLX data, which begins in January 2009, GEMX data, which starts in August 2013, and CBOE data, which starts at the beginning of 2010. Our sample ends in July of 2020.

Each of the five exchanges provides four categories of volume for each option series: open buy, open sell, close buy, and close sell. Each of the volume categories is further broken down into different types of market participants: broker/dealer, proprietary, and customer. ${ }^{6}$ Data is recorded at the close of every trade. For each type of market participant, we sum the buy and sell trades to estimate the long and short open interest at the trader-type level. The five exchanges cover a substantial proportion of the individual equity options market and it is, to the best of our knowledge, the most comprehensive dataset available at the moment. Nonetheless, we do not cover OTC option trading and other activity outside of these exchanges. ${ }^{7}$ We obtain daily bid and ask quotes, implied volatility, trading volume, open interest, and Greeks for each option contract from OptionMetrics. As individual stock options are of American type, OptionMetrics uses binomial trees to compute implied volatility and Greeks.

Leveraged ETFs. We obtain information on all leveraged ETFs from ETFGlobal for January 2012 through December 2019, including the leverage amount, the benchmark index referenced by the fund and the assets under management of each leveraged ETF at the daily frequency. We compute the constituents of the benchmark index of each leveraged ETF and use TAQ data to calculate intraday returns of each selected benchmark referenced by the leveraged ETF. Figure 2 reports the evolution of aggregate assets under management (AUM) of leveraged ETFs. This industry has grown rather significantly from about USD 40bn in 2012 to USD 130bn in 2020 in leverage-adjusted terms. Though the AUM in leveraged ETFs appears to be small compared to the total stock market capitalization, it should not obscure its impact on end-of-day returns. First, the AUM should be compared to the average dollar trading volume, instead of the market capitalization. The former is typically several orders of magnitude smaller than the latter. Second, as we argue in Section 2.3, the trading volume stemming from leveraged ETFs concentrate in a very short time window within the trading day. Third and foremost, the volume from leveraged ETFs is always directional.

Stock Markets. Information on the cash market for each individual stock is obtained

\footnotetext{
${ }^{6}$ In 2009 , the type of professional customer has been introduced alongside the customer. We merge professional customers with customers.

7 Ge, Lin, and Pearson 2016) estimate that ISE alone covers $30 \%$ of the total trading volume on individual equity options.
} 


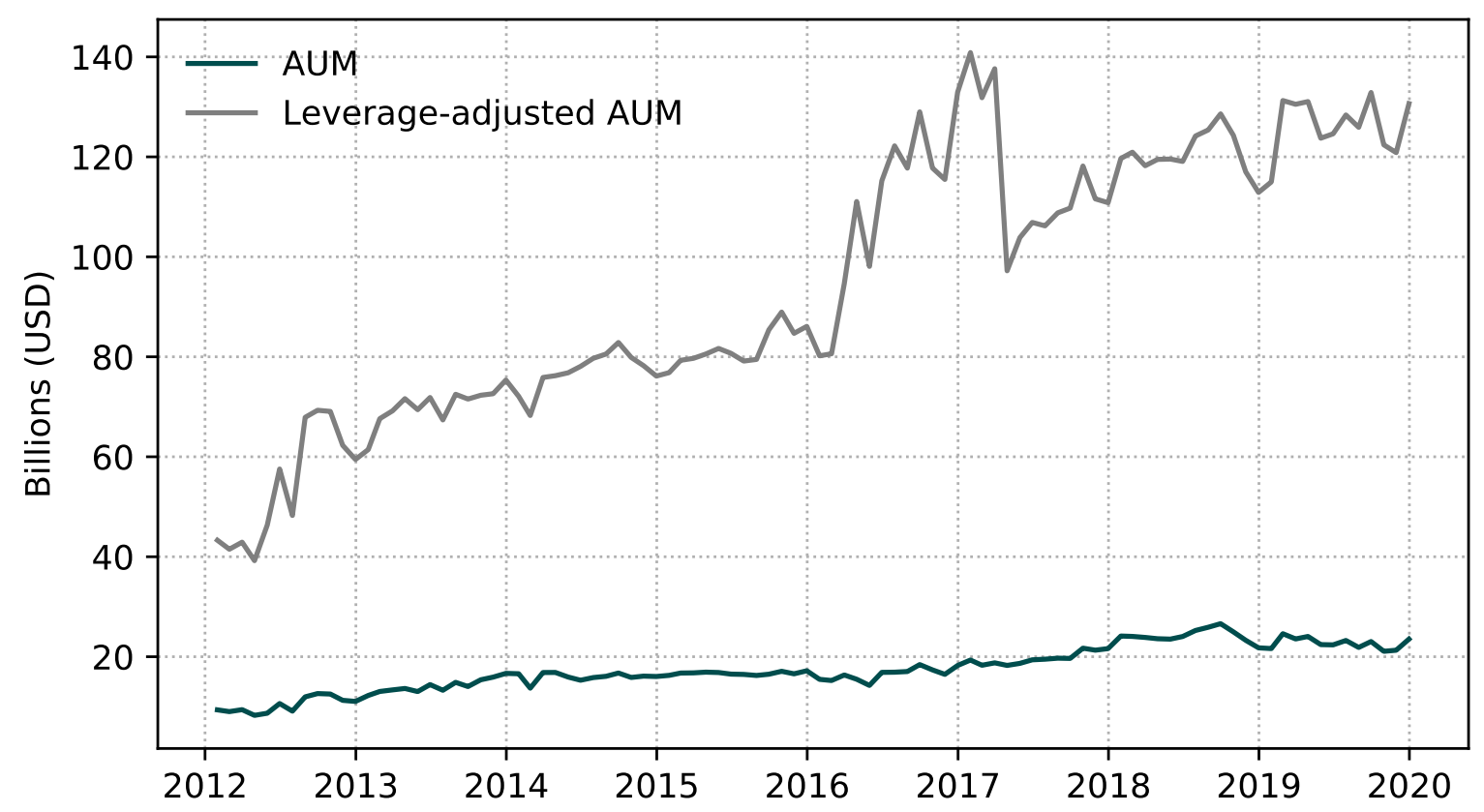

Fig. 2. Evolution of Leveraged ETF Assets under Management.

This figure shows the evolution of the assets under management (AUM) and leveraged-adjusted assets under management over time. Leverage-adjusted assets under management are computed by multiplying the assets under management by $L \times(L-1)$, where $L$ denotes the leverage factor, for each LETF-day observation. The sample period is from January 2012 to December 2019.

from the Center for Research on Security Prices (CRSP) and includes trading volume, shares outstanding, and closing prices. We restrict our analysis to stocks with CRSP share code 10 and 11, and exchange code 1, 2, 3, 31, 32, and 33. Information on any type of distribution (e.g. dividends and stock splits) is also obtained from CRSP. We match data from CRSP with our options data via the matching algorithm provided by WRDS.

High-frequency Data on Underlying Assets. Intraday stock price data and transaction volumes are obtained from TAQ. We use standard cleaning procedures and match intraday trade prices with CRSP to obtain PERMNOs as unique identifiers. More details are given in Appendix A. Equipped with intraday prices, we calculate intraday returns relative to the previous day's closing price. Following standard practice in the literature, (see Lou et al. 2019), we assume that corporate events that mechanically impact prices, e.g. dividend payments and stock splits, take place overnight and are realized at the time of the first trade on the target date. If a delisting occurs as reported by CRSP, we assume that the delisting amount is realized at the respective day's close.

Earning Announcements and News. Information on earnings announcement days are 
obtained from Compustat and I/B/E/S. Whenever the announcement date for the same stock differs between Compustat and I/B/E/S, we follow Dellavigna and Pollet (2009) and use the earlier date. Compustat and I/B/E/S are matched to our CRSP data via the matching algorithms provided by WRDS.

Finally, we use the Dow Jones version of Ravenpack News Analytics and its sentiment scores to identify days with significant news for each underlying. We restrict our news sample to articles that are most relevant for a particular stock, i.e. a relevance score of 100. Furthermore, we only include news which are highly positive (sentiment score above 0.75 ) or highly negative (sentiment score below 0.25 ).

To summarize, our sample include 3,428,010 observations on optionable stocks from May 2005 through July 2020, and 4,448,494 observations of stocks included in leveraged ETFs from January 2012 through December 2019. To study the relative importance of the two channels, we also consider a joint sample obtained from the intersection of these two. ${ }^{8}$ This comprises 1,979,544 observations from January 2012 through December 2019.

\subsection{Measuring Gamma Hedging Pressure}

Let $V(t, S)$ denote the value of an option contract. Then, $\Delta(t, S)=\frac{\partial V(t, S)}{\partial S}$ is the first derivative of the option price with respect to the underlying, whereas $\Gamma(t, S)=\frac{\partial^{2} V(t, S)}{\partial S^{2}}$ measures the change of $\Delta(t, S)$ for changes in $S$. When whereas $\Gamma(t, S)$ is non zero, $\Delta(t, S)$ changes over time and with the level of $S$ and any hedging has to be adjusted periodically. If $\Gamma(t, S)$ is large in absolute terms, $\Delta(t, S)$ is very sensitive to movements in the underlying and it implies a large amount of rebalancing for the market maker to remain delta-neutral.

Since makers and broker/dealers have similar hedging incentives, we classify both as "delta-hedgers". Consequently, we categorize proprietary and customer as non deltahedgers and refer to them jointly as end-customers in the remainder of the paper. To obtain the gamma imbalance of delta-hedgers, we proceed as follows.

Let $O I_{j, t}^{B u y, x}$ be the open interest of an investor of type $x$ in long positions in asset $j$

\footnotetext{
${ }^{8}$ To appear in the joint sample, each stock has to be optionable and included in one or more leveraged ETFs.
} 
at time $t$, which is relate to daily volume as follows:(see Ni et al., 2020)

$$
\begin{gathered}
O I_{j, t}^{\text {Buy,x }}=O I_{j, t-1}^{\text {Buy,x }}+\text { Volume }_{j, t}^{\text {OpenBuy,y }}-\text { Volume }_{j, t}^{\text {CloseSell }, y} \\
O I_{j, t}^{\text {Sell, } x}=O I_{j, t-1}^{\text {Sell, } x}+\text { Volume }_{j, t}^{\text {OpenSell }, y}-\text { Volume }_{j, t}^{\text {CloseBuy,y }},
\end{gathered}
$$

where $V_{\text {olume }}^{\text {OpenBuy,t }}$ and Volume ${ }_{j, t}^{\text {OpenSell,y }}$ denote the volume from investor type $y$ to open new long and short option positions, and Volume CloseBuy,y $_{j, t}$ and Volume CloseSell,y $_{j, t}$ refer to volumes with which investor type $y$ has closed existing long and short positions, respectively.

Second, we calculate the delta-hedger net open interest in option series $j$ at date $t$ 's close as

$$
n e t O I_{j, t}=-\left[O I_{j, t}^{\text {Buy,Customer }}-O I_{j, t}^{\text {Sell,Customer }}+O I_{j, t}^{\text {Buy,Proprietary }}-O I_{j, t}^{\text {Sell,Proprietary }}\right],
$$

where $n e t O I_{j, t}$ is measured in units of option contracts and $O I_{j, t}^{x, y}$ is the open interest of type $x$ (either buy or sell) by market participant type $y$ (either customer or proprietary) in option series $j$ at the close of date $t$. The net open interest of market makers is the opposite of the sum of the remaining market participant types. Assuming that broker/dealers are also delta-hedgers, we arrive at Equation (3).

Let $\Gamma_{j}(t, S)$ denote the gamma of option series $j$ at day $t$ and stock price $S$, expressed in shares of the underlying. To compute the day $t$ delta-hedger dollar gamma imbalance in option series $j$, we take the product of $\Gamma(t, S)$ with the stock price $S$ at 15:30 on the target day and multiply by the contract multiplier Mult $_{j}$ of $j$ (typically Mult $_{j}=100$ ). ${ }^{9}$

To obtain the aggregated gamma imbalance on an underlying stock, denoted by $\Gamma^{I B}(t, S)$, we compute the sum over all options on the underlying:

$$
\Gamma^{I B}(t, S)=\underbrace{\left(\sum_{j} \text { netOI } I_{j, t-1} \times \Gamma_{j}\left(t-1, S_{t-1}^{\text {close }}\right) \times S_{t}^{15: 30} \times M u l t_{j}\right)}_{(\star)} \times \frac{S_{t-1}^{\text {close }}}{100} \times \frac{1}{A D V_{t-1}} .
$$

The term $(\star)$ in Equation (4) denotes the total dollar gamma imbalance for a given stock at day $t$. It is the dollar amount delta-hedgers need to trade in the underlying

\footnotetext{
${ }^{9}$ Since we cannot observe intraday variations of the net open interest, we assume that $\Gamma(t, S)$ only changes due to innovations in the stock price. We hence use the observed stock price at 15:30 on day $t$ to compute the best possible estimate of the amount to be traded by delta-hedgers.
} 
for each one-dollar move in the underlying stock price $S$. By multiplying $(\star)$ by the underlying price divided by 100, we obtain the dollar gamma imbalance for a one percent move in $S$. This facilitates comparison over time and in the cross-section. Finally, we scale by the average dollar volume in the last half hour of a trading day, $A D V_{t}$, computed over the last month. ${ }^{10}$ Thereby, we express the delta-hedgers' gamma imbalance in a given stock as a fraction of the typical trading taking place in the last half hour, which allows us to obtain a timely proxy for the potential price impact of hedging adjustments.

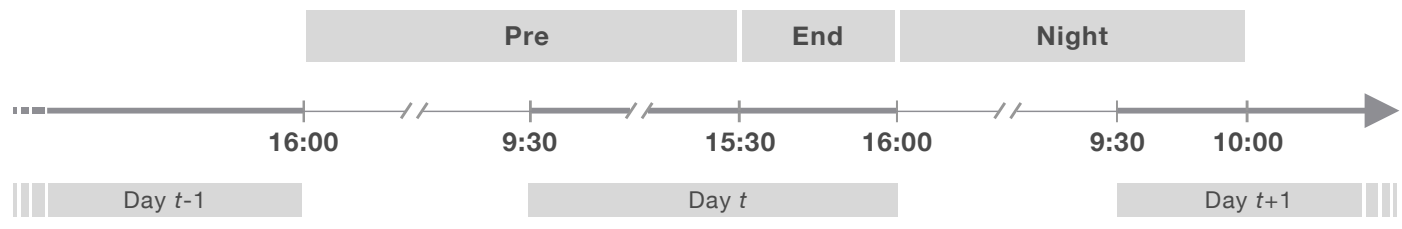

Fig. 3. Timeline.

$\Gamma^{I B}$ denotes the amount of hedging market makers would have to do for a $1 \%$-move in the underlying stock. We combine this measure with information on how much the underlying has actually moved before the start of the hedging window. The timeline is illustrated in Figure 4. The return from the close of day $t-1$ to the start of the hedging window at 15:30 is denoted as $r^{\text {pre }}$. The percentage hedging pressure is thus the interaction between $\Gamma^{I B}$ and $r^{\text {pre }}$ :

$$
\Gamma_{t}^{H P}=100 \times \Gamma^{I B}(t, S) \times r^{\mathrm{pre}}
$$

$\Gamma^{H P}$ is our main variable of interest. It directly captures the amount of hedging required for delta-hedgers to remain delta-neutral after observing intraday return $r^{\text {pre }}$

Obviously, our proxy for the delta hedging amount has some limitations. First, we cover only about 50-70\% of the transacted volume in equity options and, second, we rely solely on Gamma to approximate changes in the hedging amount. In an ideal setting we would be able to track intraday changes in the inventories of delta-hedgers, obtain intraday changes in deltas and a complete list of hedging times. These limitations introduce errors in our estimates, but as Ni et al. (2020) show bias regression coefficients toward zero. We hence argue that our analysis provides a lower bound for the real impact of gamma imbalance on stock prices.

\footnotetext{
${ }^{10}$ As Table OA3.1 shows, it is inconsequential to our main results if we compute the average dollar trading volume over a weekly or quarterly horizon. The same applies if we scale by the average absolute signed volume over the last month or the market capitalization.
} 


\subsection{Measuring LETF Rebalancing Pressure}

To understand how leveraged ETFs may contribute to intraday price momentum, let $L$ be the fund's leverage factor, say -3 for a bear and +3 for a bull fund, and $A_{t}$ the leveraged ETF's assets under management (AUM). The required notional amount of total return swaps at day $t$ is $S_{t}=L \times A_{t}$. Hence, if the return on the index at time $t+1$ is $r_{t+1}^{b e n c h}$, then $A_{t+1}=A_{t} \times\left(1+L \times r_{t+1}^{b e n c h}\right)$. Therefore, the required notional amount of total return swaps at $t+1$ becomes $S_{t+1}=L \times A_{t+1}=L \times A_{t} \times\left(1+L \times r_{t+1}^{\text {bench }}\right)$. However, the actual exposure of the total return swaps at $t+1$ is $E_{t+1}=S_{t} \times\left(1+r_{t+1}^{\text {bench }}\right)=L \times A_{t} \times\left(1+r_{t+1}^{\text {bench }}\right)$. The difference between the required and the actual notional is the rebalancing amount, equal to $S_{t+1}-E_{t+1}=L \times(L-1) \times A_{t} \times r_{t+1}^{b e n c h}$. Given that the required hedging multiple $L \times(L-1)$ is strictly positive for $L \in \mathbb{R} \backslash[0,1]$, leveraged ETF swap counterparties always have to trade in the same direction as the return of the underlying ETF, which may induce an end-of-day return momentum effect in the stocks included in the index referenced by the leveraged ETF. ${ }^{11}$ Hedging-demand originating from leveraged ETFs is proportional to the return on the underlying ETF, not to the return of an individual stock, as would be the case for the gamma imbalance effect. Therefore, leveraged ETF rebalancing may produce a return momentum in a stock, even if the specific stock's return is initially zero.

To compute the amount of rebalancing affecting an individual stock, let stock $j$ be included in the underlying of a leveraged ETF $i$ with a weight of $w_{i, j, t}$ at day $t$. If the swap counterparty starts rebalancing their exposure at 15:30, and $r_{i ; \text { bench }}^{\text {pre }}$ denotes the return on the benchmark ETF up until that point, the relative amount of rebalancing required in stock $j$ is equal to the sum of required rebalancing over all leveraged ETFs stock $j$ is included in:

$$
\Omega_{j, t}^{L E T F}=\frac{\sum_{i=1}^{N_{i, t}} L_{i} \times\left(L_{i}-1\right) \times A_{i, t-1} \times w_{i, j, t-1} \times r_{i ; \text { bench }}^{\mathrm{pre}}}{A D V_{j, t}}
$$

We scale by the average dollar volume in the last half hour to compare the impact of rebalancing with the average amount of trading at the close.

\footnotetext{
${ }^{11}$ We assume that returns swap providers (or their counterparties) ultimately need to hold a quantity of the underlying stock proportional to the size of the swap contract. If part of the swaps are based on other instruments or on correlated assets, this would introduce noise in our proxy and bias our results toward zero.
} 


\subsection{Summary Statistics}

In this Section we provide summary statistics for the gamma imbalance and leveraged ETF hedging pressure.

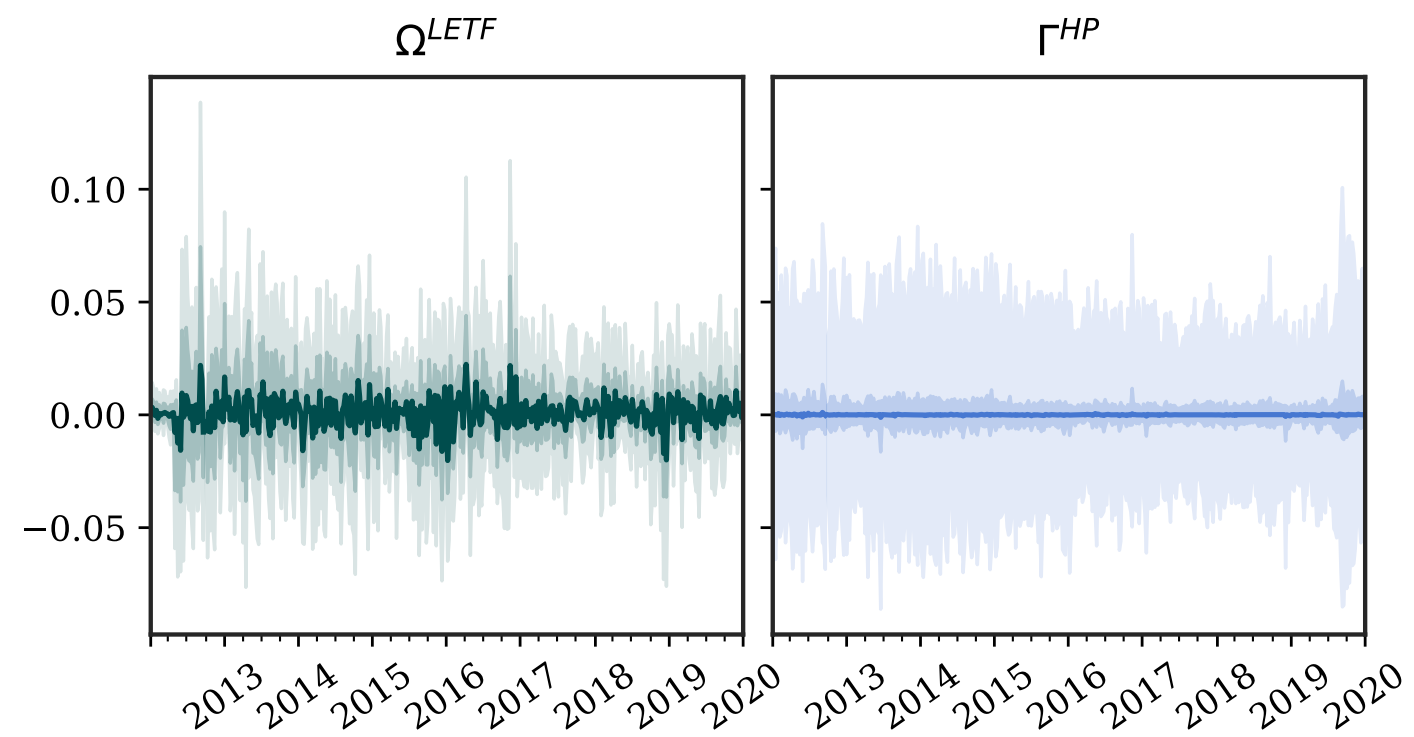

Fig. 4. $\Omega^{L E T F}$ vs. $\Gamma^{H P}$ over time

This figure shows weekly averages of the cross-sectional distribution of the demand pressure from the rebalancing of leveraged ETFs $\left(\Omega^{L E T F}\right)$ and Gamma imbalance $\left(\Gamma^{H P}\right)$. The dark line represents the cross-sectional median, the dark-colored area the 25 th/75th percentile, and the light-colored area the 5 th/95th percentile.

Figure 4 shows the cross-sectional distribution of $\Omega^{L E T F}$ over time and compares it with the distribution $\Gamma^{H P}$ in the joint sample. While both are time-varying, the crosssectional distribution of $\Omega^{L E T F}$ is wide, with a larger interquartile range, suggesting that on the same day market makers can have a large negative gamma imbalance on some stocks and, at the same time, a large positive gamma imbalance on another stock. Table B1 in the Appendix provides more granular summary statistics on $\Gamma^{H P}$ and $\Omega^{L E T F}$. Table B1 shows that the aggregate pressure arising from leveraged ETFs is normally higher than the one from delta-hedging. Moreover, it the distribution of absolute $\Gamma^{H P}$ has a heavy right tail.

Table 1 documents the economic significance of the demand pressure arising from the rebalancing activity of the leveraged ETFs and the delta hedging activity of market makers in the option market. The second column reports the average number of stocks in 
Table 1: The Cross-Section of Demand Pressure from Gamma and LETFs Rebalancing The table shows the average number $(\mathrm{N})$ and percentage (Share) of stocks per day with a combined rebalancing amount in the last 30 minutes of the trading day exceeding a certain threshold (first column), as a percentage of the average dollar volume. The forth column (\% Gamma) reports the proportion of the total demand pressure due to the Gamma imbalance $\Gamma^{H P}$ relative to the combined rebalancing amount: $\left|\Gamma^{H P}\right| /\left(\left|\Gamma^{H P}\right|+\left|\Omega^{L E T F}\right|\right)$, since $\Gamma^{H P}$ and $\Omega^{L E T F}$ are signed. Additionally, the table reports the average mean (Mean), standard deviation (Std) and 10\%- and 90\%-percentile of the share of the combined rebalancing amount conditional on exceeding the specified level. The sample contains stocks which are optionable and included in the benchmark index of at least one leveraged ETF. The sample period is from January 2012 - December 2019.

\begin{tabular}{lccccccc}
\hline & $\mathrm{N}$ & Share & \% Gamma & Mean & Std & $10 \%$ & $90 \%$ \\
\hline $1 \%$ & 601.7 & $60.23 \%$ & $49.95 \%$ & 5.11 & 8.29 & 1.30 & 9.81 \\
$2 \%$ & 354.4 & $35.48 \%$ & $55.76 \%$ & 7.68 & 10.41 & 2.86 & 13.67 \\
$5 \%$ & 182.6 & $18.28 \%$ & $63.01 \%$ & 12.07 & 13.72 & 5.47 & 20.28 \\
$10 \%$ & 69.5 & $6.95 \%$ & $71.86 \%$ & 21.23 & 19.63 & 10.83 & 34.30 \\
$15 \%$ & 34.0 & $3.41 \%$ & $76.47 \%$ & 30.50 & 24.34 & 16.43 & 48.97 \\
$25 \%$ & 12.5 & $1.25 \%$ & $80.91 \%$ & 49.00 & 31.88 & 28.92 & 76.72 \\
$50 \%$ & 3.4 & $0.34 \%$ & $84.75 \%$ & 94.33 & 44.86 & 72.69 & 122.20 \\
\hline
\end{tabular}

the joint sample for which the combined dollar rebalancing amount due to both channels exceeds a certain threshold (first column) of the average dollar volume in the last 30 minutes of the trading day $\left(\mathrm{ADV}^{\mathrm{end}}\right)$. We find that, on average, for 69 (12) stocks the combined rebalancing amount exceeds the $10 \%$ (25\%) threshold. For these stocks the average rebalancing dollar amount is equal to $21.23 \%(49.00 \%)$ of $\mathrm{ADV}^{\text {end }}$. The cross-sectional dispersion is large and for stocks in the 90th percentile (last column) the average rebalancing dollar amount exceeds $34.30 \%$ (76.72\%) of the total trading volume. The fourth column provides summary information about the relative importance of each channel. The majority of the rebalancing amount is driven by $\Gamma^{H P}$. For the group exceeding a rebalancing threshold of $10 \%(25 \%), 71.86 \%(80.91 \%)$ of the average absolute combined rebalancing originates from the hedging activity of option market makers. Moreover, Table 1 displays a monotonically increasing relationship between the share of $\Gamma^{H P}$ in the combined rebalancing amount and the threshold level suggesting that gamma imbalance from option market makers can have strong non-linear effects on the end-of-day trading.

An important difference between the two channels is that while a large and positive Gamma imbalance of a market maker could be compensated by a large and negative Gamma imbalance of another, for leveraged ETFs the hedging pressure is positively 
correlated, thus it could still have a larger price impact.

Table OA2.1 in the Online Appendix provides an overview of the properties of leveraged ETFs included in our sample. On average, we consider 72 leveraged ETFs for 24 underlying benchmark ETFs, with a cross-sectional distribution which is fairly stable over time. On average, $45 \%$ of the funds we consider are inverse, or bear funds. Weighted by the AUM (VW), this number drops to $33 \%$, but fluctuates more substantially over time, with a proportion of just $16 \%$ at the 10 th percentile and $63 \%$ at the 90 th. The average fund is leveraged by an absolute value of 2.35 .

\section{Empirical Methodology}

Consider the case in which $\Gamma_{t, j}^{I B}$ for stock $j$ at time $t$ is negative. If delta-hedgers want to maintain delta-neutrality, they will have to sell the underlying stock if it has depreciated intraday. Additionally, if $\Omega_{t, j}^{L E T F}$ is negative, rebalancing of leveraged ETFs will cause further downward price pressure. Table 2 provides an overview of these two effects. To conduct the empirical analysis, let us define the abnormal order flow in the last 30 minutes of trading day $t$ for stock $j$ as

$$
\mathrm{RSVOL}_{j, t}^{\mathrm{end}}=\mathrm{SVOL}_{j, t}^{\mathrm{end}} / \mathrm{ADV}_{j, t}^{\mathrm{end}}
$$

$\mathrm{SVOL}_{j, t}^{\text {end }}$ is the difference between the trading volumes in up- and down-minutes, defined as

$$
\mathrm{SVOL}_{j, t}^{\text {end }}=\sum_{m \in 15: 30 \rightarrow \text { Close }} \operatorname{VOL}_{j, t, m} \times \mathbb{1}_{r_{j, t, m}>0}-\sum_{m \in 15: 30 \rightarrow \text { Close }} \operatorname{VOL}_{j, t, m} \times \mathbb{1}_{r_{j, t, m}<0}
$$

where $m$ denotes the minutes within the hedging window for target day $t{ }^{12}$

Based on these considerations, we articulate the following hypothesis regarding deltahedging and LETF rebalancing effects.

$\mathbf{H O}^{\Gamma}$ : Positive (negative) Gamma hedging pressure leads to additional selling (buying) at the end of the trading day and, consequently, to negative (positive) end-of-day stock returns.

$\mathbf{H O}^{\Omega}$ : If the previous return on the benchmark index was positive (negative), the rebal-

\footnotetext{
${ }^{12}$ We scale by $\mathrm{ADV}^{\text {end }}$ to make the signed volume comparable across stocks in the cross-section and over time.
} 
ancing activity of leveraged ETF market makers adds to buying (selling) at the close and, consequently, to positive (negative) end-of-day stock returns.

Table 2: The Impact of $\Gamma^{H P}$ and $\Omega^{L E T F}$ on End-of-Day Returns

The table depicts the effects of $\Gamma^{H P}$, as defined in Equation (5), and $\Omega^{L E T F}$, as defined in Equation (6), on end-of-day returns. RSVOL denotes the relative signed trading volume, as defined in Equation (7). The upper half of the table visualizes the interaction of gamma imbalance $\Gamma^{I B}$ and the return until the last hour of the trading day, $r_{t}^{\text {pre }}$. The lower half of the table visualizes directly the impact of $\Omega^{L E T F}$ on $r_{t}^{\text {pre }}$.

\begin{tabular}{|c|c|c|}
\hline & $r_{t}^{\text {pre }}>0$ & $r_{t}^{\text {pre }}<0$ \\
\hline$\Gamma_{t-1}^{I B}>0$ & $\Gamma_{t}^{H P}>0 \Rightarrow$ RSVOL $\searrow \Rightarrow r_{t}^{\text {end }} \searrow$ & $\Gamma_{t}^{H P}<0 \Rightarrow$ RSVOL $\nearrow \Rightarrow r_{t}^{\text {end }} \nearrow$ \\
$\Gamma_{t-1}^{I B}<0$ & $\Gamma_{t}^{H P}<0 \Rightarrow \operatorname{RSVOL} \nearrow \Rightarrow r_{t}^{\text {end }} \nearrow$ & $\Gamma_{t}^{H P}>0 \Rightarrow$ RSVOL $\searrow \Rightarrow r_{t}^{\text {end }} \searrow$ \\
\hline$\Omega_{t-1}^{L E T F}>0$ & RSVOL $\nearrow \Rightarrow r_{t}^{\text {end }} \nearrow$ & RSVOL $\nearrow \Rightarrow r_{t}^{\text {end }} \nearrow$ \\
$\Omega_{t-1}^{L E T F}<0$ & RSVOL $\searrow \Rightarrow r_{t}^{\text {end }} \searrow$ & RSVOL $\searrow \Rightarrow r_{t}^{\text {end }} \searrow$ \\
\hline
\end{tabular}

An important difference between $\mathrm{H}^{\Gamma}$ and $\mathrm{H} 0^{\Omega}$ is in the cross-section. Since $\Gamma^{H P}$ can greatly differ across stocks even at the same time t, the effect is stock-specific. For $\Omega^{L E T F}$, in contrast, all stocks that belong to the same referenced index are exposed to the same price pressure.

\section{Empirical Results}

\subsection{Discretionary Rebalancing: Gamma Hedging Pressure}

Order Flow

The first part of $\mathrm{H} 0^{\Gamma}$ predicts that $\Gamma^{H P}$ is negatively related to the order flow of the underlying stock. We run panel regressions of the following form:

$$
\mathrm{RSVOL}_{j, t}^{\mathrm{end}}=\beta_{0} \Gamma_{j, t}^{H P}+\gamma^{\prime} \boldsymbol{X}_{j, t}+F E_{j}+F E_{t}+\epsilon_{j, t}
$$


where we include both asset $\left(F E_{j}\right)$ and date fixed effects $\left(F E_{t}\right)$ and $\boldsymbol{X}_{j, t}$ contains additional control variables. Standard errors throughout this paper are clustered by day $t$ and asset $j$. We weight return observations by the market capitalization in the previous month to rule out that our results are driven by microstructure effects in small stocks. $\mathrm{H} 0^{\Gamma}$ predicts that the sign of $\beta_{0}$ is negative

\section{Table 3: Option Hedging Pressure and End-of-day Order Flow}

The table reports the results of a regression of relative signed trading volume in the last half hour of a trading day on market maker hedging pressure $\Gamma^{H P}$, following Equation $(7) . I V_{t-1}$ denotes implied volatility at time $t-1 . \hat{R V} \hat{t}_{t}^{\text {end }}$ denote the square root of predicted realized variance for the time period from 15:30 to 16:00. $P C_{t-1}$ is the put-call-ratio and $O / S_{t-1}^{\Phi}$ denotes the option-to-stock volume in dollar terms. T-statistics in parentheses are derived from standard errors clustered by date and entity. ***, $* *, *$ denotes significance at the $1 \%, 5 \%, 10 \%$ level. We include entity fixed effects and weight returns by the stock's market capitalization. The sample period is May 2005 - July 2020.

\begin{tabular}{|c|c|c|c|c|c|}
\hline Dependent & $\begin{array}{c}(1) \\
\operatorname{RSVOL}_{t}^{\text {end }}\end{array}$ & $\begin{array}{c}(2) \\
\mathrm{RSVOL}_{t}^{\text {end }}\end{array}$ & $\begin{array}{c}(3) \\
\mathrm{RSVOL}_{t}^{\text {end }}\end{array}$ & $\begin{array}{c}(4) \\
\operatorname{RSVOL}_{t}^{\text {end }}\end{array}$ & $\begin{array}{c}(5) \\
\mathrm{RSVOL}_{t}^{\text {end }}\end{array}$ \\
\hline$\Gamma_{t}^{H P}$ & $\begin{array}{c}-13.368^{* * *} \\
(-3.892)\end{array}$ & $\begin{array}{c}-13.369 * * * \\
(-3.891)\end{array}$ & $\begin{array}{c}-13.372^{* * * *} \\
(-3.890)\end{array}$ & $\begin{array}{c}-13.378^{* * *} \\
(-3.894)\end{array}$ & $\begin{array}{c}-13.367^{* * *} \\
(-3.899)\end{array}$ \\
\hline$I V_{t-1}$ & & $\begin{array}{c}-0.434 \\
(-0.296)\end{array}$ & & & \\
\hline$\hat{R V_{t}^{e n d}}$ & & & $\begin{array}{l}73.938 \\
(0.628)\end{array}$ & & \\
\hline$P C_{t-1}$ & & & & $\begin{array}{c}0.689 * * \\
(2.170)\end{array}$ & \\
\hline$O / S_{t-1}^{\$}$ & & & & & $\begin{array}{c}1177.611 \\
(1.402)\end{array}$ \\
\hline Observations & $3,331,713$ & $3,331,713$ & $3,331,360$ & $3,325,116$ & $3,331,706$ \\
\hline Entity FE & Yes & Yes & Yes & Yes & Yes \\
\hline Time FE & Yes & Yes & Yes & Yes & Yes \\
\hline SEs & {$[\mathrm{t} ; \mathrm{j}]$} & {$[\mathrm{t} ; \mathrm{j}]$} & {$[\mathrm{t} ; \mathrm{j}]$} & {$[\mathrm{t} ; \mathrm{j}]$} & {$[\mathrm{t} ; \mathrm{j}]$} \\
\hline
\end{tabular}

Column (1) in Table 3 confirms our hypothesis. The slope coefficient of $\Gamma^{H P}$ is -13.37 (t-value: -3.89 ). It is statistically significantly different from zero at the $1 \%$ confidence level, and provides supporting evidence of a link between the hedging pressure of market makers due to their gamma imbalance and the order flow in the underlying stock. Economically, the result suggests that a $10 \%$ increase in $\Gamma^{H P}$ leads to abnormal selling pressure at the close of $-1.34 \%$ of $\mathrm{ADV}^{\mathrm{end}}$, or $-3.33 \%$ of the average absolute order flow 
at the close.

We investigate if the result is robust to alternative hypotheses. The first alternative hypothesis is that end-of-day effects are influenced by changes in the level of intraday risk. For instance, volatility-target investors might rebalance their portfolio away from risky assets towards the end of the trading day if the volatility changes. Option demand depends on investors expectations about future volatility. An increased demand of option open interest by retail and professional investors increases the short inventory of market makers and potentially their $\Gamma$ imbalance. In turn, this could lead to higher end-of-day hedging pressure. Specification in column (2) and (3) add the level of the at-the-money $I V$ on day $t-1$ and a forecast of future variance using an EGARCH model to the summed 1-minute squared returns for each stock in the last half hour of a trading day using historical data up until day $t-1$ (see Moskowitz, Ooi, and Pedersen (2012)). The results are provided in Columns (2) and (3), respectively. Neither of these two coefficients is significant, nor does the inclusion of either materially alter the coefficient and statistically significance of $\Gamma^{H P}$.

Besides risk-based explanations, our findings may arise from information being transmitted from the options to the equity market. A stream of the literature argues that options are often used because of their implicit leverage in presence of market frictions (for instance when short selling is expensive), e.g. (Ge et al., 2016). To this end, Blau et al. (2014) find that an increase in the put-call ratio negatively predicts future returns at the daily, weekly or monthly frequency. Roll et al. (2010) and $\mathrm{Hu}(2014)$ show that the option-to-stock volume predicts options' underlying returns. We extend the baseline regression and control for these explanatory variable. Columns (4) and (5) of Table 4 summarize the results. The slope coefficient of $\Gamma^{H P}$ is unchanged, both in magnitude and significance. Together, these findings confirm that our results are robust to extensions of the main specification that allow for a risk- or information-based explanation.

\section{End-of-day returns}

Given that higher hedging pressure from the options market is associated with additional signed volume at the end of the trading day, it is natural to study the extent to which this hedging pressure affects end-of-day stock returns. To test the second half of the joint hypothesis $\mathrm{H} 0^{\Gamma}$, we regress the returns from 15:30 to the close of day $t(r$ end $)$ onto $\Gamma^{H P}$, after controlling for the return from the open to 15:30 $\left(r^{\mathrm{pre}}\right)$. As in the previous 
specification we control for fixed effects and other control variables stock specific $\boldsymbol{X}_{j, t}$ :

$$
r_{j, t}^{\mathrm{end}}=\beta_{0} r_{j, t}^{\mathrm{pre}}+\beta_{1} \Gamma_{j, t}^{H P}+\gamma^{\prime} \boldsymbol{X}_{j, t}+F E_{j}+F E_{t}+\epsilon_{j, t}
$$

Table 4: End-of-day effects of Option Market Maker's Delta Rebalancing

The table summarizes the results of regressions of returns in the last half hour of a trading day on market maker hedging pressure $\Gamma^{H P}$, after controlling for returns until 15:30 $\left(r^{\mathrm{pre}}\right)$, as in specification Equation 10. $I V_{t-1}$ denotes implied volatility at time $t-1 . R \hat{V}_{t}^{\text {end }}$ denote the square root of predicted realized variance for the time period from 15:30 to 16:00. $P C_{t-1}$ is the put-call-ratio and $O / S_{t-1}^{\Phi}$ denotes the option-to-stock volume in dollar terms. T-statistics are in parentheses below and are computed using time-and-entity-clustered standard errors. ${ }^{* * *},{ }^{* *},{ }^{*}$ denotes significance at the $1 \%, 5 \%, 10 \%$ level. We include entity fixed effects in all specifications and value-weight observations. The sample period is May 2005 - July 2020.

\begin{tabular}{|c|c|c|c|c|c|}
\hline Dependent & $\begin{array}{c}(1) \\
r_{t}^{\text {end }} \\
\end{array}$ & $\begin{array}{c}(2) \\
r_{t}^{\text {end }} \\
\end{array}$ & $\begin{array}{c}(3) \\
r_{t}^{\text {end }} \\
\end{array}$ & $\begin{array}{c}(4) \\
r_{t}^{\text {end }} \\
\end{array}$ & $\begin{array}{c}(5) \\
r_{t}^{\text {end }} \\
\end{array}$ \\
\hline$\overline{\Gamma_{t}^{H P}}$ & $\begin{array}{c}-11.947^{* * *} \\
(-5.367)\end{array}$ & $\begin{array}{c}-11.916^{* * *} \\
(-5.368)\end{array}$ & $\begin{array}{c}-11.941^{* * *} \\
(-5.344)\end{array}$ & $\begin{array}{c}-11.954^{* * *} \\
(-5.369)\end{array}$ & $\begin{array}{c}-11.947^{* * *} \\
(-5.376)\end{array}$ \\
\hline$r_{t}^{\text {pre }}$ & $\begin{array}{c}-0.718^{* * *} \\
(-4.560)\end{array}$ & $\begin{array}{c}-0.719^{* * *} \\
(-4.573)\end{array}$ & $\begin{array}{c}-0.718^{* * *} \\
(-4.560)\end{array}$ & $\begin{array}{c}-0.718^{* * *} \\
(-4.558)\end{array}$ & $\begin{array}{c}-0.718^{* * *} \\
(-4.560)\end{array}$ \\
\hline$I V_{t-1}$ & & $\begin{array}{c}5.974^{* * *} \\
(3.077)\end{array}$ & & & \\
\hline$\hat{R V_{t}^{e n d}}$ & & & $\begin{array}{c}521.440^{*} \\
(1.889)\end{array}$ & & \\
\hline$P C_{t-1}$ & & & & $\begin{array}{l}0.354^{*} \\
(1.736)\end{array}$ & \\
\hline$O / S_{t-1}^{\Phi}$ & & & & & $\begin{array}{c}622.216 \\
(1.062)\end{array}$ \\
\hline Observations & $3,365,367$ & $3,365,367$ & $3,365,009$ & $3,358,722$ & $3,365,359$ \\
\hline Entity FE & Yes & Yes & Yes & Yes & Yes \\
\hline Time FE & Yes & Yes & Yes & Yes & Yes \\
\hline SEs & {$[\mathrm{t} ; \mathrm{j}]$} & {$[\mathrm{t} ; \mathrm{j}]$} & {$[\mathrm{t} ; \mathrm{j}]$} & {$[\mathrm{t} ; \mathrm{j}]$} & {$[\mathrm{t} ; \mathrm{j}]$} \\
\hline
\end{tabular}

The results are reported in Table 4. The slope coefficient $\beta_{1}$ equals -11.947 (t-stat. $=-5.37)$ and is statistically significant at the 1\%-level, suggesting that a negative shock to $\Gamma^{H P}$ amplifies end-of-day returns.Comparing the results in column (1) to those reported in column (2)-(5), we find little changes to the slope coefficient, suggesting that the results is robust to adding various control variables. While proxies for expected volatility $I V$ and 
$\hat{R V}$ are both significant in the regression setup, the inclusion of neither proxy materially changes the impact of $\Gamma^{H P}$. The same applies to the proxies of informed trading. ${ }^{13}$

\subsection{Leveraged ETFs}

\section{Order Flow}

We investigate the first part of the prediction $\mathrm{H}^{\Omega}$, which suggests the existence of a positive relationship between end-of-day order flow in single equities and the rebalancing pressure from leveraged ETFs. Similar to Equation (10), we run the following regression:

$$
\operatorname{RSVOL}_{j, t}^{\text {end }}=\beta_{0} \Omega_{j, t}^{L E T F}+\gamma^{\prime} \boldsymbol{X}_{j, t}+F E_{j}+F E_{t}+\epsilon_{j, t}
$$

\section{Table 5: Order Flow Effects of ETF Rebalancing}

The table reports the results to regressing relative signed trading volume in the last half hour of a trading day on leveraged ETF rebalancing quantity $\Omega^{L E T F}$ following Equation 11$) . R \hat{V}_{t}^{e n d}\left(\hat{R V_{t}^{p r e}}\right)$ denote the square root of predicted realized variance for the time period from 15:30 to 16:00 (from previous day's close to 15:30) on day $t$. T-statistics are in parentheses below and are computed using time-and-entityclustered standard errors. ${ }^{* * *},{ }^{* *},{ }^{*}$ denotes significance at the $1 \%, 5 \%, 10 \%$ level. We include entity fixed effects in all specifications and value-weight observations. The sample period is January $2012-$ December 2019.

\begin{tabular}{|c|c|c|c|}
\hline Dependent & $\begin{array}{c}(1) \\
\operatorname{RSVOL}_{t}^{\text {end }}\end{array}$ & $\begin{array}{c}(2) \\
\operatorname{RSVOL}_{t}^{\text {end }}\end{array}$ & $\begin{array}{c}(3) \\
\operatorname{RSVOL}_{t}^{\text {end }} \\
\end{array}$ \\
\hline$\Omega_{t}^{L E T F}$ & $\begin{array}{c}70.206^{* * *} \\
(6.075)\end{array}$ & $\begin{array}{c}70.096^{* * *} \\
(6.065)\end{array}$ & $\begin{array}{c}70.137^{* * *} \\
(6.064)\end{array}$ \\
\hline$\hat{R V_{t}^{p r e}}$ & & $\begin{array}{c}-46.954^{*} \\
(-1.873)\end{array}$ & \\
\hline$\hat{R V_{t}^{e n d}}$ & & & $\begin{array}{l}10.641 \\
(0.063)\end{array}$ \\
\hline Observations & $4,359,817$ & $4,342,509$ & $4,342,509$ \\
\hline Entity FE & Yes & Yes & Yes \\
\hline Time FE & Yes & Yes & Yes \\
\hline SEs & {$[t ; j]$} & {$[t ; j]$} & {$[t ; j]$} \\
\hline
\end{tabular}

The results are summarized in Table Table 6. We find that signed volume in the last

\footnotetext{
${ }^{13}$ To further rule out the possibility of informed trading, we adopt the idea of Ni et al. (2020) and compute $\Gamma^{H P}$ based on "old" positions. Appendix D
} 
half hour of a trading day is positively correlated with $\Omega^{L E T F}$, our proxy of rebalancing pressure by leveraged ETF rebalancing. Consistent with the prediction, the estimated coefficient is positive (70.206) and highly significant (t-value: 6.08 ). The absolute value of the slope coefficient on $\Omega^{L E T F}$ is more than twice the magnitude for $\Gamma^{H P}$. Consequently, an increase in the per-stock rebalancing from leveraged ETF market makers of $10 \%$ generates additional buying volume of $7.02 \%$ of $\mathrm{ADV}^{\mathrm{end}}(10 \% \times 70.206)$, or $13.69 \%$ of the average absolute order flow at the close.

When we control for ex-ante forecast for realized volatility before $\left(\hat{R V^{\text {pre }}}\right)$ and at the close $\left(\hat{R V}{ }^{\text {end }}\right)$, the coefficients to $\Omega^{L E T F}$ are unchanged.

\section{End-of-day returns}

For the second part of $\mathrm{H}^{\Omega}$, we analyze whether the documented order flow arising from leveraged ETF rebalancing further translates into additional price pressure. The regression setup takes the following form:

$$
r_{j, t}^{\mathrm{end}}=\beta_{0} r_{j, t}^{\mathrm{pre}}+\beta_{1} \Omega_{j, t}^{L E T F}+F E_{j}+F E_{t}+\epsilon_{j, t}
$$

The results are summarized in table Table 6 and show that the impact of leveraged ETF rebalancing is positive and significant with a coefficient equal to 33.214 (t-value: 5.42 ). The impact of $\Omega^{L E T F}$ is unaffected by the inclusion of measures of single-stock riskiness, and it becomes even stronger if we account for other intraday return effects (Heston et al., 2010; Gao et al., 2018; Baltussen et al., 2020)

\subsection{Assessing Rebalancing Jointly}

The two rebalancing channels may affect closing stock returns in different ways. In the Amazon example, for instance, an investor considering only Gamma hedging flows would have predicted positive returns for Amazon on June 23rd, 2016, given the large and negative magnitude of $\Gamma^{H P}$. On the other hand, had she also known about the significant amount of selling expected from leveraged ETFs, she may have revised her prediction. In this section we discuss the relative importance of these two channels. To conduct this analysis, we consider a joint sample, which comprises all stocks that are included in at least one leveraged ETF and for which options are traded on one of the five exchanges 


\section{Table 6: End-of-day effects of Leverage ETF Rebalancing}

The table reports the results of regressions of returns in the last half hour of a trading day on the leveraged ETF rebalancing quantity $\Omega^{L E T F}$, after controlling for the returns until 15:30 ( $\left.r^{\text {pre }}\right)$ as in Equation 12 . $R V_{t}^{15: 30 \rightarrow \text { close }}\left(\hat{R V_{t}^{\text {close-1 }} \rightarrow 15: 30}\right)$ denote the square root of predicted realized variance for the time period from 15:30 to 16:00 (from previous day's close to 15:30) on day $t$. T-statistics are in parentheses below and are computed using time-and-entity-clustered standard errors. ${ }^{* * *},{ }^{* *},{ }^{*}$ denotes significance at the $1 \%, 5 \%, 10 \%$ level. We include entity fixed effects in all specifications and value-weight observations. The sample period is January 2012 - December 2019.

\begin{tabular}{|c|c|c|c|c|}
\hline Dependent & $\begin{array}{c}(1) \\
r_{t}^{\text {end }}\end{array}$ & $\begin{array}{c}(2) \\
r_{t}^{\text {end }}\end{array}$ & $\begin{array}{c}(3) \\
r_{t}^{\text {end }}\end{array}$ & $\begin{array}{c}(4) \\
r_{t}^{\text {end }}\end{array}$ \\
\hline$\Omega_{t}^{L E T F}$ & $\begin{array}{c}33.214^{* * *} \\
(5.421)\end{array}$ & $\begin{array}{c}41.350^{* * *} \\
(6.752)\end{array}$ & $\begin{array}{c}41.386^{* * *} \\
(6.751)\end{array}$ & $\begin{array}{c}41.358^{* * *} \\
(6.745)\end{array}$ \\
\hline$r_{t}^{\text {pre }}$ & & $\begin{array}{c}-0.900 * * * \\
(-9.897)\end{array}$ & $\begin{array}{c}-0.908^{* * *} \\
(-10.031)\end{array}$ & $\begin{array}{c}-0.909 * * * \\
(-10.032)\end{array}$ \\
\hline$\hat{R V_{t}^{p r e}}$ & & & $\begin{array}{c}36.481^{* *} \\
(2.484)\end{array}$ & \\
\hline$\hat{R V_{t}^{e n d}}$ & & & & $\begin{array}{c}408.311^{* * *} \\
(4.165)\end{array}$ \\
\hline Observations & $4,403,855$ & $4,403,855$ & $4,386,322$ & $4,386,322$ \\
\hline Entity FE & Yes & Yes & Yes & Yes \\
\hline Time FE & Yes & Yes & Yes & Yes \\
\hline SEs & {$[\mathrm{t} ; \mathrm{j}]$} & {$[\mathrm{t} ; \mathrm{j}]$} & {$[\mathrm{t} ; \mathrm{j}]$} & {$[\mathrm{t} ; \mathrm{j}]$} \\
\hline
\end{tabular}

we consider. We run the following panel regression:

$$
r^{\mathrm{end}}=\beta_{0} r_{j, t}^{\mathrm{pre}}+\beta_{1} \Gamma_{j, t}^{H P}+\beta_{2} \Omega_{j, t}^{L E T F}+F E_{j}+F E_{t}+\epsilon_{j, t}
$$

The results are summarized in table Table 7. We find that slope coefficients of both $\Gamma^{H P}$ and $\Omega^{L E T F}$ are statistically significant. The slope coefficient of $\Gamma^{H P}$ is equal to -9.16 (t-value: -4.53 ); the slope coefficient of $\Omega^{L E T F}$ is equal to 44.36 (t-value: 4.56 ). When we run the regression jointly, each coefficient increases in absolute magnitude to -10.677 for $\Gamma^{H P}$ and 47.611 for $\Omega^{L E T F}$. Accounting for the average size of each explanatory variable in the sample, the average impact of leveraged ETF rebalancing is about 4 times larger than that of $\Gamma^{H P}$. It is important to notice that the joint sample restricts the universe to larger stock, given the two requirements of being optionable and included in leveraged ETFs. For these stocks, a one standard deviation decrease in $\Gamma^{H P}$ (increase in $\Omega^{L E T F}$ ) leads to additional end-of-day returns of 2.11-times (4.03-times) the unconditional return 
at the close. The effect sizes are comparable to those estimated for the separate samples.

\section{Table 7: Joint Impact of Delta-Hedging and Leverage ETF Rebalancing}

The table reports the results to regressing returns in the last half hour of a trading day on returns until 15:30 $\left(r^{\text {pre }}\right)$, on option market maker hedging pressure $\Gamma^{H P}$ and leveraged ETF rebalancing quantity $\Omega^{L E T F}$ following Equation $(13)$. We also consider the impact of joint rebalancing activity using the variables defined in Equation (14) in the regression setup proposed in Equation (15). T-statistics are in parentheses below and are computed using time-and-entity-clustered standard errors. ${ }^{* * *},{ }^{* *},{ }^{*}$ denotes significance at the 1\%,5\%,10\% level. We include entity fixed effects in all specifications and value-weight observations. The sample period is 2012 - December 2019.

\begin{tabular}{|c|c|c|c|c|}
\hline Dependent & $\begin{array}{c}(1) \\
r_{t}^{\text {end }}\end{array}$ & $\begin{array}{c}(2) \\
r_{t}^{\text {end }} \\
\end{array}$ & $\begin{array}{c}(3) \\
r_{t}^{\text {end }} \\
\end{array}$ & $\begin{array}{c}(4) \\
r_{t}^{\text {end }} \\
\end{array}$ \\
\hline$\Gamma_{t}^{H P}$ & $\begin{array}{c}-9.164^{* * *} \\
(-4.531)\end{array}$ & & $\begin{array}{c}-10.677^{* * *} \\
(-5.324)\end{array}$ & \\
\hline$\Omega_{t}^{L E T F}$ & & $\begin{array}{c}44.357^{* * *} \\
(4.563)\end{array}$ & $\begin{array}{c}47.611^{* * *} \\
(4.935)\end{array}$ & \\
\hline$r_{t}^{\mathrm{pre}}$ & $\begin{array}{c}-0.821^{* * *} \\
(-6.982)\end{array}$ & $\begin{array}{c}-0.959 * * * \\
(-8.172)\end{array}$ & $\begin{array}{c}-0.882^{* * *} \\
(-7.479)\end{array}$ & \\
\hline $\mathrm{BB}$ & & & & $\begin{array}{c}41.412^{\text {*** }} \\
(5.183)\end{array}$ \\
\hline SS & & & & $\begin{array}{c}-44.044^{* * *} \\
(-3.747)\end{array}$ \\
\hline BS & & & & $\begin{array}{c}-24.422^{* * *} \\
(-2.949)\end{array}$ \\
\hline SB & & & & $\begin{array}{c}19.074^{* * *} \\
(2.619)\end{array}$ \\
\hline Observations & $1,940,150$ & $1,940,150$ & $1,940,150$ & $1,940,150$ \\
\hline Entity FE & Yes & Yes & Yes & Yes \\
\hline Time FE & Yes & Yes & Yes & - \\
\hline SEs & {$[\mathrm{t} ; \mathrm{j}]$} & {$[\mathrm{t} ; \mathrm{j}]$} & {$[\mathrm{t} ; \mathrm{j}]$} & {$[\mathrm{t} ; \mathrm{j}]$} \\
\hline
\end{tabular}

To further investigate the relative importance of the two channels, we construct four variables, which capture the amount of price pressure in four distinct states. We define the first state as one in which $\Gamma_{i, t}^{H P}<0$ and $\Omega_{i, t}^{L E T F}>0$. We label this state as "BB". The first letter denotes the trade direction for option market makers ( $\mathrm{B}$ for buy, $\mathrm{S}$ for sell) and the second letter the trade direction for the rebalancing of leveraged ETFs. We 
define the other three states in a similar way:

$$
\begin{aligned}
\mathrm{BB} & =\left(\Omega_{i, t}^{L E T F}-\Gamma_{i, t}^{H P}\right) \times \mathbb{1}_{\left(\Gamma_{i, t}^{H P}<0\right),\left(\Omega_{i, t}^{L E T F}>0\right)} \\
\mathrm{SS} & =\left(\Gamma_{i, t}^{H P}-\Omega_{i, t}^{L E T F}\right) \times \mathbb{1}_{\left(\Gamma_{i, t}^{H P}>0\right),\left(\Omega_{i, t}^{L E T F}<0\right)} \\
\mathrm{BS} & =\left(\Omega_{i, t}^{L E T F}-\Gamma_{i, t}^{H P}\right) \times \mathbb{1}_{\left(\Gamma_{i, t}^{H P}<0\right),\left(\Omega_{i, t}^{L E T F}<0\right)} \\
\mathrm{SB} & =\left(\Omega_{i, t}^{L E T F}-\Gamma_{i, t}^{H P}\right) \times \mathbb{1}_{\left(\Gamma_{i, t}^{H P}>0\right),\left(\Omega_{i, t}^{L E T F}>0\right)}
\end{aligned}
$$

Thus, BB captures the joint buying pressure likely to occur in the last half hour, conditional on both sources of rebalancing requiring market makers to buy additional shares of the underlying stock. The joint effect should lead to a larger end-of-day volumen and return effect. On the other hand, SS captures states in which both sources of rebalancing induce added selling pressure at the close. BS (SB), captures the impact of joint rebalancing whenever option market makers have to buy (sell) shares, while the rebalancing of leveraged ETFs requires the sale (purchase) of additional shares. ${ }^{14}$ We run a joint regression of the following form:

$$
r^{\mathrm{end}}=\beta_{0} r_{j, t}^{\mathrm{pre}}+\beta_{1} \mathrm{BB}_{j, t}+\beta_{2} \mathrm{SS}_{j, t}+\beta_{3} \mathrm{BS}_{j, t}+F E_{j}+F E_{t}+\epsilon_{j, t}
$$

Column (4) of Table 7 summarizes the results of the joint regression. Joint buying pressure $(\mathrm{BB})$ is associated with significantly positive returns in the last half hour of a trading day. The slope coefficient of BB is 41.41 (t-value: 5.18) and it is highly significant both statistically and economically. The same applies to SS. The coefficient is roughly comparable to that of $\mathrm{BB}$ at -44.044 (t-value: -3.747 ). A one standard deviation increase in the joint rebalancing amount from leveraged ETF and option market makers on BB (SS) days amplifies (depresses) end-of-day returns by 2.87 bps ( $-2.87 \mathrm{bps}$ ). The average return at the close amounts to only 0.24 bps. We find smaller absolute coefficients for BS and SB. Once again, however, we find evidence supporting that idea that the impact of leveraged ETF rebalancing outweighs the impact of $\Gamma^{H P}$. Indeed, the coefficient for BS is negative (t-value: 2.95) and for SB it is positive (t-value: 2.62). A one standard deviation increase in the joint rebalancing leads to additional returns of $-1.53 \mathrm{bps}(1.18$ bps) on BS (SB) days, highlighting the relative dominance of leveraged ETF rebalancing.

\footnotetext{
${ }^{14}$ In our sample, BB occurs for $24.4 \%$, SS for $20.3 \%$, BS for 23.8 and SB for $29.0 \%$ of observations. Given that the estimated effect of $\Omega^{L E T F}$ is larger, we expect it to dominate the joint effect of the two sources of rebalancing disagree in the trade direction. However, a reduction of the estimated coefficient suggests that a) our identification approach is working and b) that knowing about Gamma flows is still useful in these cases.
} 


\subsection{Trading Strategy}

Next, we assess the usefulness of the previously established predictability by means of a trading strategy, using $\Gamma^{H P}$ and $\Omega^{L E T F}$ as timing signals. First, we construct decile portfolios based on $\Gamma^{H P}$ and take a long (short) position in the lowest (highest) decile. Specifically, on each day at 15:30, we sort our stock sample according to $\Gamma^{H P}$ into decile portfolios. Subsequently, we build a long-short strategy, denoted by $\eta\left(\Gamma^{H P}\right)$, by taking a long (short) position in the lowest (highest) decile portfolio. We close our positions at the market close of the same trading day, such that we effectively hold the securities in our strategy for 30 minutes each day.

As a second strategy, $\eta\left(\Omega^{L E T F}\right)$, we use $\Omega^{L E T F}$ as a timing signal. If $\Omega^{L E T F}$ is negative (positive) for a given stock, we assume selling (buying) pressure from LETF rebalancing. We construct decile portfolios based on $\Omega^{L E T F}$ and take a long (short) position in the highest (lowest) decile.

Finally, we use both $\Gamma^{H P}$ and $\Omega^{L E T F}$ as signals in a combined strategy. For each stock at 15:30, we compute its cross-sectional rank according to $\Gamma^{H P}$ and $\Omega^{L E T F}$, respectively. ${ }^{15}$ We sum the individual ranks to obtain a combined ranking. Based on the combined ranking, we once again build decile portfolios and go long (short) the highest (lowest) decile portfolio.

Table 8 reports summary statistics of the resulting strategies on the joint sample. ${ }^{16}$ In Panel A, decile portfolios are equally-weighted, whereas Panel B shows results for value-weighted portfolios. $\eta\left(\Gamma^{H P}\right)$ yields average total excess returns of $5.16 \%$ per year, which are significant at the $1 \%$-level. Interestingly, it is inconsequential for the trading strategy on $\Gamma^{H P}$ whether we equally- or value-weight returns within each portfolio (Panel B). In order to get a better understanding of the performance, we consider a benchmark strategy Market ${ }^{\text {end }}$ which takes a long position in all available stocks at the beginning of the last half hour of a trading day and closes each position at the close. For our sample from 2012 through 2019, Market ${ }^{\text {end }}$ yields an insignificant annual return of $0.62 \%$.

Contrasting $\eta\left(\Gamma^{H P}\right)$ with $\eta\left(\Omega^{L E T F}\right)$, we find that equally-weighted average returns to the latter are twice as high. Risk-adjusted returns are also slightly higher, with a Sharpe-ratio of 4.65 for $\eta\left(\Omega^{L E T F}\right)$ vs. 4.13 for $\eta\left(\Gamma^{H P}\right)$. Here, however, we document that the average and risk-adjusted performance is halved if we weight observations by

\footnotetext{
${ }^{15}$ In the combined strategy, we reverse the $\Gamma^{H P}$ ranking, such that a higher rank denotes buying pressure.

${ }^{16}$ Appendix $\mathrm{OA} 7$ in the Internet Appendix reports summary statistics for $\eta\left(\Gamma^{H P}\right)$ and $\eta\left(\Omega^{L E T F}\right)$ on their respective sample periods.
} 


\section{Table 8: Trading Strategy}

The table reports the economic value of timing the last half-hour market return using $\Gamma^{H P}, \Omega^{L E T F}$ and a joint signal based on both. The $\Gamma^{H P}$-strategy, $\eta\left(\Gamma^{H P}\right)$, takes a long (short) position in a stock when the stock's $\Gamma^{H P}$ is in the lowest (highest) decile. The $\Omega^{L E T F}$-strategy, $\eta\left(\Omega^{L E T F}\right)$, takes a long (short) position in a stock when the stock's $\Omega^{L E T F}$ is in the highest (lowest) decile. The combined strategy, $\eta\left(\Gamma^{H P}, \Omega^{L E T F}\right)$, computes a cross-sectional rank according to $\Gamma^{H P}$ and $\Omega^{L E T F}$ and takes a long (short) position in a stock when the stock's aggregated ranking is in the highest (lowest) decile. As a benchmark, Market ${ }^{\text {end }}$ denotes investing in all stocks from 15:30 to 16:00. We consider equally weighted (EW) and value weighted (VW) portfolios, including for Market ${ }^{\text {end }}$. For each strategy, we report the average return (Avg ret), standard deviation (Std dev), Sharpe ratio (Sharpe), skewness, kurtosis, and success rate (Success). The returns are annualized and in percentage. Newey and West (1987) robust t-statistics are in parentheses, and significance at the $1 \%, 5 \%$, or $10 \%$ level is denoted by ***, **, or *, respectively. The sample period is January 2012 - December 2019.

\begin{tabular}{|c|c|c|c|c|c|c|}
\hline & Avg ret & Std dev & Sharpe & Skewness & Kurtosis & Success \\
\hline \multicolumn{7}{|c|}{ Panel A: Equally Weighted } \\
\hline$\eta\left(\Gamma^{H P}\right)$ & $5.16^{* * *}$ & 1.25 & 4.13 & 0.33 & 3.48 & 62.34 \\
\hline$\eta\left(\Omega^{L E T F}\right)$ & $11.82^{* * *}$ & 2.54 & 4.65 & 0.46 & 2.98 & 60.81 \\
\hline$\eta\left(\Gamma^{H P}, \Omega^{L E T F}\right)$ & $11.00^{* * *}$ & 2.16 & 5.09 & 0.22 & 3.10 & 61.91 \\
\hline Market $^{\text {end }}$ & 0.62 & 3.29 & 0.19 & -0.61 & 6.18 & 54.02 \\
\hline \multicolumn{7}{|c|}{ Panel B: Value Weighted } \\
\hline$\eta\left(\Gamma^{H P}\right)$ & $5.20 * * *$ & 1.36 & 3.83 & 0.17 & 3.00 & 61.07 \\
\hline$\eta\left(\Omega^{L E T F}\right)$ & $5.78^{* * *}$ & 2.31 & 2.51 & 0.13 & 3.54 & 56.29 \\
\hline$\eta\left(\Gamma^{H P}, \Omega^{L E T F}\right)$ & $6.21^{* * *}$ & 1.98 & 3.14 & 0.31 & 3.21 & 58.13 \\
\hline Market $^{\text {end }}$ & -1.39 & 3.26 & -0.43 & -1.05 & 12.27 & 51.92 \\
\hline
\end{tabular}

the company's market capitalization. This suggests that the effect of leveraged ETF rebalancing is outsized for smaller stocks.

Finally, Table 8 includes the summary statistics of the trading strategy that combines $\Gamma^{H P}$ and $\Omega^{L E T F}$ as trading signals. Considering both $\Gamma^{H P}$ and $\Omega^{L E T F}$ yields an annualized average return of $11.00 \%$, at an improved annual Sharpe-ratio of 5.09. ${ }^{17} \eta\left(\Gamma^{H P}, \Omega^{L E T F}\right)$ also shows the best performance if stocks are value-weighted, at an average annual return of $6.21 \%$ with a Sharpe-ratio of 3.14. At the same time, the success rates of all three strategies are high, above $56 \%$ and highest for $\eta\left(\Gamma^{H P}\right)$, with values upwards of $61 \%{ }^{18}$

\footnotetext{
${ }^{17}$ The daily return $\eta\left(\Gamma^{H P}, \Omega^{L E T F}\right)$ equates to 4.36 basis points on average. This compares well to Bogousslavsky (2020) who documents that a mispricing factor earns an alpha of -2.43 basis points in the last 30 minutes of the trading day.

${ }^{18}$ To put this in context, Jiang, Kelly, and Xiu (2020) use convolutional neural networks on price path images to predict the future return direction. They achieve a success rate of up to $53.6 \%$.
} 


\section{Table 9: Risk-adjusted Returns}

The table reports the estimation results from regressing returns of strategies timing the last half-hour based on $\Gamma^{H P}, \Omega^{L E T F}$ and a combination of both on the returns of all stocks from 15:30 to 16:00 (Market ${ }^{\text {end }}$ ), the equity market excess return (MKT), size (SMB), book-to-market (HML), profitability (RMW), investment (CMA), momentum (MOM), and an intermediary capital asset pricing factor (IC, proposed by He et al. 2017). The $\Gamma^{H P}$-strategy, $\eta\left(\Gamma^{H P}\right)$, takes a long (short) position in a stock when the stock's $\Gamma^{H P}$ is in the lowest (highest) decile. The $\Omega^{L E T F}$-strategy, $\eta\left(\Omega^{L E T F}\right)$, takes a long (short) position in a stock when the stock's $\Omega^{L E T F}$ is in the highest (lowest) decile. The combined strategy, $\eta\left(\Gamma^{H P}, \Omega^{L E T F}\right)$, computes a cross-sectional rank according to $\Gamma^{H P}$ and $\Omega^{L E T F}$ and takes a long (short) position in a stock when the stock's aggregated ranking is in the highest (lowest) decile. We consider equally weighted (EW) and value weighted (VW) portfolios. Newey and West (1987) robust t-statistics are in parentheses, and significance at the $1 \%, 5 \%$, or $10 \%$ level is denoted by $* * *, * *$, or $*$, respectively. The sample period is January 2012 - December 2019.

\begin{tabular}{|c|c|c|c|c|c|c|c|c|c|c|c|}
\hline & Intercept & Market $^{\text {end }}$ & MKT & SMB & HML & RMW & CMA & MOM & IC & $\mathrm{R} 2$ & $\mathrm{R} 2 \mathrm{adj}$ \\
\hline \multicolumn{12}{|c|}{ Panel A: Equally Weighted } \\
\hline \multirow[t]{2}{*}{$\eta\left(\Gamma^{H P}\right)$} & $\begin{array}{c}5.15 \\
\left(9.51^{* * *}\right)\end{array}$ & $\begin{array}{c}0.01 \\
(1.27)\end{array}$ & & & & & & & & $0.10 \%$ & $0.05 \%$ \\
\hline & $\begin{array}{c}5.10 \\
\left(9.00^{* * *}\right)\end{array}$ & & $\begin{array}{c}0.92 \\
(0.99)\end{array}$ & $\begin{array}{c}-0.29 \\
(-0.24)\end{array}$ & $\begin{array}{l}-1.00 \\
(-0.59)\end{array}$ & $\begin{array}{c}3.06 \\
(1.52)\end{array}$ & $\begin{array}{c}4.59 \\
\left(1.90^{*}\right)\end{array}$ & $\begin{array}{c}1.12 \\
(1.33)\end{array}$ & $\begin{array}{c}0.77 \\
(1.08)\end{array}$ & $0.78 \%$ & $0.36 \%$ \\
\hline \multirow[t]{2}{*}{$\eta\left(\Omega^{L E T F}\right)$} & $\begin{array}{c}11.83 \\
\left(8.56^{* * *}\right)\end{array}$ & $\begin{array}{l}-0.02 \\
(-0.72)\end{array}$ & & & & & & & & $0.04 \%$ & $-0.01 \%$ \\
\hline & $\begin{array}{c}12.92 \\
\left(8.49^{* * *}\right)\end{array}$ & & $\begin{array}{c}-0.45 \\
(-0.21)\end{array}$ & $\begin{array}{c}3.77 \\
(1.48)\end{array}$ & $\begin{array}{l}-1.64 \\
(-0.42)\end{array}$ & $\begin{array}{c}2.62 \\
(0.62)\end{array}$ & $\begin{array}{c}-1.07 \\
(-0.20)\end{array}$ & $\begin{array}{l}-1.47 \\
(-0.80)\end{array}$ & $\begin{array}{c}1.00 \\
(0.64)\end{array}$ & $0.33 \%$ & $-0.09 \%$ \\
\hline \multirow[t]{2}{*}{$\eta\left(\Gamma^{H P}, \Omega^{L E T F}\right)$} & $\begin{array}{c}11.01 \\
\left(9.96^{* * *}\right)\end{array}$ & $\begin{array}{c}-0.01 \\
(-0.45)\end{array}$ & & & & & & & & $0.02 \%$ & $-0.03 \%$ \\
\hline & $\begin{array}{c}11.54 \\
\left(9.26^{* * *}\right)\end{array}$ & & $\begin{array}{c}0.58 \\
(0.29)\end{array}$ & $\begin{array}{c}3.67 \\
(1.63)\end{array}$ & $\begin{array}{l}-1.54 \\
(-0.49)\end{array}$ & $\begin{array}{c}5.07 \\
(1.50)\end{array}$ & $\begin{array}{c}-0.84 \\
(-0.19)\end{array}$ & $\begin{array}{c}-0.28 \\
(-0.17)\end{array}$ & $\begin{array}{c}0.70 \\
(0.55)\end{array}$ & $0.46 \%$ & $0.03 \%$ \\
\hline \multicolumn{12}{|c|}{ Panel B: Value Weighted } \\
\hline \multirow[t]{2}{*}{$\overline{\eta\left(\Gamma^{H P}\right)}$} & $\begin{array}{c}5.21 \\
\left(9.37^{* * *}\right)\end{array}$ & $\begin{array}{c}0.01 \\
(0.42)\end{array}$ & & & & & & & & $0.03 \%$ & $-0.02 \%$ \\
\hline & $\begin{array}{c}4.84 \\
\left(7.99^{* * *}\right)\end{array}$ & & $\begin{array}{c}1.24 \\
(1.00)\end{array}$ & $\begin{array}{c}1.11 \\
(0.88)\end{array}$ & $\begin{array}{c}0.46 \\
(0.27)\end{array}$ & $\begin{array}{c}2.89 \\
(1.58)\end{array}$ & $\begin{array}{c}0.89 \\
(0.31)\end{array}$ & $\begin{array}{c}2.13 \\
\left(2.10^{* *}\right)\end{array}$ & $\begin{array}{c}0.72 \\
(0.86)\end{array}$ & $0.88 \%$ & $0.45 \%$ \\
\hline \multirow[t]{2}{*}{$\eta\left(\Omega^{L E T F}\right)$} & $\begin{array}{c}5.77 \\
\left(6.07^{* * *}\right)\end{array}$ & $\begin{array}{l}-0.01 \\
(-0.30)\end{array}$ & & & & & & & & $0.02 \%$ & $-0.03 \%$ \\
\hline & $\begin{array}{c}6.22 \\
\left(5.87^{* * *}\right)\end{array}$ & & $\begin{array}{c}0.24 \\
(0.09)\end{array}$ & $\begin{array}{c}0.93 \\
(0.42)\end{array}$ & $\begin{array}{l}-1.11 \\
(-0.36)\end{array}$ & $\begin{array}{l}-4.98 \\
(-1.27)\end{array}$ & $\begin{array}{c}1.03 \\
(0.25)\end{array}$ & $\begin{array}{c}-4.06 \\
\left(-2.87^{* * *}\right)\end{array}$ & $\begin{array}{c}-1.04 \\
(-0.61)\end{array}$ & $0.72 \%$ & $0.29 \%$ \\
\hline \multirow[t]{2}{*}{$\eta\left(\Gamma^{H P}, \Omega^{L E T F}\right)$} & $\begin{array}{c}6.19 \\
\left(7.44^{* * *}\right)\end{array}$ & $\begin{array}{l}-0.02 \\
(-0.58)\end{array}$ & & & & & & & & $0.07 \%$ & $0.02 \%$ \\
\hline & $\begin{array}{c}6.58 \\
\left(6.92^{* * *}\right)\end{array}$ & & $\begin{array}{l}-1.86 \\
(-0.91)\end{array}$ & $\begin{array}{c}1.54 \\
(0.80)\end{array}$ & $\begin{array}{l}-4.23 \\
(-1.62)\end{array}$ & $\begin{array}{c}0.67 \\
(0.23)\end{array}$ & $\begin{array}{c}2.44 \\
(0.68)\end{array}$ & $\begin{array}{l}-1.46 \\
(-0.96)\end{array}$ & $\begin{array}{c}1.65 \\
(1.36)\end{array}$ & $0.36 \%$ & $-0.07 \%$ \\
\hline
\end{tabular}

As indicated in Table 9, returns of our trading strategies are neither explained by the market return in the last half hour, nor standard equity risk-factors. Precisely, we obtain alphas that are very close to average returns when we regress strategy returns on either the benchmark strategy Market ${ }^{\text {end }}$, or the Fama-French five-factor model (Fama and French, 2015), augmented by a momentum factor and an intermediary capital asset 
pricing factor (He et al., 2017). ${ }^{19,20}$

Fig. 5. Performance and drawdown curve.

Shows cumulative performance of a one dollar investment into as well as the drawdown curve in percent for the respective trading strategies. The sample period is January 2012 - December 2019.
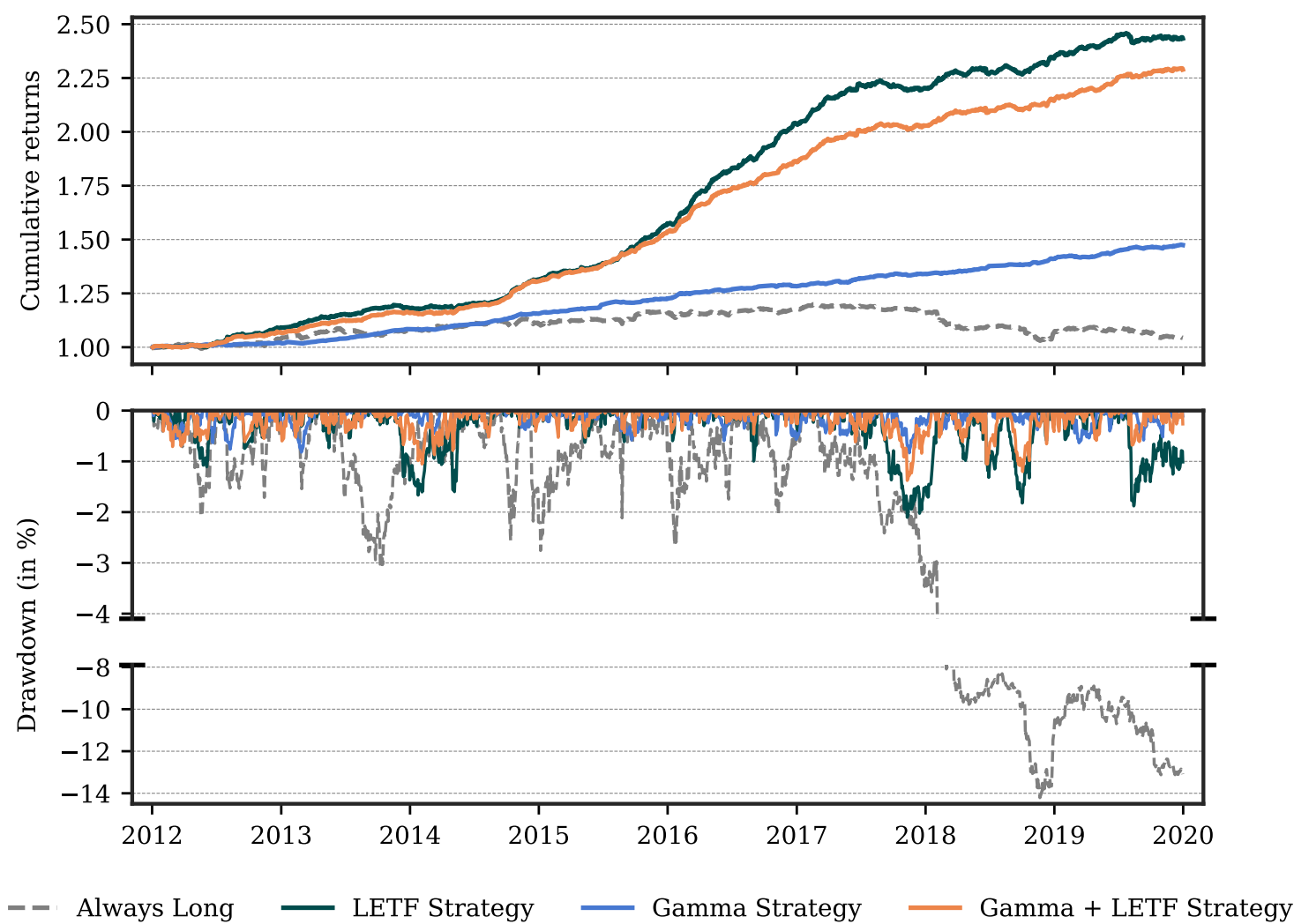

Figure 5 depicts the performance and drawdown curves of the trading strategies between 2012 and 2019. Neither do the trading strategies experience significant fluctuation, nor do we visually spot any structural breaks. Instead, cumulative returns are fairly smooth over time. All strategies except for Market $^{\text {end }}$ exhibit a maximum drawdown below $-2 \%$. The maximum drawdown is smaller for the combined strategy compared to

\footnotetext{
${ }^{19}$ Data on the Fama-French five-factor model and the momentum factor is taken from Kenneth French's website, https://mba.tuck.dartmouth.edu/pages/faculty/ken.french/data_ library.html, whereas data on the intermediary capital asset pricing factor is obtained from Zhiguo He's website, https://voices.uchicago.edu/zhiguohe/data-and-empirical-patterns/intermediarycapital-ratio-and-risk-factor/

${ }^{20}$ Appendix $\mathrm{OA} 8$ in the Internet Appendix reports results for $\eta\left(\Gamma^{H P}\right)$ and $\eta\left(\Omega^{L E T F}\right)$ on their respective sample periods.
} 
the $\Omega^{L E T F}$ strategy. That is due to the inclusion of $\Gamma^{H P}$, as the standalone $\Gamma^{H P}$ strategy obeys the smallest maximum drawdown.

\section{Characteristics of Delta-Hedging and Leveraged ETF Rebalancing}

In this section, we investigate the effects of delta-hedging and leveraged ETF rebalancing in more detail.

\subsection{Hedging Windows}

Throughout the paper, our working assumption is that rebalancing occurs during the last 30 minutes of the trading day. We now challenge this assumption, and explore rebalancing effects on alternative hedging windows $W$, one for each 30-minute interval between 09:30 and the close at 16:00. We compute cumulative returns from the previous day's close until the beginning of interval $W$, and recalculate $\Gamma^{H P}$ and $\Omega^{L E T F}$ based on the new values for $r^{\text {pre }}$ and $r_{\text {bench }}^{\text {pre }}$, following Equation (5) and Equation (6).

Figure 6 shows the resulting intraday evolution of the impact of Gamma and leveraged ETF rebalancing flows on end-of-day returns. For $\Gamma^{H P}$ (upper panel), we find significantly negative coefficients only for the last two hedging windows, suggesting that some rebalancing may already take place an hour before the market closes. Nonetheless, the bulk of rebalancing seems to occur between $3: 30 \mathrm{pm}$ and $4 \mathrm{pm}$, when the coefficient is the largest in absolute magnitude at roughly -10 . We find no significant effect during the other hedging windows apart from 10am to 10:30am, where the estimated coefficient is only marginally significant. For leveraged ETFs (lower panel), we find virtually no impact of rebalancing for any hedging window different from the last one. Only the endof-day coefficient is significantly different from zero. In conjunction, these results support the view that option market makers enjoy some level of discretion regarding the timing of their rebalancing activity. Market makers for swaps replicating leveraged ETFs, in contrast, are bound by their contractual obligation to deliver a multiple exposure at the market close, and time their rebalancing activity accordingly. 

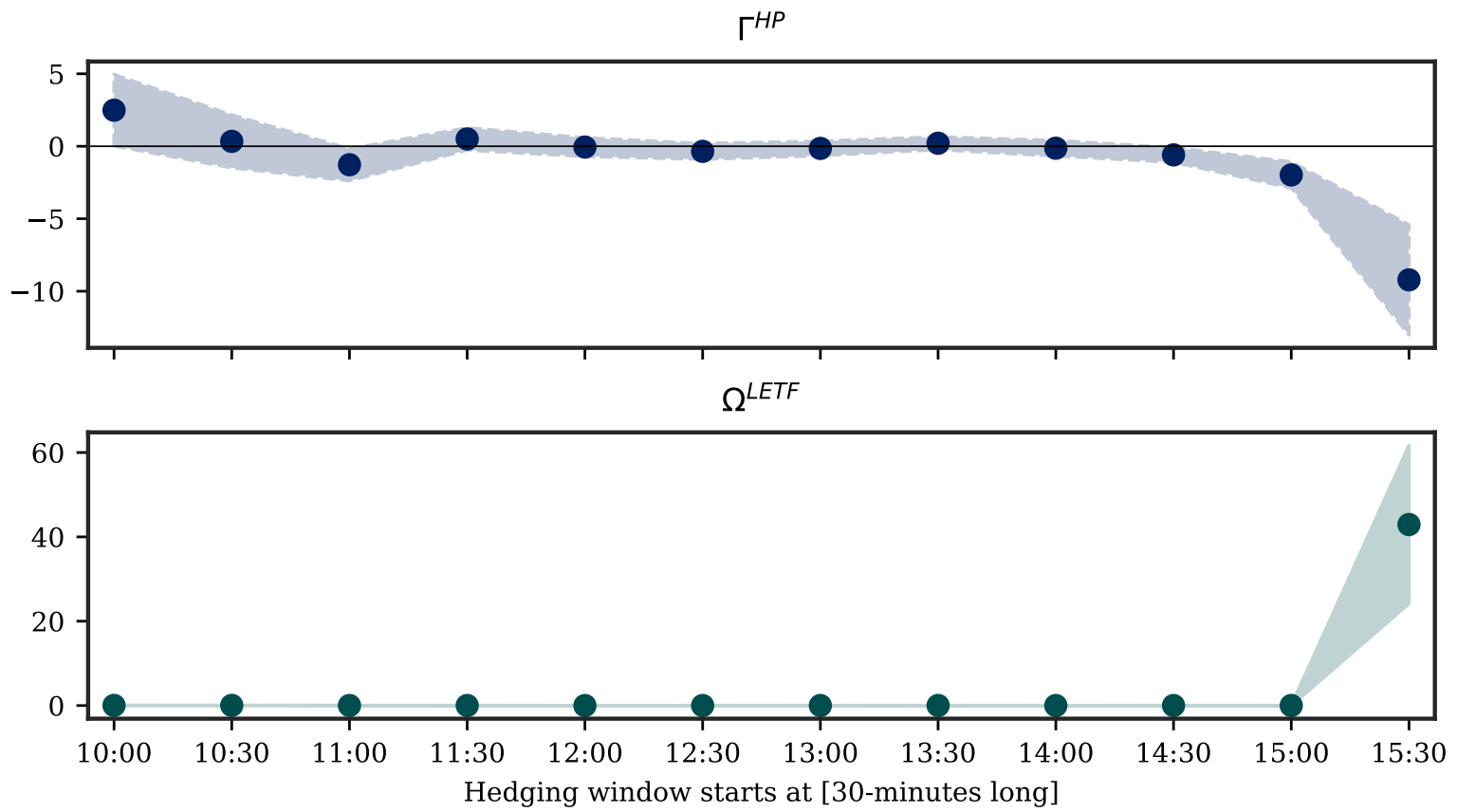

Fig. 6. Alternative Delta-Hedging and Leveraged ETF Hedging Windows

The figure depicts the effect on $\Gamma^{H P}$ and $\Omega^{L E T F}$ when varying the time interval over which $r^{\text {pre }}$ is measured. The $\mathrm{x}$-axis displays the time until we measure the cumulative return from the previous trading day's close price. For the $\Gamma^{H P}$-analysis, we take returns of the underlying stock $\left(r^{\mathrm{pre}}\right)$, whereas we take the returns of the LETF benchmark indices for the $\Omega^{L E T F}$-analysis $\left(r_{\text {bench }}^{\mathrm{pre}}\right)$. We also record returns in the subsequent 30 -minute time interval $\left(r^{\text {next }}\right)$. Next, we reconstruct $\Gamma^{H P}$ and $\Omega^{L E T F}$ with the new values for $r^{\mathrm{pre}}$ and $r_{\text {bench }}^{\mathrm{pre}}$ following Equation (5) and Equation (6), respectively. Finally, we re-estimate Equation (10) and Equation (12) using $r^{\text {next }}$ as the dependent variable and plot the estimated coefficients for each window. The filled areas denote $95 \%$ confidence bounds.

\subsection{Discretionary vs. non-discretionary}

The previous section has indicated that some rebalancing activity of option market makers may occur before the close. In order to investigate in how far they act at their own discretion with regards to the timing of these activities, we focus on the price effects of rebalancing activities following large price movements. Intuitively, a market maker may be inclined to hedge her directional exposure immediately after observing substantial jumps in the underlying. Given the evidence above, we would assume that this applies only to option market makers.

We detect price jumps for the underlying stocks in the case of $\Gamma^{H P}$ and the benchmark ETF for $\Omega^{L E T F}$. For this, we compare the return in each 30-minute interval of a given trading day with the return distribution of the same interval over the last year. We denote as "jump events" those stock-intervals where this metric is in the top or bottom $2.5 \%$ of the distribution. We then record the cumulative return from the previous' day 


\section{Table 10: Delta-Hedging and Leveraged ETF Rebalancing After Intraday Jumps}

The table reports the results to regressing intraday jump returns on returns in the subsequent 30minute interval. For delta-hedging, we identify jumps in the underlying stock returns. For leverage ETF rebalancing, we identify jumps in the benchmark of the leverage ETF. To detect jumps, we compare each non-overlapping 30-minute return with returns of the same interval over the last year. If the return is higher (lower) than the $97.5 \%(2.5 \%)$ percentile, we regard the return as a jump. Next, we record the return from yesterday's close until the end of the 30-minute interval, where the jump has occurred $\left(r_{t}^{\text {incl. jump }}\right)$. We collect also the return of the subsequent 30 -minute interval $\left(r_{t}^{\text {next }}\right)$ on the stock-level. In case of leveraged ETFs, we select all stocks in leveraged ETFs for which a jump in the benchmark index of the leverage ETF has occurred. Finally, we disregard jumps which have occurred after a certain time (given in row "Jumps Until"). Equipped with $r_{t}^{\text {incl. jump }}, r_{t}^{\text {next }}$, and the intraday return of the benchmark index, we reconstruct $\Gamma_{t}^{H P}$ and $\Omega_{t}^{L E T F}$ for each affected stock $j$. Subsequently, we run Equation 10 and Equation (12). T-statistics are in parentheses below and are computed using time-and-entity-clustered standard errors. ${ }^{* * *},{ }^{* *}, *$ denotes significance at the $1 \%, 5 \%, 10 \%$ level. We include entity fixed effects in all specifications and value-weight observations. The sample period is January 2012 - December 2019.

\begin{tabular}{lcccccc}
\hline & $(1)$ & $(2)$ & $(3)$ & $(4)$ & $(5)$ & $(6)$ \\
Dependent & $r_{t}^{\text {next }}$ & $r_{t}^{\text {next }}$ & $r_{t}^{\text {next }}$ & $r_{t}^{\text {next }}$ & $\begin{array}{c}r_{t}^{\text {next }} \\
\Gamma_{t}^{\text {next }}\end{array}$ \\
\hline$\Gamma_{t}^{H E T P}$ & $-44.416^{* *}$ & $-41.310^{*}$ & -31.825 & & & \\
& $(-1.984)$ & $(-1.875)$ & $(-1.492)$ & & & \\
$r_{t}^{\text {incl. jump }}$ & & & & -0.220 & -0.349 & -0.405 \\
& $-0.952^{* * *}$ & $-0.965^{* * *}$ & $-0.951^{* * *}$ & $-0.711^{* *}$ & $-0.596^{* *}$ & $-0.596^{* *}$ \\
\hline Observations & 339,552 & 559,520 & 645,246 & 500,036 & 716,298 & 795,337 \\
Entity FE & Yes & Yes & Yes & Yes & Yes & Yes \\
Time FE & Yes & Yes & Yes & Yes & Yes & Yes \\
SEs & {$[\mathrm{t} ; \mathrm{j}]$} & {$[\mathrm{t} ; \mathrm{j}]$} & {$[\mathrm{t} ; \mathrm{j}]$} & {$[\mathrm{t} ; \mathrm{j}]$} & {$[\mathrm{t} ; \mathrm{j}]$} & {$[\mathrm{t} ; \mathrm{j}]$} \\
Jumps Until & $12: 00$ & $14: 00$ & $15: 00$ & $12: 00$ & $14: 00$ & $15: 00$ \\
\hline
\end{tabular}

close up to the end of the interval when the jump has occurred $\left(r_{t}^{\text {incl. jump }}\right)$ and relate it to the return in the subsequent 30-minute interval $\left(r_{t}^{\text {next }}\right)$, and to $\Gamma^{H P}$ and $\Omega^{L E T F}$ computed using $r_{t}^{\text {incl. jump }}$. In Table 10 we separately report regressions for jump events occurring on expanding portions of a trading, from those observed until 12:00 in columns (1) and (4), to those observed until 15:00 in columns (3) and (6). The underlying idea is that market makers may want to hedge large price movements only if they occur early during the day, and wait for favorable market conditions at the close otherwise. Notice that we intentionally leave out the last 30 minutes of the trading day from this exercise to avoid conflating the results presented here with the end-of-day evidence.

For $\Gamma^{H P}$ we find large and significant negative coefficients, indicating a stronger effect 
than in our baseline specification. This suggests that option market makers aggressively rebalance their exposure after particularly large price movements. Interestingly, the effect is stronger for jumps in the first part of the trading day, supporting the idea that option market makers may decide to wait to re-hedge after late jump events to take advantage of favorable liquidity patterns at the close (Lou et al., 2019; Andersen and Bollerslev, 1997). The impact for leveraged ETF rebalancing, instead, is not significantly different from zero in all specifications. These results confirm Figure 6, indicating that leveraged ETFs market makers rebalance only at the very end of the trading day, even if large price swings occurred intraday.

\section{Table 11: End-of-day Delta-Hedging on Identified Jump Days}

The table reports the effect of end-of-day delta-hedging on end-of-day returns, conditional on the occurrence of an intraday jump. Precisely, we reset the Gamma exposure of option market makers at the time the jump has occurred and re-estimate the aggregate Gamma exposure of option market makers at 15:30, $\left(\Gamma_{t}^{H P}\right)$, given by the product of the return after the jump until 15:30 ( $\left.r^{\text {after jump }}\right)$ and the gamma imbalance. We vary times until we consider jumps (Jumps Until). T-statistics are in parentheses below and are computed using time-and-entity-clustered standard errors. ${ }^{* * *},{ }^{* *},{ }^{*}$ denotes significance at the $1 \%, 5 \%, 10 \%$ level. We include entity fixed effects in all specifications and value-weight observations. The sample period is January 2012 - December 2019.

\begin{tabular}{lccc}
\hline & $(1)$ & $(2)$ & $(3)$ \\
Dependent & $r_{t}^{\text {end }}$ & $r_{t}^{\text {end }}$ & $r_{t}^{\text {end }}$ \\
\hline$\Gamma_{t}^{H P}$ & -34.546 & $-43.904^{* *}$ & $-46.904^{* *}$ \\
& $(-1.575)$ & $(-2.069)$ & $(-2.330)$ \\
$r^{\text {after jump }}$ & $-0.825^{* * *}$ & $-0.832^{* * *}$ & $-0.862^{* * *}$ \\
& $(-3.678)$ & $(-3.762)$ & $(-3.953)$ \\
\hline Observations & 339,552 & 559,520 & 645,246 \\
Entity FE & Yes & Yes & Yes \\
Time FE & Yes & Yes & Yes \\
SEs & {$[\mathrm{t} ; \mathrm{j}]$} & {$[\mathrm{t} ; \mathrm{j}]$} & {$[\mathrm{t} ; \mathrm{j}]$} \\
Jumps Until & $12: 00$ & $14: 00$ & $15: 00$ \\
\hline
\end{tabular}

To further investigate how option market makers exploit the discretionary nature of their re-hedging needs, we focus on the gamma imbalance accumulated only during and after a jump event. We thus assume that the market maker re-hedges her accrued directional exposure after the jump, such that the remaining exposure amounts to

$$
\Gamma_{t}^{H P}=100 \times \Gamma^{I B}(t-1, S) \times r^{\text {after jump }},
$$


where $r^{\text {after jumps }}$ measures the return of the underlying after the identified jump period until 15:30.

The results reported in Table 11 provide evidence of end-of-day rebalancing on identified jump-days only for jumps that happen relatively late during a trading day. In fact, the pattern of significance and the magnitude of coefficients inversely match the pattern in Table 10 for the impact of hedging directly after large price movements. The later the identified jump, the less likely will a market maker rebalance her exposure right away. Adding to the considerations of Clewlow and Hodges (1997), we find that market makers tend to rapidly rebalance after early jumps, while they tend to wait until trading closes for later jumps. ${ }^{21}$

Considering the amount of trading on identified jump days corroborates this idea. In Figure 7 we show the trading volume for the average stock in our sample, relative to the intraday volume pattern we observe on the typical day (also shown in the last panel of the Figure). From the plot we can make three observations: First, if a jump occurs on a given day, the 30 minutes immediately after the jump and the last 30 minutes of the trading day experience the most trading activity. Second, if the jump occured early in the day (before 13:30) we find the trading activity in the 30 minutes after the jump to occasionally exceed that end-of-day. Third, if instead we consider late jumps (after 13:30), most trading happens in the last half hour. Together, these results are consistent with the idea that option market makers hedge mostly early jumps immediately.

\subsection{Mechanical}

We hypothesize that rebalancing activities of option market makers and leveraged ETF swap counterparties do not reflect fundamental values, but solely originate from the existence of derivative markets. If this is the case, neither source of rebalancing should depend on the current market environment or the reason for why stocks and benchmark ETFs moved before the hedging window.

\section{Index versus Stock Specific Effects}

While Gamma rebalancing activity depends on the return of the underlying stock, the rebalancing amount for leveraged ETFs instead depends on the return of the benchmark index of the leveraged ETF. We exploit this unique structure of the rebalancing flows from

\footnotetext{
${ }^{21}$ We show that the rebalancing impact after jumps differs between large and small stocks in our sample in Tables OA6.1- OA6.3 in the Internet Appendix.
} 

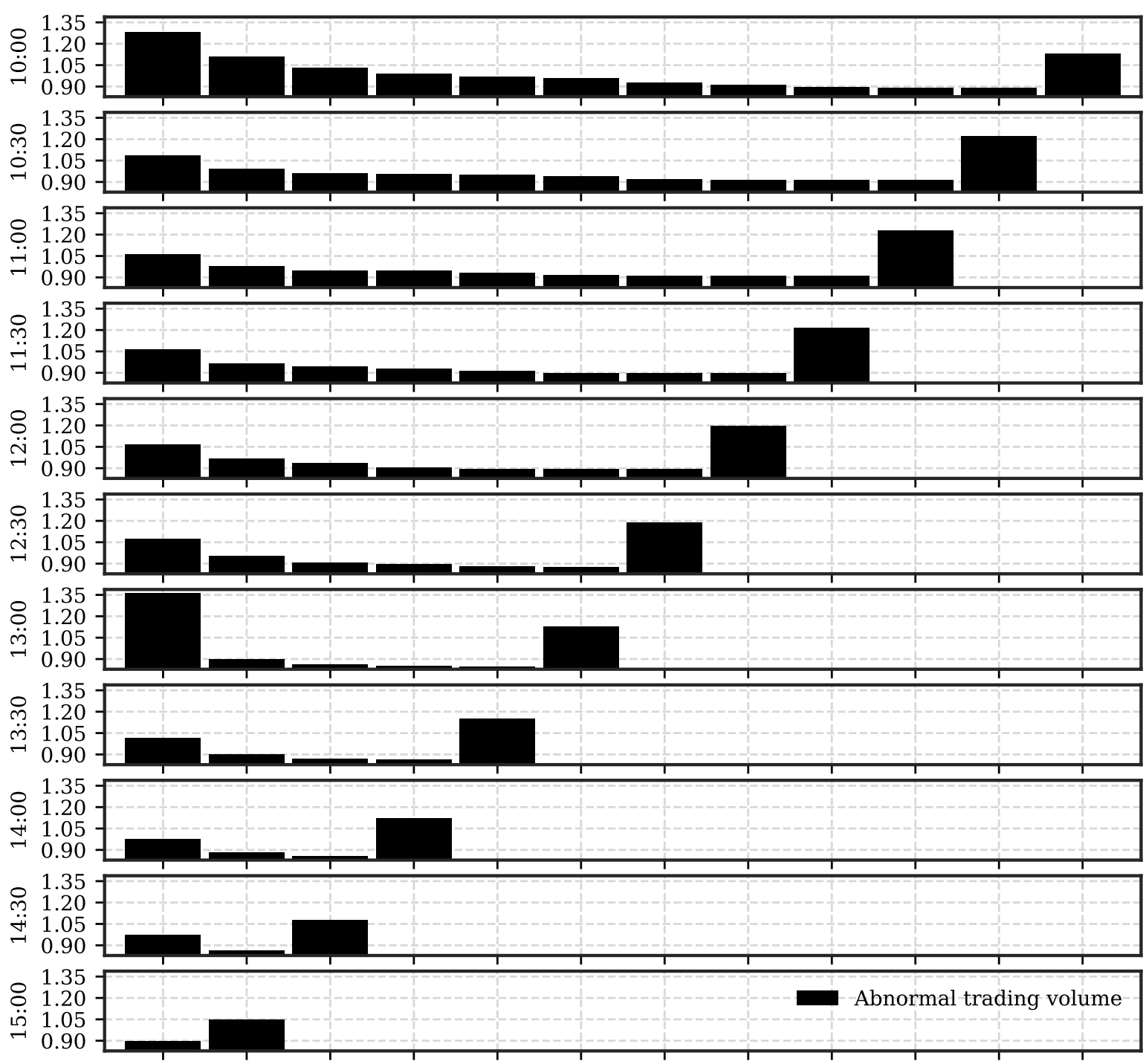

Interval after jump

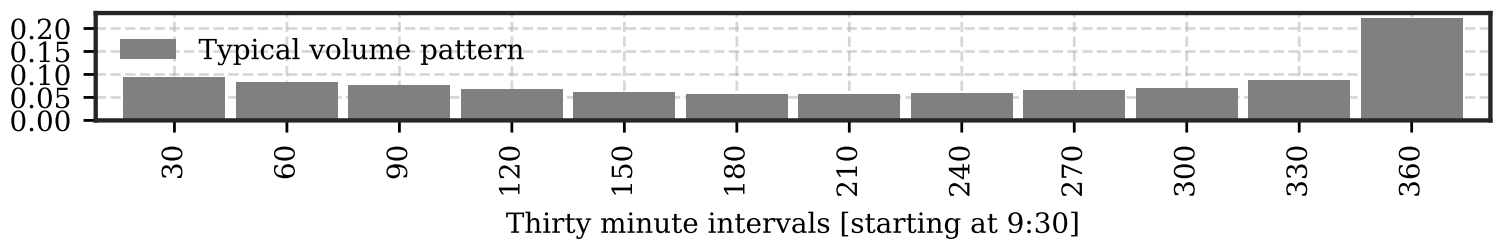

Fig. 7. Volume Patterns on Jump Days

The figure shows the intraday volume pattern for the average stock in our sample between 2012 and 2019 on identified jump days. The intraday volume pattern is expressed relative to the average volume pattern on a typical day, which is shown in the last panel in gray. The other panels show the relative trading activity conditional on when the jump in the underlying stock occurred, varying between all but the last possible thirty minute interval. 
leveraged ETFs, by conditioning on those stocks for which the return until hedging begins is near zero (below $10 \mathrm{bps}$ ). Given that the impact of rebalancing flows is mechanical, we still expect an effect of $\Omega^{L E T F}$ in roughly the same magnitude as for the full sample. This approach allows us to investigate the impact of leveraged ETF rebalancing without being conflated by other intraday return phenomena (Heston et al., 2010; Lou et al., 2019; Bogousslavsky, 2020), or option rebalancing in the form of $\Gamma^{H P}$. The results in Table 12 confirm our prior.

Table 12: Near Zero Returns of the Underlying Stock

The table reports the results to regressing returns in the last half hour of a trading day on the Leverage ETF rebalancing quantity $\Omega^{L E T F}$. We have included only stock-day observations for which the absolute return from previous day's close until 15:30 of stock $j$ is below 10 basis points. T-statistics are in parentheses below and are computed using time-and-entity-clustered standard errors. ${ }^{* * *},{ }^{* *},{ }^{*}$ denotes significance at the $1 \%, 5 \%, 10 \%$ level. We include entity fixed effects in all specifications and value-weight observations. The sample period is January 2012 - December 2019.

\begin{tabular}{lccc}
\hline & $(1)$ & $(2)$ & $(3)$ \\
Dependent & $r_{t}^{\text {end }}$ & $r_{t}^{\text {end }}$ & $r_{t}^{\text {end }}$ \\
\hline$\Omega_{t}^{\text {LETF }}$ & & $71.441^{* * *}$ & $71.697^{* * *}$ \\
$r_{t}^{\text {pre }}$ & & $(5.212)$ & $(5.246)$ \\
& -0.912 & & -1.242 \\
Observations & $(-0.427)$ & & $(-0.579)$ \\
Entity FE & Yes & Yes & Yes \\
Time FE & Yes & Yes & Yes \\
SEs & {$[\mathrm{t} ; \mathrm{j}]$} & {$[\mathrm{t} ; \mathrm{j}]$} & {$[\mathrm{t} ; \mathrm{j}]$} \\
\hline
\end{tabular}

What is the role of news on fundamentals?

To test that delta-hedging effects are unrelated to fundamental news on the underlying stock, we perform sample splits on earnings announcements and material news. We identify the two weeks centered around earnings announcements and the releases of material news as indicated by RavenPack for each stock in our sample. The estimated coefficients for stocks with and without material news releases or earnings announcements in Table 13 barely differ, confirming the mechanical nature of $\Gamma^{H P}$-flows. 


\section{Table 13: Impact of Fundamental Information}

The table reports the results to regressing returns in the last half hour of a trading day on returns until $15: 30, r^{\text {pre }}$, and gamma hedging pressure $\Gamma^{H P}$. The regression results are reported for several subsamples where we focus on or exclude days with fundamental information, either earnings announcements (EA) or fundamental news releases identified by RavenPack. Specification (1) uses the subsample for which Compustat and/or I/B/E/S do not report earnings announcements (EA). Specification (2) excludes dayasset observations for which Compustat and/or I/B/E/S report earnings announcements. In specification (3) we exclude asset-day observations for which RavenPack documents either at least one negative (score $\geq 25$ ) or one positive (score $\leq 75$ ) news appearance, whereas specification (4) includes only these observations. Whenever earnings announcements or fundamental news are released on day $t$ for asset $j$, we exclude also a window of 5 trading days around $t$ for asset $j$. t-statistics are in parentheses below. T-statistics are in parentheses below and are computed using time-and-entity-clustered standard errors. $* * *, * *, *$ denotes significance at the $1 \%, 5 \%, 10 \%$ level. We include entity fixed effects in all specifications and value-weight observations. The sample period is January 2012 - December 2019.

\begin{tabular}{lcccc}
\hline & $(1)$ & $(2)$ & $(3)$ & $(4)$ \\
Dependent & $r_{t}^{\text {end }}$ & $r_{t}^{\text {end }}$ & $r_{t}^{\text {end }}$ & $r_{t}^{\text {end }}$ \\
\hline$\Gamma_{t}^{H P}$ & $-9.430^{* * *}$ & $-9.274^{* *}$ & $-9.589^{* * *}$ & $-9.386^{* * *}$ \\
& $(-4.713)$ & $(-2.317)$ & $(-5.968)$ & $(-2.716)$ \\
$r_{t}^{\text {pre }}$ & $-0.746^{* * *}$ & $-0.933^{* * *}$ & $-0.728^{* * *}$ & $-0.897^{* * *}$ \\
& $(-6.454)$ & $(-5.034)$ & $(-6.268)$ & $(-5.407)$ \\
\hline Observations & $1,639,105$ & 301,045 & $1,603,389$ & 336,761 \\
Entity FE & Yes & Yes & Yes & Yes \\
Time FE & Yes & Yes & Yes & Yes \\
SEs & {$[\mathrm{t} ; \mathrm{j}]$} & {$[\mathrm{t} ; \mathrm{j}]$} & {$[\mathrm{t} ; \mathrm{j}]$} & {$[\mathrm{t} ; \mathrm{j}]$} \\
Subsample & Excluding EA & Only EA & Excluding News & Only News \\
\hline
\end{tabular}

\subsection{Transitory versus Persistent Components}

If the rebalancing activity of market makers exerts enough pressure to push prices from fundamental values, other market participants should pick up on this mispricing and quickly correct it. We therefore expect to see a quick reversal of these effects at the next open. If the impact of rebalancing activity is indeed transitory, we expect returns on the following market open to relate positively to $\Gamma^{H P}$ and negatively to $\Omega^{L E T F}$. To test this hypothesis, we run the panel regressions

$$
r_{j, t}^{\mathrm{night}}=\beta_{0} r_{j, t}^{\mathrm{end}}+\beta_{1} \Gamma_{j, t}^{H P}+\beta_{2} \Omega_{j, t}^{L E T F}+F E_{j}+F E_{t}+\epsilon_{j, t},
$$

where $r_{j, t}^{\text {night }}$ is the return from the close of day $t$ to 10am on day $t+1$.

Table 14 provides evidence for the reversal of $\Gamma^{H P}$ and $\Omega^{L E T F}$ effects at the next 
Table 14: Impact of Joint Rebalancing - Transitory Impact

The table reports the results to regressing returns from closure of day $t$ to 10am on day $t+1$ on returns until 15:30, $r^{\text {pre }}$, on option market maker hedging pressure $\Gamma^{H P}$ and leveraged ETF rebalancing quantity $\Omega^{L E T F}$ following Equation $\sqrt{13}$. We also consider the impact of joint rebalancing activity using the variables defined in Equation (14) in the regression setup proposed in Equation (15). T-statistics are in parentheses below and are computed using time-and-entity-clustered standard errors. ${ }^{* * *}, * *, *$ denotes significance at the $1 \%, 5 \%, 10 \%$ level. We include entity fixed effects in all specifications and value-weight observations. The sample period is January 2012 - December 2019.

\begin{tabular}{lccc}
\hline & $(1)$ & $(2)$ & $(3)$ \\
Dependent & $r_{t}^{\text {night }}$ & $r_{t}^{\text {night }}$ & $r_{t}^{\text {night }}$ \\
\hline$\Gamma_{t}^{H P}$ & $31.868^{* * *}$ & & $34.339^{* * *}$ \\
& $(3.532)$ & & $(3.734)$ \\
$\Omega_{t}^{L E T F}$ & & $-45.959^{* *}$ & $-59.984^{* * *}$ \\
& & $(-2.108)$ & $(-2.685)$ \\
$r_{t}^{\text {end }}$ & $-12.439^{* * *}$ & $-12.553^{* * *}$ & $-12.364^{* * *}$ \\
& $(-4.902)$ & $(-4.927)$ & $(-4.887)$ \\
\hline Observations & $1,939,895$ & $1,939,895$ & $1,939,895$ \\
Entity FE & Yes & Yes & Yes \\
Time FE & Yes & Yes & Yes \\
SEs & {$[\mathrm{t} ; \mathrm{j}]$} & {$[\mathrm{t} ; \mathrm{j}]$} & {$[\mathrm{t} ; \mathrm{j}]$} \\
\hline
\end{tabular}

open. In specifications (1) and (2), the coefficient on $\Gamma^{H P}$ is positive at 31.868 (t-value: 3.53 ), while that on $\Omega^{L E T F}$ is negative at -45.959 (t-value: -2.108 ), suggesting that price effects from the previous day are short-lived. In column (3), where both channels are considered jointly, the estimated reversal effects are even stronger. Returns at the open are about four times as disperse than end-of-day returns when measured by the respective standard deviation. In economic terms, we therefore find that on average $82 \%$ of the impact of delta-hedging and $32 \%$ of the impact of leveraged ETF rebalancing is reversed at the next open.

\subsection{Subsample Analysis}

We re-run our baseline regression for the first three years in our sample, shift the starting and end date by one day, and repeat this procedure for all years in the joint sample (20122019). The resulting coefficients for $\Gamma^{H P}$ are provided as the blue line in Figure 8, while those for $\Omega^{L E T F}$ are provided as the green line. Corresponding t-statistics are presented in the lower panel. The impact of $\Gamma^{H P}$ has stayed nearly unchanged until the end 2016 at 

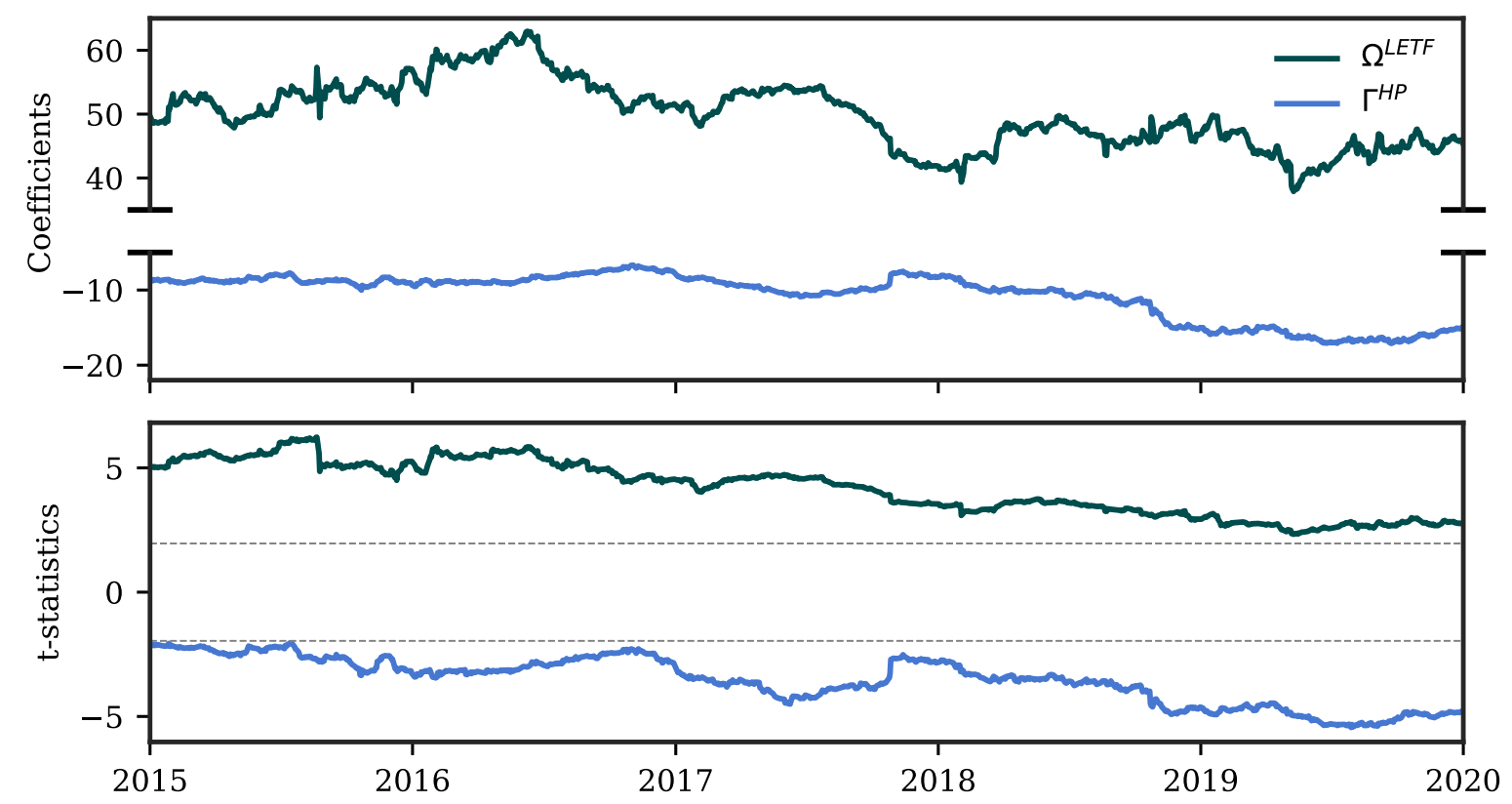

Fig. 8. Rolling Regressions

The figure depicts the impact of $\Gamma^{H P}$ and $\Omega^{L E T F}$ over time, as measured on a rolling basis for each three year-period starting in January 2012. Specifically, we estimate Equation (10) and Equation (6) for the first three years in our sample, shift the starting and end date by one day, and repeat this for all days in our joint sample (January 2012 - December 2019). The upper panel depicts the estimated coefficients for $\Gamma^{H P}$ and $\Omega^{L E T F}$, whereas the lower panel shows the corresponding $t$-statistics.

an estimated coefficient of roughly -9 , but has started to increase in absolute magnitude afterwards. In fact, during 2019 the magnitude of the effect has increased to a coefficient of -16 . The estimated coefficient for $\Omega^{L E T F}$ stayed within the same ballpark over time, fluctuating between 40 and 60, with a mean around 50 for the years 2012 through 2019 . The impact of both rebalancing activities was statistically highly significant throughout our sample.

\subsection{Market Capitalization Effects}

The impact of rebalancing flows may differ between stocks of different market capitalization. On the one hand, we might find a stronger impact for small stocks, given that the same amount of nominal trading potentially influences prices more, as a result of their limited liquidity. On the other hand, large stocks are typically included in multiple leveraged ETFs and enjoy a bigger and more liquid options market. The results in Table 8 have already hinted towards roughly constant effects of $\Gamma^{H P}$ for stocks of differing market size, but outsized effects of $\Omega^{L E T F}$ on small issues. To investigate this more formally, we 
Table 15: Impact of Joint Rebalancing - Small vs. Large Caps

The table reports the results to regressing returns in the last half hour of a trading day on returns until 15:30, $r^{\text {pre }}$, on option market maker hedging pressure $\Gamma^{H P}$ and leveraged ETF rebalancing quantity $\Omega^{L E T F}$ following Equation $(13)$. We also consider the impact of joint rebalancing activity using the variables defined in Equation (14) in the regression setup proposed in Equation (15). T-statistics are in parentheses below and are computed using time-and-entity-clustered standard errors. ${ }^{* * *},{ }^{* *},{ }^{*}$ denotes significance at the 1\%,5\%,10\% level. We include entity fixed effects in all specifications and value-weight observations. The sample period is January 2012 - December 2019.

\begin{tabular}{lcccccc}
\hline & $(1)$ & $(2)$ & $(3)$ & $(4)$ & $(5)$ & $(6)$ \\
Dependent & $r_{t}^{\text {end }}$ & $r_{t}^{\text {end }}$ & $r_{t}^{\text {end }}$ & $r_{t}^{\text {end }}$ & $r_{t}^{\text {end }}$ & $r_{t}^{\text {end }}$ \\
\hline$\Gamma_{t}^{H P}$ & $-14.997^{* * *}$ & & $-14.748^{* * *}$ & $-7.917^{* * *}$ & & $-9.424^{* * *}$ \\
& $(-5.542)$ & & $(-5.461)$ & $(-3.826)$ & & $(-4.602)$ \\
$\Omega_{t}^{L E T F}$ & & $47.120^{* * *}$ & $46.951^{* * *}$ & & $41.185^{* * *}$ & $44.714^{* * *}$ \\
& & $(8.366)$ & $(8.342)$ & & $(3.663)$ & $(3.977)$ \\
$r_{t}^{\text {pre }}$ & $-0.253^{* * *}$ & $-0.271^{* * *}$ & $-0.265^{* * *}$ & $-0.955^{* * *}$ & $-1.090^{* * *}$ & $-1.012^{* * *}$ \\
& $(-3.191)$ & $(-3.435)$ & $(-3.358)$ & $(-7.083)$ & $(-8.177)$ & $(-7.487)$ \\
\hline Observations & 970,574 & 970,574 & 970,574 & 969,576 & 969,576 & 969,576 \\
Entity FE & Yes & Yes & Yes & Yes & Yes & Yes \\
Time FE & Yes & Yes & Yes & Yes & Yes & Yes \\
SEs & {$[\mathrm{t} ; \mathrm{j}]$} & {$[\mathrm{t} ; \mathrm{j}]$} & {$[\mathrm{t} ; \mathrm{j}]$} & {$[\mathrm{t} ; \mathrm{j}]$} & {$[\mathrm{t} ; \mathrm{j}]$} & {$[\mathrm{t} ; \mathrm{j}]$} \\
Market Cap & Small & Small & Small & Large & Large & Large \\
\hline
\end{tabular}

split our sample by the prevailing cross-sectional median of last month's average market capitalization and redo the regression in Equation (13) for each subsample. The results are shown in Table 15. The estimated coefficient of $\Gamma^{H P}$ is elevated for small stocks. At the same time, however, small stocks are known to be more volatile (Fama and French, 1993). Empirically, the standard deviation of $r^{\text {end }}$ is twice as large for small stocks as it is for large stocks. Taken together, we find that a one standard deviation increase in $\Gamma^{H P}$ depresses end-of-day returns on large stocks by $1.03 \%$ return standard deviations, while the effect amounts to only $0.73 \%$ return standard deviations for small stocks.

In contrast, while the estimated coefficient for $\Omega^{L E T F}$ is roughly the same between the larger and smaller stocks in our sample, the resulting impact in terms of standard deviations of $r^{\text {end }}$ is slightly larger for small stocks (2.71\% vs. $\left.2.33 \%\right)$. The larger fluctuation of end-of-day returns of small stocks is offset by a comparably large increase in the fluctuation of $\Omega^{L E T F}$. 


\subsection{Other Robustness Tests}

The Online Appendix contains a battery of additional robustness tests. Our results are robust to the choice of the look-back window to compute ADV (Appendix OA3) or to using scaled returns following Moskowitz et al. (2012) (Appendix OA4). Furthermore, delta-hedging and leveraged ETF rebalancing are present across all industries (Appendix OA5).

\section{Conclusion}

A growing literature focuses on cross-sectional intraday return variation, linking it to investor heterogeneity on the stock-level. In this paper, we provide novel insights in how derivative markets add to cross-sectional variation towards the end of the trading day. By drawing upon a unique dataset merging data from several exchanges identifying types of market participants in U.S. stock options and the portfolio composition of U.S. equity-focused leveraged ETFs, we document large price pressure on end-of-day returns when market makers engage in delta-hedging their option portfolios and rebalance their positional exposure from total return swaps replicating leveraged ETFs.

We show that delta-hedging and leveraged ETF rebalancing exert economically large price pressure on end-of-day returns. Whereas leveraged ETFs contribute to a market wide momentum effect, delta-hedging can either have a stabilizing effect in the form of end-of-day reversal, but also exaggerate intraday momentum. The direction is determined by the previous return of the underlying and aggregate option inventory of market makers. Moreover, our results reveal that option market makers have discretion on the execution of their hedging strategies, especially after intraday jumps. On the contrary, leveraged ETF swap counterparties are required to establish the target exposure of the fund at the close. We find that both rebalancing effects are mechanical, that is, they do not impound new fundamental information into prices. Given that the impact of rebalancing is mechanical in nature, we also document that it is transitory, as the effects reverse at the next open. The documented effects are present for all years between 2012 and 2019 and the impact of delta-hedging is amplified within the largest stocks in the CRSP universe. 


\section{References}

Andersen, T. G., Bollerslev, T., 1997. Intraday periodicity and volatility persistence in financial markets. Journal of Empirical Finance 4, 115-158.

Andersen, T. G., Bondarenko, O., Gonzalez-Perez, M. T., 2015. Exploring return dynamics via corridor implied volatility. Review of Financial Studies 28, 2902-2945.

Baltussen, G., Da, Z., Lammers, S., Martens, M., 2020. Hedging demand and market intraday momentum. Journal of Financial Economics Forthcoming.

Barbon, A., Buraschi, A., 2020. Gamma fragility. Working paper, University of St.Gallen, School of Finance Research Paper.

Black, F., 1975. Fact and Fantasy in the Use of Options. Financial Analysts Journal 31, $36-41+61-72$.

Blau, B. M., Nguyen, N., Whitby, R. J., 2014. The information content of option ratios. Journal of Banking and Finance 43, 179 - 187.

Bogousslavsky, V., 2020. The Cross-Section of Intraday and Overnight Returns. Working paper.

Bogousslavsky, V., Muravyev, D., 2020. Who trades at the close? implications for price discovery, liquidity. Working paper.

Cheng, M., Madhavan, A., 2010. The dynamics of leveraged and inverse exchange-traded funds. Journal of Investment Management 7, 43-62.

Clewlow, L., Hodges, S., 1997. Optimal delta-hedging under transactions costs. Journal of Economic Dynamics and Control 21, 1353-1376.

Cremers, M., Weinbaum, D., 2010. Deviations from put-call parity and stock return predictability. Journal of Financial and Quantitative Analysis 45, 335-367.

Davies, P. J., 2019. Markets are calm, then suddenly go crazy. some investors think they know why. Wallstreet Journal, July 9, 2019.

Dellavigna, S., Pollet, J. M., 2009. Investor Inattention and Friday Earnings Announcements. Journal of Finance 64, 709-749. 
Fama, E. F., French, K. R., 1993. Common risk factors in the returns on stocks and bonds. Journal of Financial Economics 33, 3 - 56.

Fama, E. F., French, K. R., 2015. A five-factor asset pricing model. Journal of Financial Economics 116, 1-22.

Fournier, M., Jacobs, K., 2020. A Tractable Framework for Option Pricing with Dynamic Market Maker Inventory and Wealth. Journal of Financial and Quantitative Analysis $55,1117-1162$.

Frey, R., 1998. Perfect option hedging for a large trader. Finance and Stochastics 2, $115-141$.

Frey, R., Stremme, A., 1997. Market volatility and feedback effects from dynamic hedging. Mathematical Finance 7, 351-374.

Gao, L., Han, Y., Zhengzi Li, S., Zhou, G., 2018. Market intraday momentum. Journal of Financial Economics 129, 394-414.

Ge, L., Lin, T.-C., Pearson, N. D., 2016. Why does the option to stock volume ratio predict stock returns? Journal of Financial Economics 120, 601-622.

Golez, B., Jackwerth, J. C., 2012. Pinning in the s\&p 500 futures. Journal of Financial Economics 106, $566-585$.

Gârleanu, N., Pedersen, L. H., Poteshman, A. M., 2009. Demand-Based Option Pricing. Review of Financial Studies 22, 4259-4299.

He, Z., Kelly, B., Manela, A., 2017. Intermediary asset pricing: New evidence from many asset classes. Journal of Financial Economics 126, 1-35.

Heston, S. L., Korajczyk, R. A., Sadka, R., 2010. Intraday patterns in the cross-section of stock returns. Journal of Finance 65, 1369-1407.

$\mathrm{Hu}$, J., 2014. Does option trading convey stock price information $\alpha$. Journal of Financial Economics 111, 625-645.

Jacobs, K., Mai, A. T., 2020. The role of intermediaries in derivatives markets: Evidence from vix options. Working paper. 
Jiang, J., Kelly, B. T., Xiu, D., 2020. (re-) imag (in) ing price trends. Chicago Booth Research Paper .

Johnson, T., Liang, M., Liu, Y., 2016. What Drives Index Options Exposures?*. Review of Finance 22, 561-593.

Komarov, O., 2017. Intra-day momentum. Working paper.

Lou, D., Polk, C., Skouras, S., 2019. A tug of war: Overnight versus intraday expected returns. Journal of Financial Economics 134, 192-213.

Moskowitz, T. J., Ooi, Y. H., Pedersen, L. H., 2012. Time series momentum. Journal of Financial Economics 104, 228 - 250, special Issue on Investor Sentiment.

Ni, S. X., Pearson, N. D., Poteshman, A. M., 2005. Stock price clustering on option expiration dates. Journal of Financial Economics 78, 49-87.

Ni, S. X., Pearson, N. D., Poteshman, A. M., White, J., 2020. Does Option Trading Have a Pervasive Impact on Underlying Stock Prices? Review of Financial Studies Hhaa082.

Pan, J., Poteshman, A. M., 2006. The Information in Option Volume for Future Stock Prices. Review of Financial Studies 19, 871-908.

Platen, E., Schweizer, M., 1998. On feedback effects from hedging derivatives. Mathematical Finance 8, 67-84.

Roll, R., Schwartz, E., Subrahmanyam, A., 2010. O/s: The relative trading activity in options and stock. Journal of Financial Economics 96, 1 - 17.

Sircar, K. R., Papanicolaou, G., 1998. General black-scholes models accounting for increased market volatility from hedging strategies. Applied Mathematical Finance 5, $45-82$.

Wilmott, P., Schönbucher, P. J., 2000. The feedback effect of hedging in illiquid markets. SIAM Journal on Applied Mathematics 61, 232-272. 


\section{Appendix A. Cleaning of High-Frequency Data}

To analyze intraday momentum effects in individual stocks, we rely on the NYSE Trades and Quote (TAQ) database for January 1996 through July 2019. Since the NYSE provides the raw tape of all trades performed on the included exchanges, multiple cleaning steps are required. Additionally, we merge the TAQ database with CRSP to use the PERMNO as a unique identifier per common share of any company.

\section{A.1. Cleaning Procedure}

We retain only trades with trade correction indicators "00" an "01", which refer to correctly recorded trades, and those that have been subsequently altered, but reflect the actual trade price at the time. We further keep only trades with trade sale corrections "Z", "B", "U", "T", "L", "G", "W", "K", and "J", as well as an accompanying "I" reflecting odd lot trades. To rely on trade prices during regular trading hours only, we discard all observations before 9:30 and after 16:01. We explicitly include the minute of $4 \mathrm{pm}$, as many closing trades (denoted by sale conditions "6" or "M") fall within the first few seconds afterwards.

If multiple trades occur at exactly the same point in time, we take the median price as the "correct price". To make sure that prices are consistent by Ticker, we employ a bounce-back filter following Andersen, Bondarenko, and Gonzalez-Perez (2015), which effectively checks whether any trade's price deviates by more than 15 times the median absolute deviation of the day. If this is the case, we will kick this observation if we observe a reversion to the previous price within the next five minutes, or 10 trades, whichever encompasses more trades. We also drop price observations which deviate by more than two times $\left|\log \left(p_{t} / \hat{p}\right)\right|$, where $\hat{p}$ is the median for the day. We choose trade-based filters to check for the internal consistency, instead of relying on the Quote database also provided by the NYSE, as some observations are falsely recorded in both. Afterwards, we span a minute-by-minute grid between 9:30 and 16:01 and map trades to these trading minutes, taking the volume-weighted average price within each minute to limit the impact of microstructure noise and single trades.

\section{A.2. Merge with $C R S P$}

The TAQ database provides intraday trade prices, but lacks information about distributions, mergers, and delistings. We obtain this information from CRSP, as the low- 
frequency database in financial economics.

We use the PERMNO provided by CRSP as an identifier that is unique over time. In a first step, we merge the historical CUSIP by CRSP (NCUSIP) with the CUSIPs in the master file taken from TAQ. In some occasions, we cannot merge available tickers in the trade file this way, and in a second step merge the two databases by the root ticker and ticker suffix, which indicates different share classes. We keep only stocks with share codes 10 and 11, denoting common shares, as well as exchange codes 1, 2, 3, 31, 32 and 32, representing the NYSE, AMEX and NASDAQ, respectively. Using this procedure, we can merge most stocks for which we have intraday data available and cover most of the CRSP sample. Since we are interested in the impact of market maker hedging activity, we retain only those stocks that are optionable, i.e. for which options have traded between May 2005 and July 2020. 


\section{Appendix B. Detailed Summary Statistics on $\Gamma^{H P}$ and $\Omega^{L E T F}$}

Table B1 provides detailed summary statistics on the main variables of interest in the main paper. Panel A in Table B1 provides the summary statistics for the joint sample, that is, every stock in the joint sample is optionable and included in a benchmark index of at least on leveraged ETF. Panel B in Table B1 provides the summary statistics for the sample of optionable stocks. Panel C in Table B1 provides the summary statistics for the sample of stocks included in benchmark indices of leveraged ETFs. 
Table B1: Summary Statistics

The table reports means, standard deviations, and quantiles for the gamma, leveraged ETF variables and returns used in the regression models. The descriptive statistics are first computed for each day and subsequently averaged across all days. $r^{\text {pre }}, r^{\text {night }}$ and $r^{\text {end }}$ are denoted in basis points. ADV ${ }^{\text {end }}$ is given in million USD. $\Gamma^{I B}, \Gamma^{H P}, \Omega^{L E T F}$ and their corresponding absolute values are given percentage. The sample periods and data sets are given in the panel titles.

\begin{tabular}{|c|c|c|c|c|c|c|c|c|c|}
\hline & Mean & Std & $2.5 \%$ & $10 \%$ & $25 \%$ & $50 \%$ & $75 \%$ & $90 \%$ & $97.5 \%$ \\
\hline \multicolumn{10}{|c|}{ Panel A: Joint (2012-2019) } \\
\hline$r^{\text {pre }}$ & 6.26 & 240.49 & -405.97 & -194.44 & -83.0 & 4.92 & 91.94 & 202.79 & 429.13 \\
\hline$r^{\text {end }}$ & 0.32 & 45.57 & -81.2 & -40.28 & -18.45 & -0.53 & 17.81 & 41.16 & 87.12 \\
\hline$r^{\text {night }}$ & 4.25 & 174.25 & -258.07 & -119.93 & -51.63 & 3.0 & 57.79 & 127.89 & 276.07 \\
\hline $\mathrm{ADV}^{\mathrm{end}}$ & 22.87 & 65.36 & 0.23 & 0.74 & 2.13 & 6.75 & 20.24 & 49.5 & 147.74 \\
\hline$\Gamma^{I B}$ & 0.55 & 3.66 & -4.26 & -1.37 & -0.26 & 0.08 & 0.94 & 3.0 & 7.51 \\
\hline$\left|\Gamma^{I B}\right|$ & 1.56 & 3.34 & 0.0 & 0.03 & 0.14 & 0.56 & 1.72 & 3.95 & 8.82 \\
\hline$\Gamma^{H P}$ & 0.03 & 6.42 & -8.22 & -2.4 & -0.49 & 0.0 & 0.53 & 2.53 & 8.51 \\
\hline$\left|\Gamma^{H P}\right|$ & 2.06 & 6.06 & 0.0 & 0.02 & 0.1 & 0.49 & 1.85 & 4.97 & 13.2 \\
\hline$\Omega^{L E T F}$ & 0.15 & 2.71 & -3.54 & -1.91 & -0.95 & 0.1 & 1.2 & 2.27 & 4.08 \\
\hline$\left|\Omega^{L E T F}\right|$ & 1.88 & 2.66 & 0.03 & 0.17 & 0.44 & 1.1 & 2.56 & 4.32 & 7.46 \\
\hline$\Omega^{L E T F}-\Gamma^{H P}$ & 0.12 & 7.25 & -9.8 & -3.65 & -1.38 & 0.1 & 1.62 & 3.92 & 9.91 \\
\hline$\left|\Omega^{L E T F}-\Gamma^{H P}\right|$ & 3.3 & 6.64 & 0.06 & 0.23 & 0.65 & 1.75 & 3.8 & 7.14 & 15.31 \\
\hline \multicolumn{10}{|c|}{ Panel B: Gamma Exposure (2005-2020) } \\
\hline$r^{\text {pre }}$ & 6.06 & 233.35 & -397.66 & -192.07 & -83.06 & 4.4 & 91.48 & 200.9 & 421.69 \\
\hline$r^{\text {end }}$ & 0.42 & 53.35 & -96.42 & -46.93 & -21.04 & -0.47 & 20.64 & 48.06 & 102.65 \\
\hline$r^{\text {night }}$ & 3.21 & 168.23 & -252.12 & -117.57 & -51.26 & 2.03 & 55.45 & 122.94 & 267.22 \\
\hline $\mathrm{ADV}^{\mathrm{end}}$ & 13.93 & 49.65 & 0.08 & 0.22 & 0.7 & 2.68 & 9.84 & 29.94 & 97.8 \\
\hline$\Omega^{L E T F}$ & 0.36 & 48.13 & -6.0 & -3.35 & -1.7 & 0.16 & 2.09 & 3.98 & 7.04 \\
\hline$\left|\Omega^{L E T F}\right|$ & 4.83 & 48.11 & 0.02 & 0.2 & 0.61 & 2.1 & 4.38 & 7.51 & 12.95 \\
\hline \multicolumn{10}{|c|}{ Panel C: LETF Rebalancing (2012-2019) } \\
\hline$r^{\text {pre }}$ & 3.53 & 260.04 & -442.13 & -222.4 & -100.77 & 0.23 & 101.71 & 226.63 & 470.58 \\
\hline$r^{\text {end }}$ & 1.13 & 56.7 & -95.23 & -46.36 & -21.02 & 0.03 & 21.68 & 48.96 & 104.39 \\
\hline$r^{\text {night }}$ & 2.4 & 183.8 & -281.23 & -138.01 & -63.03 & -0.05 & 63.75 & 142.38 & 301.99 \\
\hline $\mathrm{ADV}^{\mathrm{end}}$ & 19.51 & 52.36 & 0.26 & 0.79 & 2.14 & 6.27 & 18.0 & 43.17 & 119.79 \\
\hline$\Gamma^{I B}$ & 0.38 & 3.57 & -4.7 & -1.84 & -0.53 & 0.05 & 0.95 & 2.87 & 7.01 \\
\hline$\left|\Gamma^{I B}\right|$ & 1.64 & 3.17 & 0.01 & 0.06 & 0.22 & 0.72 & 1.91 & 4.01 & 8.46 \\
\hline$\Gamma^{H P}$ & 0.01 & 6.99 & -9.05 & -2.87 & -0.68 & -0.0 & 0.69 & 2.94 & 9.22 \\
\hline$\left|\Gamma^{H P}\right|$ & 2.34 & 6.53 & 0.0 & 0.03 & 0.16 & 0.68 & 2.24 & 5.6 & 14.13 \\
\hline
\end{tabular}




\section{Appendix C. Different Sets of Delta-Hedgers}

We investigate whether the choice of the set of delta-hedgers skews our results. In the main part of the paper, we have assumed that delta-hedgers are composed of market makers and broker/dealers. We exchange the set of delta-hedgers to include only market makers (Table C2) or to include market makers, broker/dealers, and firm proprietary traders (Table C3). The choice of the set of likely delta-hedgers has little impact on our results.

\section{Table C2: Market Makers as the only Delta-Hedgers}

The table reports the results to regressing returns in the last half hour of a trading day on returns until 15:30, $r^{\text {pre }}$ and market maker hedging pressure $\Gamma^{H P}$, following Equation 107 . We assume that market makers are delta-hedgers. T-statistics in parentheses are derived from standard errors clustered by date and entity. ${ }^{* *},{ }^{* *},{ }^{*}$ denotes significance at the $1 \%, 5 \%, 10 \%$ level. We include entity fixed effects and weight returns by the stock's market capitalization. The sample period is May 2005 - July 2020.

\begin{tabular}{|c|c|c|c|c|c|}
\hline Dependent & $\begin{array}{c}(1) \\
r_{t}^{\text {end }}\end{array}$ & $\begin{array}{c}(2) \\
r_{t}^{\text {end }} \\
\end{array}$ & $\begin{array}{c}(3) \\
r_{t}^{\text {end }} \\
\end{array}$ & $\begin{array}{c}(4) \\
r_{t}^{\text {end }} \\
\end{array}$ & $\begin{array}{c}(5) \\
r_{t}^{\text {end }}\end{array}$ \\
\hline$\Gamma_{t}^{H P}$ & $\begin{array}{c}-11.619^{* * *} \\
(-3.926)\end{array}$ & $\begin{array}{c}-11.560^{* * *} \\
(-3.926)\end{array}$ & $\begin{array}{c}-11.564^{* * *} \\
(-3.901)\end{array}$ & $\begin{array}{c}-11.625^{* * *} \\
(-3.928)\end{array}$ & $\begin{array}{c}-11.619^{* * *} \\
(-3.929)\end{array}$ \\
\hline$r_{t}^{\text {pre }}$ & $\begin{array}{c}-0.714^{* * *} \\
(-4.495)\end{array}$ & $\begin{array}{c}-0.715^{* * *} \\
(-4.509)\end{array}$ & $\begin{array}{c}-0.714^{* * *} \\
(-4.497)\end{array}$ & $\begin{array}{c}-0.713^{* * *} \\
(-4.493)\end{array}$ & $\begin{array}{c}-0.713^{* * *} \\
(-4.495)\end{array}$ \\
\hline$I V_{t-1}$ & & $\begin{array}{c}6.095^{* * * *} \\
(3.153)\end{array}$ & & & \\
\hline$\hat{R V_{t}^{e n d}}$ & & & $\begin{array}{c}540.566^{*} \\
(1.957)\end{array}$ & & \\
\hline$P C_{t-1}$ & & & & $\begin{array}{c}0.334 \\
(1.629)\end{array}$ & \\
\hline$O / S_{t-1}^{\$}$ & & & & & $\begin{array}{c}680.601 \\
(1.162) \\
\end{array}$ \\
\hline Observations & $3,365,367$ & $3,365,367$ & $3,365,008$ & $3,358,727$ & $3,365,359$ \\
\hline Entity FE & Yes & Yes & Yes & Yes & Yes \\
\hline Time FE & Yes & Yes & Yes & Yes & Yes \\
\hline SEs & {$[t ; j]$} & {$[\mathrm{t} ; \mathrm{j}]$} & {$[t ; j]$} & {$[\mathrm{t} ; \mathrm{j}]$} & {$[t ; j]$} \\
\hline
\end{tabular}




\section{Table C3: Market Makers, Broker/Dealer, and Firm Proprietary Traders as}

Delta-Hedgers

The table reports the results to regressing returns in the last half hour of a trading day on returns until 15:30, $r^{\text {pre }}$ and market maker hedging pressure $\Gamma^{H P}$, following Equation 10 . We assume that market makers, broker/dealer, and firm proprietary traders are delta-hedgers. T-statistics in parentheses are derived from standard errors clustered by date and entity. ${ }^{* * *}, * *, *$ denotes significance at the $1 \%, 5 \%$, $10 \%$ level. We include entity fixed effects and weight returns by the stock's market capitalization. The sample period is May 2005 - July 2020.

\begin{tabular}{|c|c|c|c|c|c|}
\hline Dependent & $\begin{array}{c}(1) \\
r_{t}^{\text {end }} \\
\end{array}$ & $\begin{array}{c}(2) \\
r_{t}^{\text {end }} \\
\end{array}$ & $\begin{array}{c}(3) \\
r_{t}^{\text {end }} \\
\end{array}$ & $\begin{array}{c}(4) \\
r_{t}^{\text {end }} \\
\end{array}$ & $\begin{array}{c}(5) \\
r_{t}^{\text {end }} \\
\end{array}$ \\
\hline$\Gamma_{t}^{H P}$ & $\begin{array}{c}-16.345^{* * *} \\
(-8.931)\end{array}$ & $\begin{array}{c}-16.309^{* * *} \\
(-8.939)\end{array}$ & $\begin{array}{c}-16.305^{* * *} \\
(-8.915)\end{array}$ & $\begin{array}{c}-16.350^{* * *} \\
(-8.934)\end{array}$ & $\begin{array}{c}-16.341^{* * *} \\
(-8.932)\end{array}$ \\
\hline$r_{t}^{\text {pre }}$ & $\begin{array}{c}-0.627^{* * *} \\
(-3.906)\end{array}$ & $\begin{array}{c}-0.628^{* * *} \\
(-3.920)\end{array}$ & $\begin{array}{c}-0.627^{* * *} \\
(-3.908)\end{array}$ & $\begin{array}{c}-0.626^{* * *} \\
(-3.904)\end{array}$ & $\begin{array}{c}-0.627^{* * *} \\
(-3.906)\end{array}$ \\
\hline$I V_{t-1}$ & & $\begin{array}{c}6.010^{* * * *} \\
(3.104)\end{array}$ & & & \\
\hline$\hat{R V_{t}^{e n d}}$ & & & $\begin{array}{c}525.810^{*} \\
(1.907)\end{array}$ & & \\
\hline$P C_{t-1}$ & & & & $\begin{array}{l}0.341^{*} \\
(1.685)\end{array}$ & \\
\hline$O / S_{t-1}^{\$}$ & & & & & $\begin{array}{c}650.340 \\
(1.087) \\
\end{array}$ \\
\hline Observations & $3,365,367$ & $3,365,367$ & $3,365,006$ & $3,358,716$ & $3,365,359$ \\
\hline Entity FE & Yes & Yes & Yes & Yes & Yes \\
\hline Time FE & Yes & Yes & Yes & Yes & Yes \\
\hline SEs & {$[\mathrm{t} ; \mathrm{j}]$} & {$[t ; j]$} & {$[t ; j]$} & {$[\mathrm{t} ; \mathrm{j}]$} & {$[t ; j]$} \\
\hline
\end{tabular}




\section{Appendix D. $\Gamma^{H P}$ based on "Old" Positions}

Endogeneity concerns regarding Equation (10) might be raised given that traders with public and/or private information on the return of stock $j$ in the last 30 minutes, $r_{j}^{\text {end }}$, choose the option market to exploit this information. To mitigate any concerns, we adopt the idea of Ni et al. (2020). Precisely, we split $\Gamma^{H P}$ in two parts: gamma hedging pressure originating from "old" positions held by delta-hedgers at time $t-\tau$, and gamma hedging pressure stemming from new positions between $t-\tau$ and $t$. Ni et al. (2020) argue that option positions which existed at $t-\tau$ cannot be established due to private and/or public information after the close at $t-\tau$. In case of short-lived private and/or public information, positions at $t-\tau$ are of no use for predicting the return in the last 30 minutes on $t, r^{\text {pre }}$.

To decompose $\Gamma^{H P}$, we first define the gamma imbalance at time $t$ which is based on option positions of delta-hedgers at time $t-\tau$ as

$$
\begin{aligned}
\Gamma_{\tau}^{I B}(t, S) & =\underbrace{\left(\sum_{j=1}^{N_{t-\tau}^{t}} n e t O I_{j, t-1-\tau} \times \Gamma_{j}\left(t-1, S_{t-1}^{\text {close }}\right) \times S_{t}^{15: 30} \times \text { Mult }_{j}\right)}_{(\star)} \\
& \times \frac{S_{t-1}^{\text {close }}}{100} \times \frac{1}{A D V_{t-1}},
\end{aligned}
$$

where $N_{t-\tau}^{t}$ denotes the number of options contracts on an underlying stock that are available at time $t-\tau$ and expire after $t$. The difference between Equation (D1) and Equation (4) in the main paper is that Equation (D1) uses the net open interest of likely delta-hedgers at time $t-\tau$ and sums over options expiring after $t$. However, both definitions use the gamma of option contracts at the previous trading day, $t-1$. Hence, Equation (D1) denotes the gamma imbalance at time $t$ of old positions.

Next, we define the gamma hedging pressure due to old positions as

$$
\Gamma_{t ; \tau}^{H P}=100 \times \Gamma_{\tau}^{I B}(t, S) \times r^{\text {pre }}
$$

We decompose $\Gamma^{H P}$ at time $t$ into the part that is due to old positions existing at time $t-\tau, \Gamma_{t ; \tau}^{H P}$, and the part due to new positions, $\Gamma_{t ; \text { new }}^{H P}$, as follows

$$
\Gamma_{t}^{H P}=\Gamma_{t ; \tau}^{H P}-\Gamma_{t ; \text { new }}^{H P},
$$


where $\Gamma_{t ; \text { new }}^{H P}=\Gamma^{H P}-\Gamma_{t ; \tau}^{H P}$.

Finally, we run the following specification where we control for fixed effects and other control variables, $\boldsymbol{X}_{j, t}$,

$$
r_{j, t}^{\mathrm{end}}=\beta_{0} r_{j, t}^{\mathrm{pre}}+\beta_{1} \Gamma_{j, t ; \tau}^{H P}+\beta_{2} \Gamma_{j, t ; \mathrm{new}}^{H P}+\gamma^{\prime} \boldsymbol{X}_{j, t}+F E_{j}+F E_{t}+\epsilon_{j, t} .
$$

We hypothesize that $\beta_{1}$ is negative and statistically significant. Table D4 and Table D5 show results with $\tau$ set to five and ten business days, respectively. Both tables confirm our hypothesis. 
Table D4: Option Hedging Pressure based on 5-Business Day Old Positions

The table summarizes the results of regressions of returns in the last half hour of a trading day on market maker hedging pressure based on five business day old positions $\Gamma_{t ; \tau}^{H P}$ and hedging pressure based on new positions, $\Gamma_{t ; \text { new }}^{H P}$, after controlling for returns until 15:30 $\left(r^{\mathrm{pre}}\right)$, as in specification Equation (D4). $I V_{t-1}$ denotes implied volatility at time $t-1 . \hat{R V_{t}^{e n d}}$ denote the square root of predicted realized variance for the time period from 15:30 to 16:00. $P C_{t-1}$ is the put-call-ratio and $O / S_{t-1}^{\$}$ denotes the option-to-stock volume in dollar terms. T-statistics are in parentheses below and are computed using time-and-entityclustered standard errors. ${ }^{* * *},{ }^{* *},{ }^{*}$ denotes significance at the $1 \%, 5 \%, 10 \%$ level. We include entity fixed effects in all specifications and value-weight observations. The sample period is May 2005 - July 2020 .

\begin{tabular}{|c|c|c|c|c|c|}
\hline Dependent & $\begin{array}{c}(1) \\
r_{t}^{\text {end }}\end{array}$ & $\begin{array}{c}(2) \\
r_{t}^{\text {end }}\end{array}$ & $\begin{array}{c}(3) \\
r_{t}^{\text {end }} \\
\end{array}$ & $\begin{array}{c}(4) \\
r_{t}^{\text {end }}\end{array}$ & $\begin{array}{c}(5) \\
r_{t}^{\text {end }} \\
\end{array}$ \\
\hline$\Gamma_{t ; \tau}^{H P}$ & $\begin{array}{c}-16.945^{* * *} \\
(-7.220)\end{array}$ & $\begin{array}{c}-16.893^{* * *} \\
(-7.191)\end{array}$ & $\begin{array}{c}-16.916^{* * *} \\
(-7.188)\end{array}$ & $\begin{array}{c}-16.958^{* * *} \\
(-7.223)\end{array}$ & $\begin{array}{c}-16.943^{* * *} \\
(-7.225)\end{array}$ \\
\hline$\Gamma_{t ; \text { new }}^{H P}$ & $\begin{array}{c}-0.159 \\
(-0.411)\end{array}$ & $\begin{array}{c}-0.155 \\
(-0.401)\end{array}$ & $\begin{array}{c}-0.144 \\
(-0.374)\end{array}$ & $\begin{array}{c}-0.159 \\
(-0.412)\end{array}$ & $\begin{array}{c}-0.158 \\
(-0.408)\end{array}$ \\
\hline$r_{t}^{\text {pre }}$ & $\begin{array}{c}-0.835^{* * *} \\
(-4.738)\end{array}$ & $\begin{array}{c}-0.836^{* * *} \\
(-4.753)\end{array}$ & $\begin{array}{c}-0.835^{* * *} \\
(-4.739)\end{array}$ & $\begin{array}{c}-0.834^{* * *} \\
(-4.736)\end{array}$ & $\begin{array}{c}-0.835^{* * *} \\
(-4.738)\end{array}$ \\
\hline$I V_{t-1}$ & & $\begin{array}{c}7.413^{* * *} \\
(3.216)\end{array}$ & & & \\
\hline$\hat{R V_{t}^{e n d}}$ & & & $\begin{array}{c}571.432^{*} \\
(1.793)\end{array}$ & & \\
\hline$P C_{t-1}$ & & & & $\begin{array}{l}0.501^{*} \\
(1.901)\end{array}$ & \\
\hline$O / S_{t-1}^{\$}$ & & & & & $\begin{array}{c}511.163 \\
(0.893)\end{array}$ \\
\hline Observations & $1,878,136$ & $1,878,136$ & $1,877,909$ & $1,875,677$ & $1,878,131$ \\
\hline Entity FE & Yes & Yes & Yes & Yes & Yes \\
\hline Time FE & Yes & Yes & Yes & Yes & Yes \\
\hline SEs & {$[\mathrm{t} ; \mathrm{j}]$} & {$[\mathrm{t} ; \mathrm{j}]$} & {$[\mathrm{t} ; \mathrm{j}]$} & {$[t ; j]$} & {$[t ; j]$} \\
\hline
\end{tabular}


Table D5: Option Hedging Pressure based on 10-Business Day Old Positions

The table summarizes the results of regressions of returns in the last half hour of a trading day on market maker hedging pressure based on ten business day old positions $\Gamma_{t ; \tau}^{H P}$ and hedging pressure based on new positions, $\Gamma_{t ; \text { new }}^{H P}$, after controlling for returns until 15:30 $\left(r^{\mathrm{pre}}\right)$, as in specification Equation (D4). $I V_{t-1}$ denotes implied volatility at time $t-1 . \hat{R V_{t}^{e n d}}$ denote the square root of predicted realized variance for the time period from 15:30 to 16:00. $P C_{t-1}$ is the put-call-ratio and $O / S_{t-1}^{\$}$ denotes the option-to-stock volume in dollar terms. T-statistics are in parentheses below and are computed using time-and-entityclustered standard errors. ${ }^{* * *},{ }^{* *},{ }^{*}$ denotes significance at the $1 \%, 5 \%, 10 \%$ level. We include entity fixed effects in all specifications and value-weight observations. The sample period is May 2005 - July 2020.

\begin{tabular}{|c|c|c|c|c|c|}
\hline Dependent & $\begin{array}{c}(1) \\
r_{t}^{\text {end }}\end{array}$ & $\begin{array}{c}(2) \\
r_{t}^{\text {end }}\end{array}$ & $\begin{array}{c}(3) \\
r_{t}^{\text {end }} \\
\end{array}$ & $\begin{array}{c}(4) \\
r_{t}^{\text {end }}\end{array}$ & $\begin{array}{l}(5) \\
r_{t}^{\text {end }}\end{array}$ \\
\hline$\Gamma_{t ; \tau}^{H P}$ & $\begin{array}{c}-20.419^{* * *} \\
(-7.924)\end{array}$ & $\begin{array}{c}-20.370^{* * *} \\
(-7.897)\end{array}$ & $\begin{array}{c}-20.407^{* * *} \\
(-7.903)\end{array}$ & $\begin{array}{c}-20.436^{* * *} \\
(-7.926)\end{array}$ & $\begin{array}{c}-20.424^{* * *} \\
(-7.927)\end{array}$ \\
\hline$\Gamma_{t ; \text { new }}^{H P}$ & $\begin{array}{c}-0.186 \\
(-0.481)\end{array}$ & $\begin{array}{c}-0.182 \\
(-0.471)\end{array}$ & $\begin{array}{c}-0.172 \\
(-0.444)\end{array}$ & $\begin{array}{c}-0.187 \\
(-0.482)\end{array}$ & $\begin{array}{c}-0.185 \\
(-0.478)\end{array}$ \\
\hline$r_{t}^{\text {pre }}$ & $\begin{array}{c}-0.840^{* * *} \\
(-4.776)\end{array}$ & $\begin{array}{c}-0.842^{* * *} \\
(-4.791)\end{array}$ & $\begin{array}{c}-0.840^{* * *} \\
(-4.777)\end{array}$ & $\begin{array}{c}-0.840^{* * *} \\
(-4.774)\end{array}$ & $\begin{array}{c}-0.840^{* * *} \\
(-4.775)\end{array}$ \\
\hline$I V_{t-1}$ & & $\begin{array}{c}7.417^{* * *} \\
(3.218)\end{array}$ & & & \\
\hline$\hat{R V_{t}^{e n d}}$ & & & $\begin{array}{c}572.220^{*} \\
(1.796)\end{array}$ & & \\
\hline$P C_{t-1}$ & & & & $\begin{array}{l}0.500^{*} \\
(1.898)\end{array}$ & \\
\hline$O / S_{t-1}^{\$}$ & & & & & $\begin{array}{c}519.470 \\
(0.908)\end{array}$ \\
\hline Observations & $1,878,136$ & $1,878,136$ & $1,877,909$ & $1,875,677$ & $1,878,131$ \\
\hline Entity FE & Yes & Yes & Yes & Yes & Yes \\
\hline Time FE & Yes & Yes & Yes & Yes & Yes \\
\hline SEs & {$[t ; j]$} & {$[t ; j]$} & {$[t ; j]$} & {$[t ; j]$} & {$[t ; j]$} \\
\hline
\end{tabular}




\title{
The Role of Leveraged ETFs and Option Market Imbalances on End-of-Day Price Dynamics
}

\author{
Online Appendix \\ (not for publication)
}

by Andrea Barbon, Heiner Beckmeyer, Andrea Buraschi, Mathis Moerke

\begin{abstract}
This appendix provides supplementary results and additional analyses besides robustness checks not included in the paper.
\end{abstract}

Table of Contents:

- Appendix OA1 provides summary statistics for the underlying stocks in the sample.

- Appendix OA2 provides summary statistics for the leveraged ETFs in the sample.

- Appendix OA3 investigates the effect of altering the calculation of the average dollar volume.

- Appendix OA4 investigates the effect of scaling returns according to Moskowitz et al. (2012).

- Appendix OA5 investigates the effect across different industries.

- Appendix OA6 analyses the rebalancing activities around intraday jumps for small and large market cap stocks, respectively.

- Appendix OA7 provides summary statistics for trading strategies based on $\Gamma^{H P}$ and $\Omega^{L E T F}$ on their respective data samples.

- Appendix OA8 provides results for risk-adjusted returns of the trading strategies based on $\Gamma^{H P}$ and $\Omega^{L E T F}$ on their respective data samples. 


\section{Appendix OA1. Summary Statistics of the Underly- ing}

\section{Table OA1.1: Industry Distribution of Underlying Stocks}

The table reports time-series averages of industry distributions of the Fama-French 12industry classification. The industry distributions are reported for the gamma exposure, LETF and joint sample. For comparability to the CRSP universe, the distributions of the full CRSP samples for the corresponding time periods are included.

\begin{tabular}{|c|c|c|c|c|c|}
\hline FF-12 Industry & Options sample & CRSP sample (2005-2020) & LETF sample & Joint sample & CRSP sample (2012-2019) \\
\hline Consumer durables & $0.58 \%$ & $0.28 \%$ & $0.36 \%$ & $0.43 \%$ & $0.19 \%$ \\
\hline Consumer nondurables & $5.16 \%$ & $3.16 \%$ & $4.35 \%$ & $4.55 \%$ & $2.71 \%$ \\
\hline Manufacturing & $11.14 \%$ & $5.48 \%$ & $9.12 \%$ & $10.17 \%$ & $4.78 \%$ \\
\hline Energy & $6.64 \%$ & $3.49 \%$ & $4.53 \%$ & $5.71 \%$ & $3.4 \%$ \\
\hline Chemicals & $3.3 \%$ & $1.37 \%$ & $2.74 \%$ & $3.21 \%$ & $1.26 \%$ \\
\hline Business Equipment & $13.7 \%$ & $10.58 \%$ & $12.79 \%$ & $15.6 \%$ & $8.62 \%$ \\
\hline Telecom & $2.27 \%$ & $2.37 \%$ & $2.56 \%$ & $2.37 \%$ & $1.95 \%$ \\
\hline Utilities & $4.23 \%$ & $2.03 \%$ & $3.46 \%$ & $3.71 \%$ & $1.9 \%$ \\
\hline Wholesale & $12.25 \%$ & $5.69 \%$ & $9.65 \%$ & $11.73 \%$ & $4.96 \%$ \\
\hline Healthcare & $10.26 \%$ & $6.76 \%$ & $8.05 \%$ & $10.72 \%$ & $5.51 \%$ \\
\hline Finance & $10.56 \%$ & $40.92 \%$ & $16.9 \%$ & $10.29 \%$ & $44.13 \%$ \\
\hline Other & $19.91 \%$ & $17.9 \%$ & $25.61 \%$ & $21.64 \%$ & $20.61 \%$ \\
\hline
\end{tabular}




\section{Table OA1.2: Summary Statistics of Underlying Stocks}

The table reports summary statistics on the stock-day sample for the underlying stocks. Panel A reports the time-series summary statistics and Panel B reports the time-series average of cross-sectional distributions. Percent coverage of the stock universe (EW) is the number of stocks in the sample, divided by the total number of CRSP stocks. Percent coverage of the stock universe (VW) is the total market capitalization of sample stocks divided by the total CRSP market capitalization. Percent coverage of stocks traded at NYSE or AMEX is the number of stocks in the sample trading at NYSE or AMEX, divided by the total number of stocks. The firm size percentiles are computed using the full CRSP sample. Number of LETF is the number of LETF a stock is included in.

\begin{tabular}{lccccccc}
\hline & Mean & Std & 10-Pctl & Q1 & Median & Q3 & 90-Pctl \\
\hline Panel A: Time-Series Distribution & & & & & & & \\
\hline Gamma Exposure (2005-2020) & & & & & & & \\
Number of stocks in the sample each month & 892.94 & 347.42 & 320.6 & 559.0 & 1061.0 & 1157.0 & 1221.0 \\
Stock coverage of stock universe (EW) & 12.63 & 4.81 & 4.6 & 8.24 & 15.01 & 16.2 & 17.02 \\
Stock coverage of stock universe (VW) & 44.99 & 9.09 & 30.23 & 34.65 & 50.29 & 51.66 & 52.66 \\
Stock traded at NYSE or AMEX & 43.66 & 5.48 & 36.38 & 39.37 & 43.38 & 44.76 & 52.32 \\
& & & & & & & \\
LETF (2012-2019) & & & & & & & \\
Number of stocks in the sample each month & 2210.98 & 525.92 & 1611.8 & 2295.0 & 2355.0 & 2424.0 & 2464.0 \\
Stock coverage of stock universe (EW) & 30.89 & 7.43 & 21.88 & 31.22 & 32.99 & 34.5 & 35.04 \\
Stock coverage of stock universe (VW) & 65.04 & 13.57 & 63.67 & 66.72 & 68.52 & 69.23 & 69.71 \\
Stock traded at NYSE or AMEX & 38.74 & 8.07 & 35.78 & 37.91 & 40.15 & 42.89 & 43.42 \\
& & & & & & & \\
Joint (2012-2019 & & & & & & & 1140.0 \\
Number of stocks in the sample each month & 992.53 & 227.92 & 877.2 & 973.0 & 1043.0 & 1101.25 & 1140.0 \\
Stock coverage of stock universe (EW) & 13.86 & 3.17 & 12.43 & 13.65 & 14.57 & 15.26 & 15.92 \\
Stock coverage of stock universe (VW) & 48.79 & 10.17 & 48.47 & 49.76 & 50.92 & 51.85 & 52.72 \\
Stock traded at NYSE or AMEX & 38.74 & 8.07 & 35.78 & 37.91 & 40.19 & 42.88 & 43.42 \\
\hline
\end{tabular}

Panel B: Time-Series Average of Cross-Sectional Distributions

\begin{tabular}{|c|c|c|c|c|c|c|c|}
\hline \multicolumn{8}{|c|}{ Gamma Exposure (2005-2020) } \\
\hline Firm size in million & 13824 & 37492 & 530 & 1308 & 3626 & 11011 & 30004 \\
\hline Firm size CSRP percentile & 78 & 17 & 52 & 68 & 82 & 92 & 96 \\
\hline \multicolumn{8}{|l|}{ LETF (2012-2019) } \\
\hline Firm size in million & 9229 & 33225 & 286 & 577 & 1578 & 5084 & 17629 \\
\hline Firm size CSRP percentile & 69 & 19 & 42 & 54 & 71 & 85 & 94 \\
\hline Number of LETF & 8 & 3 & 6 & 6 & 8 & 10 & 13 \\
\hline \multicolumn{8}{|l|}{ Joint (2012-2019 } \\
\hline Firm size in million & 15050 & 44338 & 454 & 1079 & 3152 & 11182 & 31883 \\
\hline Firm size CSRP percentile & 77 & 17 & 51 & 66 & 81 & 92 & 96 \\
\hline Number of LETF & 9 & 3 & 6 & 7 & 9 & 11 & 14 \\
\hline
\end{tabular}




\section{Appendix OA2. Summary Statistics of Leveraged ETFs}

\section{Table OA2.1: Summary Statistics Underlying Leveraged ETFs}

The table reports time-series summary statistics on the underlying leveraged ETFs in our sample. Number of LETF is the number of leveraged ETFs. Number of benchmark indices is the number of unique benchmark indices underlying all leveraged ETFs. Aggregated AUM denotes the assets under management across all leveraged ETFs, in million. Aggregated leverage-adjusted AUM is the assets under management adjusted for the rebalancing leverage of each leveraged ETF. Percentage of inverse LETF $(\mathrm{EW})$ is the number of inverse ETFs divided by the total number of leveraged ETFs. Percentage of inverse LETF (VW) is the assets under management weighted proportion of inverse ETFs to the total leveraged ETF sample. Average absolute leverage factor (EW) is the average absolute leverage factor. Average absolute leverage factor $(\mathrm{VW})$ is the assets under management weighted absolute leverage factor. The sample period is January 2012 - December 2019.

\begin{tabular}{lccccccc}
\hline & Mean & Std & $10 \%$ & $25 \%$ & $50 \%$ & $75 \%$ & $90 \%$ \\
\hline Number of LETF & 71.67 & 11.05 & 66.0 & 72.0 & 74.0 & 76.0 & 79.0 \\
Number of benchmark indices & 23.72 & 3.7 & 21.0 & 23.0 & 25.0 & 25.0 & 27.0 \\
Agg. AUM & 17.71 & 4.69 & 12.03 & 15.29 & 16.92 & 21.33 & 24.43 \\
Agg. leverage-adjusted AUM & 95.33 & 28.55 & 64.23 & 73.01 & 86.97 & 121.12 & 131.71 \\
Perc. of inverse LETF (EW) & 45.29 & 3.38 & 41.67 & 43.24 & 45.07 & 45.95 & 51.28 \\
Perc. of inverse LETF (VW) & 33.14 & 15.66 & 16.31 & 22.75 & 28.48 & 41.77 & 62.64 \\
Avg. absolute leverage factor (EW) & 2.35 & 0.13 & 2.21 & 2.22 & 2.32 & 2.45 & 2.5 \\
Avg. absolute leverage factor (VW) & 2.43 & 0.14 & 2.29 & 2.35 & 2.44 & 2.53 & 2.6 \\
\hline
\end{tabular}




\section{Appendix OA3. Different ADV Measures}

We investigate whether the choice of scaling the proposed Gamma exposure with last month's average dollar volume skews our results. To do so, we exchange the proposed ADV measure with last week's ADV and last quarter's ADV. We also check whether results change materially when using ADV of the last half hour of a trading day (I) or the entire daily trading volume (D). Table OA3.1 and Table OA3.2 present results for the gamma and LETF sample, respectively, whereas Table OA3.3 displays results for the joint data sample. The choice of denominator for $\Gamma^{H P}$ and $\Omega^{L E T F}$ has little impact on our results.

Table OA3.1: Effect of Different ADV Measures in Gamma Sample

The table reports the results to regressing returns in the last half hour of a trading day on returns until 15:30, $r^{\text {pre }}$ and market maker hedging pressure $\Gamma^{H P}$, following Equation $10 p$. We exchange the standard ADV measure as the average volume in the last half trading hour over the last month by similar measures using weekly (W) and quarterly horizons (Q), as well as measures using daily volume in their constructed (denoted by "-D"). T-statistics in parentheses are derived from standard errors clustered by date and entity. $* * *, * *, *$ denotes significance at the $1 \%, 5 \%, 10 \%$ level. We include entity fixed effects and weight returns by the stock's market capitalization. The sample period is May 2005 - July 2020.

\begin{tabular}{lcccccc}
\hline & $(1)$ & $(2)$ & $(3)$ & $(4)$ & $(5)$ & $(6)$ \\
Dependent & $r_{t}^{\text {end }}$ & $r_{t}^{\text {end }}$ & $r_{t}^{\text {end }}$ & $r_{t}^{\text {end }}$ & $r_{t}^{\text {end }}$ & $r_{t}^{\text {end }}$ \\
\hline$\Gamma_{t}^{H P}$ & $-11.014^{* * *}$ & $-56.466^{* * *}$ & $-11.947^{* * *}$ & $-58.915^{* * *}$ & $-12.472^{* * *}$ & $-60.231^{* * *}$ \\
& $(-5.047)$ & $(-5.208)$ & $(-5.008)$ & $(-4.808)$ & $(-4.721)$ & $(-4.071)$ \\
$r_{t}^{\text {pre }}$ & $-0.719^{* * *}$ & $-0.716^{* * *}$ & $-0.718^{* * *}$ & $-0.717^{* * *}$ & $-0.717^{* * *}$ & $-0.718^{* * *}$ \\
& $(-4.337)$ & $(-4.299)$ & $(-4.341)$ & $(-4.326)$ & $(-4.360)$ & $(-4.355)$ \\
\hline Observations & $3,365,367$ & $3,365,367$ & $3,365,367$ & $3,365,367$ & $3,365,367$ & $3,365,367$ \\
Entity FE & Yes & Yes & Yes & Yes & Yes & Yes \\
Time FE & Yes & Yes & Yes & Yes & Yes & Yes \\
SEs & {$[\mathrm{t} ; \mathrm{j}]$} & {$[\mathrm{t} ; \mathrm{j}]$} & {$[\mathrm{t} ; \mathrm{j}]$} & {$[\mathrm{t} ; \mathrm{j}]$} & {$[\mathrm{t} ; \mathrm{j}]$} & {$[\mathrm{t} ; \mathrm{j}]$} \\
ADV & $\mathrm{W}-\mathrm{I}$ & $\mathrm{W}-\mathrm{D}$ & $\mathrm{M}-\mathrm{I}$ & $\mathrm{M}-\mathrm{D}$ & $\mathrm{Q}-\mathrm{I}$ & $\mathrm{Q}-\mathrm{D}$ \\
\hline
\end{tabular}




\section{Table OA3.2: Effect of Different ADV Measures in LETF Sample}

The table reports the results to regressing returns in the last half hour of a trading day on returns until 15:30, $r^{\text {pre }}$ and market maker hedging pressure $\Gamma^{H P}$, following Equation $10 p$. We exchange the standard ADV measure as the average volume in the last half trading hour over the last month by similar measures using weekly (W) and quarterly horizons (Q), as well as measures using daily volume in their constructed (denoted by "-D"). T-statistics in parentheses are derived from standard errors clustered by date and entity. ${ }^{* * *}, * *, *$ denotes significance at the $1 \%, 5 \%, 10 \%$ level. We include entity fixed effects and weight returns by the stock's market capitalization. The sample period is January 2012 - December 2019.

\begin{tabular}{lcccccc}
\hline & $(1)$ & $(2)$ & $(3)$ & $(4)$ & $(5)$ & $(6)$ \\
Dependent & $r_{t}^{\text {end }}$ & $r_{t}^{\text {end }}$ & $r_{t}^{\text {end }}$ & $r_{t}^{\text {end }}$ & $r_{t}^{\text {end }}$ & $r_{t}^{\text {end }}$ \\
\hline$\Omega_{t}^{\text {LETF }}$ & $25.285^{* * *}$ & $152.698^{* * *}$ & $41.350^{* * *}$ & $109.642^{* * *}$ & $43.195^{* * *}$ & $180.037^{* * *}$ \\
& $(3.311)$ & $(8.532)$ & $(8.569)$ & $(2.620)$ & $(8.425)$ & $(9.256)$ \\
$r_{t}^{\text {pre }}$ & $-0.878^{* * *}$ & $-0.892^{* * *}$ & $-0.900^{* * *}$ & $-0.875^{* * *}$ & $-0.901^{* * *}$ & $-0.897^{* * *}$ \\
& $(-8.654)$ & $(-9.393)$ & $(-9.299)$ & $(-7.911)$ & $(-9.253)$ & $(-9.400)$ \\
\hline Observations & $4,403,855$ & $4,403,744$ & $4,403,855$ & $4,403,854$ & $4,403,855$ & $4,403,855$ \\
Entity FE & Yes & Yes & Yes & Yes & Yes & Yes \\
Time FE & Yes & Yes & Yes & Yes & Yes & Yes \\
SEs & {$[\mathrm{t} ; \mathrm{j}]$} & {$[\mathrm{t} ; \mathrm{j}]$} & {$[\mathrm{t} ; \mathrm{j}]$} & {$[\mathrm{t} ; \mathrm{j}]$} & {$[\mathrm{t} ; \mathrm{j}]$} & {$[\mathrm{t} ; \mathrm{j}]$} \\
ADV & $\mathrm{W}-\mathrm{I}$ & $\mathrm{W}-\mathrm{D}$ & $\mathrm{M}-\mathrm{I}$ & $\mathrm{M}-\mathrm{D}$ & $\mathrm{Q}-\mathrm{I}$ & $\mathrm{Q}-\mathrm{D}$ \\
\hline
\end{tabular}


Table OA3.3: Effect of Different ADV Measures for Joint Sample

The table reports the results to regressing returns in the last half hour of a trading day on returns until 15:30, $r^{\text {pre }}$ and market maker hedging pressure $\Gamma^{H P}$, following Equation 10 . We exchange the standard ADV measure as the average volume in the last half trading hour over the last month by similar measures using weekly (W) and quarterly horizons (Q), as well as measures using daily volume in their constructed (denoted by "-D"). T-statistics in parentheses are derived from standard errors clustered by date and entity. $* * *, * *, *$ denotes significance at the $1 \%, 5 \%, 10 \%$ level. We include entity fixed effects and weight returns by the stock's market capitalization. The sample period is January 2012 - December 2019.

\begin{tabular}{lcccccc}
\hline & $(1)$ & $(2)$ & $(3)$ & $(4)$ & $(5)$ & $(6)$ \\
Dependent & $r_{t}^{\text {end }}$ & $r_{t}^{\text {end }}$ & $r_{t}^{\text {end }}$ & $r_{t}^{\text {end }}$ & $r_{t}^{\text {end }}$ & $r_{t}^{\text {end }}$ \\
\hline$\Gamma_{t}^{H P}$ & $-9.536^{* * *}$ & $-53.144^{* * *}$ & $-10.677^{* * *}$ & $-56.517^{* * *}$ & $-10.708^{* * *}$ & $-57.467^{* * *}$ \\
& $(-4.945)$ & $(-6.602)$ & $(-5.324)$ & $(-6.534)$ & $(-4.929)$ & $(-6.290)$ \\
$\Omega_{t}^{L E T F}$ & $42.696^{* * *}$ & $181.998^{* * *}$ & $47.611^{* * *}$ & $193.612^{* * *}$ & $50.017^{* * *}$ & $206.090^{* * *}$ \\
& $(4.407)$ & $(5.721)$ & $(4.935)$ & $(5.803)$ & $(4.845)$ & $(5.767)$ \\
$r_{t}^{\text {pre }}$ & $-0.882^{* * *}$ & $-0.869^{* * *}$ & $-0.882^{* * *}$ & $-0.870^{* * *}$ & $-0.887^{* * *}$ & $-0.875^{* * *}$ \\
& $(-7.484)$ & $(-7.309)$ & $(-7.479)$ & $(-7.285)$ & $(-7.519)$ & $(-7.330)$ \\
\hline Observations & $1,940,150$ & $1,940,150$ & $1,940,150$ & $1,940,150$ & $1,940,150$ & $1,940,150$ \\
Entity FE & Yes & Yes & Yes & Yes & Yes & Yes \\
Time FE & Yes & Yes & Yes & Yes & Yes & Yes \\
SEs & {$[\mathrm{t} ; \mathrm{j}]$} & {$[\mathrm{t} ; \mathrm{j}]$} & {$[\mathrm{t} ; \mathrm{j}]$} & {$[\mathrm{t} ; \mathrm{j}]$} & {$[\mathrm{t} ; \mathrm{j}]$} & {$[\mathrm{t} ; \mathrm{j}]$} \\
ADV & $\mathrm{W}-\mathrm{I}$ & $\mathrm{W}-\mathrm{D}$ & $\mathrm{M}-\mathrm{I}$ & $\mathrm{M}-\mathrm{D}$ & $\mathrm{Q}-\mathrm{I}$ & $\mathrm{Q}-\mathrm{D}$ \\
\hline
\end{tabular}




\section{Appendix OA4. Scaled Returns as in Moskowitz et al. (2012)}

In the main analyses we use plain returns and value-weight observations in the panel regressions. Instead, Moskowitz et al. (2012) proposes the use of scaled returns, which expresses returns in terms of units of expected risk:

$$
\hat{r}=\frac{r}{\sigma_{r}}
$$

where $\sigma_{r}$ is calculated using an exponentially-weighted moving average from the realized variance of using 5-minute squared returns from last close to 15:30. The half life is chosen to equal 60 days.

Table OA4.1 and Table OA4.2 present results for the gamma and LETF sample, respectively, whereas Table OA4.3 displays results for the joint data sample. Scaling returns does not alter our results. 


\section{Table OA4.1: Using Scaled Returns for the Gamma Sample}

The table reports the results to regressing returns in the last half hour of a trading day on returns until 15:30, $r^{\text {pre }}$ and market maker hedging pressure $\Gamma^{H P}$, following Equation 10 . The regression setup follows Table 4 but uses scaled returns. T-statistics in parentheses are derived from standard errors clustered by date and entity. $* * *, * *, *$ denotes significance at the $1 \%, 5 \%, 10 \%$ level. We include entity fixed effects and weight returns by the stock's market capitalization. The sample period is May $2005-$ July 2020.

\begin{tabular}{|c|c|c|c|c|c|}
\hline Dependent & $\begin{array}{c}(1) \\
r_{t}^{\text {end }} \\
\end{array}$ & $\begin{array}{c}(2) \\
r_{t}^{\text {end }} \\
\end{array}$ & $\begin{array}{c}(3) \\
r_{t}^{\text {end }} \\
\end{array}$ & $\begin{array}{c}(4) \\
r_{t}^{\text {end }} \\
\end{array}$ & $\begin{array}{c}(5) \\
r_{t}^{\text {end }} \\
\end{array}$ \\
\hline$\Gamma_{t}^{H P}$ & $\begin{array}{c}-29.475^{* * *} \\
(-4.171)\end{array}$ & $\begin{array}{c}-29.410 * * * \\
(-4.166)\end{array}$ & $\begin{array}{c}-29.486^{* * *} \\
(-4.169)\end{array}$ & $\begin{array}{c}-29.489^{* * *} \\
(-4.172)\end{array}$ & $\begin{array}{c}-29.475^{* * * *} \\
(-4.175)\end{array}$ \\
\hline$r_{t}^{\text {pre }}$ & $\begin{array}{c}-0.071^{* * *} \\
(-9.206)\end{array}$ & $\begin{array}{c}-0.071^{* * *} \\
(-9.204)\end{array}$ & $\begin{array}{c}-0.071^{* * *} \\
(-9.205)\end{array}$ & $\begin{array}{c}-0.071^{* * *} \\
(-9.208)\end{array}$ & $\begin{array}{c}-0.071^{* * *} \\
(-9.206)\end{array}$ \\
\hline$I V_{t-1}$ & & $\begin{array}{c}12.640^{* * *} \\
(3.966)\end{array}$ & & & \\
\hline$\hat{R V_{t}^{\text {close }-1 \rightarrow 15: 30}}$ & & & $\begin{array}{l}77.456 \\
(1.541)\end{array}$ & & \\
\hline$P C_{t-1}$ & & & & $\begin{array}{c}0.561 \\
(0.917)\end{array}$ & \\
\hline$O / S_{t-1}^{\$}$ & & & & & $\begin{array}{c}1521.516 \\
(0.918)\end{array}$ \\
\hline Observations & $3,365,009$ & $3,365,009$ & $3,365,009$ & $3,358,408$ & $3,365,001$ \\
\hline Entity FE & Yes & Yes & Yes & Yes & Yes \\
\hline Time FE & Yes & Yes & Yes & Yes & Yes \\
\hline SEs & {$[\mathrm{t} ; \mathrm{j}]$} & {$[\mathrm{t} ; \mathrm{j}]$} & {$[\mathrm{t} ; \mathrm{j}]$} & {$[\mathrm{t} ; \mathrm{j}]$} & {$[\mathrm{t} ; \mathrm{j}]$} \\
\hline
\end{tabular}




\section{Table OA4.2: Using Scaled Returns for the LETF Sample}

The table reports the results to regressing returns in the last half hour of a trading day on returns until 15:30, $r^{\text {pre }}$ and market maker hedging pressure $\Gamma^{H P}$, following Equation 107 . The regression setup follows Table 4 but uses scaled returns. T-statistics in parentheses are derived from standard errors clustered by date and entity. ${ }^{* *}, * *, *$ denotes significance at the $1 \%, 5 \%, 10 \%$ level. We include entity fixed effects and weight returns by the stock's market capitalization. The sample period is January 2012 - December 2019.

\begin{tabular}{lcccc}
\hline & $(1)$ & $(2)$ & $(3)$ & $(4)$ \\
Dependent & $r_{t}^{\text {end }}$ & $r_{t}^{\text {end }}$ & $r_{t}^{\text {end }}$ & $r_{t}^{\text {end }}$ \\
\hline$\Omega_{t}^{\text {LETF }}$ & $54.287^{* * * *}$ & $95.759^{* * *}$ & $95.753^{* * *}$ & $95.756^{* * *}$ \\
& $(2.761)$ & $(5.054)$ & $(5.055)$ & $(5.052)$ \\
$r_{t}^{\text {pre }}$ & & $-0.064^{* * *}$ & $-0.064^{* * *}$ & $-0.064^{* * *}$ \\
& & $(-10.184)$ & $(-10.183)$ & $(-10.182)$ \\
$R V_{t}^{\text {close-1 } \rightarrow 15: 30}$ & & & -7.640 & \\
& & & $(-0.156)$ & \\
$R V_{t}^{15: 30 \rightarrow \text { close }}$ & & & & $630.649^{* *}$ \\
& & & & $(2.062)$ \\
\hline Observations & $4,386,322$ & $4,386,322$ & $4,386,322$ & $4,386,322$ \\
Entity FE & Yes & Yes & Yes & Yes \\
Time FE & Yes & Yes & Yes & Yes \\
SEs & {$[\mathrm{t} ; \mathrm{j}]$} & {$[\mathrm{t} ; \mathrm{j}]$} & {$[\mathrm{t} ; \mathrm{j}]$} & {$[\mathrm{t} ; \mathrm{j}]$} \\
\hline
\end{tabular}




\section{Table OA4.3: Using Scaled Returns for the Joint Sample}

The table reports the results to regressing returns in the last half hour of a trading day on returns until 15:30, $r^{\text {pre }}$ and market maker hedging pressure $\Gamma^{H P}$, following Equation 10 . The regression setup follows Table 4 but uses scaled returns. T-statistics in parentheses are derived from standard errors clustered by date and entity. ***,**,* denotes significance at the $1 \%, 5 \%, 10 \%$ level. We include entity fixed effects and weight returns by the stock's market capitalization. The sample period is January 2012 - December 2019.

\begin{tabular}{|c|c|c|c|c|}
\hline Dependent & $\begin{array}{c}(1) \\
r_{t}^{\text {end }}\end{array}$ & $\begin{array}{c}(2) \\
r_{t}^{\text {end }}\end{array}$ & $\begin{array}{c}(3) \\
r_{t}^{\text {end }}\end{array}$ & $\begin{array}{c}(4) \\
r_{t}^{\text {end }}\end{array}$ \\
\hline$\overline{\Omega_{t}^{L E T F}}$ & & $\begin{array}{c}66.908^{* * *} \\
(4.700)\end{array}$ & $\begin{array}{c}175.169^{* * *} \\
(4.975)\end{array}$ & \\
\hline$\Gamma_{t}^{H P}$ & $\begin{array}{c}-26.845^{* * *} \\
(-3.201)\end{array}$ & & $\begin{array}{c}-31.727^{* * *} \\
(-3.841)\end{array}$ & \\
\hline$r_{t}^{\mathrm{pre}}$ & $\begin{array}{c}-0.063^{* * *} \\
(-7.883)\end{array}$ & $\begin{array}{c}-0.071^{* * *} \\
(-8.958)\end{array}$ & $\begin{array}{c}-0.067^{* * *} \\
(-8.185)\end{array}$ & \\
\hline $\mathrm{BB}$ & & & & $\begin{array}{c}170.872^{* * *} \\
(5.279)\end{array}$ \\
\hline SS & & & & $\begin{array}{c}-179.481^{* * *} \\
(-3.963)\end{array}$ \\
\hline BS & & & & $\begin{array}{c}-96.936^{* * *} \\
(-2.874)\end{array}$ \\
\hline $\mathrm{SB}$ & & & & $\begin{array}{c}75.525^{* * *} \\
(2.744)\end{array}$ \\
\hline Observations & $1,940,048$ & $1,940,048$ & $1,940,048$ & $1,940,048$ \\
\hline Entity FE & Yes & Yes & Yes & Yes \\
\hline Time FE & Yes & Yes & Yes & - \\
\hline SEs & {$[\mathrm{t} ; \mathrm{j}]$} & {$[\mathrm{t} ; \mathrm{j}]$} & {$[\mathrm{t} ; \mathrm{j}]$} & {$[\mathrm{t} ; \mathrm{j}]$} \\
\hline
\end{tabular}




\section{Appendix OA5. Effects Across Industries}

Investor attention for stocks in respective sectors changes over time. To compare how hedging pressure from the options market impacts end-of-day returns, we sort stocks into their respective industry following the classification on Kenneth French's website.

Table OA5.1 and Table OA5.2 present results for the gamma and LETF sample, respectively, whereas Table OA5.3 displays results for the joint data sample. $\Gamma^{I B}-$ and $\Omega^{L E T F}$-effects are present and statistically significant in all industries.

Table OA5.1: Effects in Different Industries for the Gamma Sample

The table reports the results to regressing returns in the last half hour of a trading day on returns until 15:30, $r^{\text {pre }}$ and market maker hedging pressure $\Gamma^{H P}$, following Equation (10). The sample is split by the industry classification based on SIC codes, following Kenneth French's website, https://mba.tuck.dartmouth.edu/pages/faculty/ken.french/data_library.html. T-statistics in parentheses are derived from standard errors clustered by date and entity. ${ }^{* * *},{ }^{* *},{ }^{*}$ denotes significance at the 1\%,5\%,10\% level. We include entity fixed effects and weight returns by the stock's market capitalization. The sample period is May 2005 - July 2020.

\begin{tabular}{lccccc}
\hline & $(1)$ & $(2)$ & $(3)$ & $(4)$ & $(5)$ \\
Dependent & $r_{t}^{\text {end }}$ & $r_{t}^{\text {end }}$ & $r_{t}^{\text {end }}$ & $r_{t}^{\text {end }}$ & $r_{t}^{\text {end }}$ \\
\hline$\Gamma_{t}^{H P}$ & $-9.646^{* * *}$ & $-6.965^{* *}$ & $-10.429^{* *}$ & $-14.460^{* * *}$ & $-17.307^{* * *}$ \\
& $(-4.789)$ & $(-2.196)$ & $(-2.283)$ & $(-3.286)$ & $(-6.063)$ \\
$r_{t}^{\text {pre }}$ & $-0.890^{* * *}$ & $-1.009^{* * *}$ & $-0.971^{* * *}$ & $-1.179^{* * *}$ & $-0.651^{* * *}$ \\
& $(-6.985)$ & $(-3.705)$ & $(-4.488)$ & $(-5.006)$ & $(-3.239)$ \\
\hline Observations & 637,729 & 798,830 & 624,852 & 363,951 & 940,005 \\
Entity FE & Yes & Yes & Yes & Yes & Yes \\
Time FE & Yes & Yes & Yes & Yes & Yes \\
SEs & {$[\mathrm{t} ; \mathrm{j}]$} & {$[\mathrm{t} ; \mathrm{j}]$} & {$[\mathrm{t} ; \mathrm{j}]$} & {$[\mathrm{t} ; \mathrm{j}]$} & {$[\mathrm{t} ; \mathrm{j}]$} \\
Industry & Consumer & Manuf.+Energy & Business & Health & Other \\
\hline
\end{tabular}




\section{Table OA5.2: Effects in Different Industries for the LETF Sample}

The table reports the results to regressing returns in the last half hour of a trading day on returns until 15:30, $r^{\text {pre }}$ and market maker hedging pressure $\Gamma^{H P}$, following Equation 10p. The sample is split by the industry classification based on SIC codes, following Kenneth French's website, https://mba.tuck.dartmouth.edu/pages/faculty/ken.french/data_library.html. T-statistics in parentheses are derived from standard errors clustered by date and entity. ${ }^{* * *},{ }^{* *},{ }^{*}$ denotes significance at the 1\%,5\%,10\% level. We include entity fixed effects and weight returns by the stock's market capitalization. The sample period is January 2012 - December 2019.

\begin{tabular}{lccccc}
\hline & $(1)$ & $(2)$ & $(3)$ & $(4)$ & $(5)$ \\
Dependent & $r_{t}^{\text {end }}$ & $r_{t}^{\text {end }}$ & $r_{t}^{\text {end }}$ & $r_{t}^{\text {end }}$ & $r_{t}^{\text {end }}$ \\
\hline$\Omega_{t}^{\text {LETF }}$ & $40.190^{* * *}$ & $20.354^{* * *}$ & $43.533^{* * *}$ & $70.799^{* * *}$ & $48.152^{* * *}$ \\
& $(8.611)$ & $(3.823)$ & $(6.716)$ & $(5.911)$ & $(9.913)$ \\
$r_{t}^{\text {pre }}$ & $-0.766^{* * *}$ & $-0.889^{* * *}$ & $-1.075^{* * *}$ & $-0.929^{* * *}$ & $-0.780^{* * *}$ \\
& $(-7.154)$ & $(-5.781)$ & $(-6.432)$ & $(-4.889)$ & $(-5.734)$ \\
\hline Observations & 705,758 & 867,361 & 721,391 & 355,840 & $1,753,505$ \\
Entity FE & Yes & Yes & Yes & Yes & Yes \\
Time FE & Yes & Yes & Yes & Yes & Yes \\
SEs & {$[\mathrm{t} ; \mathrm{j}]$} & {$[\mathrm{t} ; \mathrm{j}]$} & {$[\mathrm{t} ; \mathrm{j}]$} & {$[\mathrm{t} ; \mathrm{j}]$} & {$[\mathrm{t} ; \mathrm{j}]$} \\
Industry & Consumer & Manuf.+Energy & Business & Health & Other \\
\hline
\end{tabular}




\section{Table OA5.3: Effects in Different Industries for the Joint Sample}

The table reports the results to regressing returns in the last half hour of a trading day on returns until 15:30, $r^{\text {pre }}$ and market maker hedging pressure $\Gamma^{H P}$, following Equation (10). The sample is split by the industry classification based on SIC codes, following Kenneth French's website, https://mba.tuck.dartmouth.edu/pages/faculty/ken.french/data_library.html. T-statistics in parentheses are derived from standard errors clustered by date and entity. ${ }^{* * *}, * *,{ }^{*}$ denotes significance at the $1 \%, 5 \%, 10 \%$ level. We include entity fixed effects and weight returns by the stock's market capitalization. The sample period is January 2012 - December 2019.

\begin{tabular}{lccccc}
\hline & $(1)$ & $(2)$ & $(3)$ & $(4)$ & $(5)$ \\
Dependent & $r_{t}^{\text {end }}$ & $r_{t}^{\text {end }}$ & $r_{t}^{\text {end }}$ & $r_{t}^{\text {end }}$ & $r_{t}^{\text {end }}$ \\
\hline$\Gamma_{t}^{H P}$ & $-8.632^{* * *}$ & $-6.315^{* *}$ & $-7.902^{*}$ & $-19.952^{* * *}$ & $-15.017^{* * *}$ \\
& $(-5.343)$ & $(-2.573)$ & $(-1.887)$ & $(-4.262)$ & $(-5.092)$ \\
$\Omega_{t}^{\text {LETF }}$ & $30.339^{* * *}$ & $20.801^{* * *}$ & $50.707^{* * *}$ & $96.362^{* * *}$ & $38.856^{* * *}$ \\
& $(6.439)$ & $(2.871)$ & $(9.469)$ & $(6.680)$ & $(4.287)$ \\
$r_{t}^{\text {pre }}$ & $-0.710^{* * *}$ & $-0.955^{* * *}$ & $-1.034^{* * *}$ & $-0.963^{* * *}$ & $-0.696^{* * *}$ \\
& $(-5.262)$ & $(-4.391)$ & $(-5.054)$ & $(-4.543)$ & $(-3.720)$ \\
\hline Observations & 354,699 & 437,271 & 378,458 & 210,157 & 559,565 \\
Entity FE & Yes & Yes & Yes & Yes & Yes \\
Time FE & Yes & Yes & Yes & Yes & Yes \\
SEs & {$[\mathrm{t} ; \mathrm{j}]$} & {$[\mathrm{t} ; \mathrm{j}]$} & {$[\mathrm{t} ; \mathrm{j}]$} & {$[\mathrm{t} ; \mathrm{j}]$} & {$[\mathrm{t} ; \mathrm{j}]$} \\
Industry & Consumer & Manuf.+Energy & Business & Health & Other \\
\hline
\end{tabular}




\section{Appendix OA6. Discretionary Rebalancing - The Case of Jumps}

Table OA6.1: Delta-Hedging After Intraday Jumps - Market Cap Effects

The table reports the results to regressing intraday jump returns on returns in the subsequent 30-minute interval for large and small stocks in our sample. We identify jumps in the underlying stock returns. To detect jumps, we compare each non-overlapping 30-minute return with returns of the same interval over the last year. If the return is higher (lower) than the $97.5 \%(2.5 \%)$ percentile, we regard the return as a jump. Next, we record the return from yesterday's close until the end of the 30-minute interval, where the jump has occurred ( $r_{t}^{\text {incl. jump }}$ ). We collect also the return of the subsequent 30-minute interval $\left(r_{t}^{\text {next }}\right)$ on the stock-level. Finally, we disregard jumps which have occurred after a certain time (given in row "Jumps Until"). Equipped with $r_{t}^{\text {incl. jump }}, r_{t}^{\text {next }}$, and the intraday return of the benchmark index, we reconstruct $\Gamma_{t}^{H P}$ for each affected stock $j$. Subsequently, we run Equation 10). The sample period is January 2012 - December 2019.

\begin{tabular}{lcccccc}
\hline & $(1)$ & $(2)$ & $(3)$ & $(4)$ & $(5)$ & $(6)$ \\
Dependent & $r_{t}^{\text {next }}$ & $r_{t}^{\text {next }}$ & $r_{t}^{\text {next }}$ & $r_{t}^{\text {next }}$ & $r_{t}^{\text {next }}$ & $r_{t}^{\text {next }}$ \\
\hline$\Gamma_{t}^{H P}$ & $-71.878^{*}$ & $-77.413^{* *}$ & $-72.054^{* *}$ & $-41.922^{*}$ & $-39.247^{*}$ & -29.792 \\
& $(-1.651)$ & $(-2.214)$ & $(-2.239)$ & $(-1.813)$ & $(-1.732)$ & $(-1.363)$ \\
$r_{t}^{\text {incl. jump }}$ & $-0.787^{* *}$ & $-0.925^{* * *}$ & $-0.977^{* * *}$ & $-1.016^{* * *}$ & $-1.004^{* * *}$ & $-0.976^{* * *}$ \\
& $(-2.419)$ & $(-3.253)$ & $(-3.601)$ & $(-4.004)$ & $(-4.517)$ & $(-4.519)$ \\
\hline Observations & 173,131 & 287,164 & 331,109 & 166,421 & 272,356 & 314,137 \\
Entity FE & Yes & Yes & Yes & Yes & Yes & Yes \\
Time FE & Yes & Yes & Yes & Yes & Yes & Yes \\
SEs & {$[\mathrm{t} ; \mathrm{j}]$} & {$[\mathrm{t} ; \mathrm{j}]$} & {$[\mathrm{t} ; \mathrm{j}]$} & {$[\mathrm{t} ; \mathrm{j}]$} & {$[\mathrm{t} ; \mathrm{j}]$} & {$[\mathrm{t} ; \mathrm{j}]$} \\
Jumps Until & $12: 00$ & $14: 00$ & $15: 00$ & $12: 00$ & $14: 00$ & $15: 00$ \\
Market Cap & Small & Small & Small & Large & Large & Large \\
\hline
\end{tabular}




\section{Table OA6.2: Leveraged ETF Rebalancing After Intraday Jumps - Market Cap Effects}

The table reports the results to regressing intraday jump returns on returns in the subsequent 30-minute interval for large and small stocks in our sample. For leverage ETF rebalancing, we identify jumps in the benchmark of the leverage ETF. To detect jumps, we compare each non-overlapping 30-minute return with returns of the same interval over the last year. If the return is higher (lower) than the $97.5 \%(2.5 \%)$ percentile, we regard the return as a jump. Next, we record the return from yesterday's close until the end of the 30-minute interval, where the jump has occurred ( $\left.r_{t}^{\text {incl. jump }}\right)$. We collect also the return of the subsequent 30-minute interval $\left(r_{t}^{\text {next }}\right)$ on the stock-level. In case of leveraged ETFs, we select all stocks in leveraged ETFs for which a jump in the benchmark index of the leverage ETF has occurred. Finally, we disregard jumps which have occurred after a certain time (given in row "Jumps Until"). Equipped with $r_{t}^{\text {incl. jump }}, r_{t}^{\text {next }}$, and the intraday return of the benchmark index, we reconstruct $\Omega_{t}^{L E T F}$ for each affected stock $j$. Subsequently, we run Equation (12). The sample period is January $2012-$ December 2019.

\begin{tabular}{lcccccc}
\hline & $(1)$ & $(2)$ & $(3)$ & $(4)$ & $(5)$ & $(6)$ \\
Dependent & $r_{t}^{\text {next }}$ & $r_{t}^{\text {next }}$ & $r_{t}^{\text {next }}$ & $r_{t}^{\text {next }}$ & $r_{t}^{\text {next }}$ & $r_{t}^{\text {next }}$ \\
\hline$\Omega_{t}^{\text {LETF }}$ & -0.612 & $-0.707^{* *}$ & $-0.592^{*}$ & -0.304 & -0.430 & -0.502 \\
& $(-1.618)$ & $(-2.075)$ & $(-1.793)$ & $(-0.843)$ & $(-1.198)$ & $(-1.428)$ \\
$r_{t}^{\text {incl. jump }}$ & -0.280 & -0.226 & -0.248 & $-0.772^{* *}$ & $-0.640^{* *}$ & $-0.637^{* *}$ \\
& $(-1.076)$ & $(-1.134)$ & $(-1.366)$ & $(-2.052)$ & $(-2.234)$ & $(-2.446)$ \\
\hline Observations & 232,351 & 337,343 & 376,041 & 267,685 & 378,955 & 419,296 \\
Entity FE & Yes & Yes & Yes & Yes & Yes & Yes \\
Time FE & Yes & Yes & Yes & Yes & Yes & Yes \\
SEs & {$[\mathrm{t} ; \mathrm{j}]$} & {$[\mathrm{t} ; \mathrm{j}]$} & {$[\mathrm{t} ; \mathrm{j}]$} & {$[\mathrm{t} ; \mathrm{j}]$} & {$[\mathrm{t} ; \mathrm{j}]$} & {$[\mathrm{t} ; \mathrm{j}]$} \\
Jumps Until & $12: 00$ & $14: 00$ & $15: 00$ & $12: 00$ & $14: 00$ & $15: 00$ \\
Market Cap & Small & Small & Small & Large & Large & Large \\
\hline
\end{tabular}


Table OA6.3: End-of-day Delta-Hedging on Identified Jump Days - Market Cap Effects The table reports the results to regressing intraday jump returns on returns in the subsequent 30minute interval. For delta-hedging, we identify jumps in the underlying stock returns. For leverage ETF rebalancing, we identify jumps in the benchmark of the leverage ETF. To detect jumps, we compare each non-overlapping 30-minute return with returns of the same interval over the last year. If the return is higher (lower) than the $97.5 \%(2.5 \%)$ percentile, we regard the return as a jump. Next, we record the return from yesterday's close until the end of the 30-minute interval, where the jump has occurred $\left(r_{t}^{\text {incl. jump }}\right)$. We collect also the return of the subsequent 30-minute interval $\left(r_{t}^{\text {next }}\right)$ on the stock-level. In case of leveraged ETFs, we select all stocks in leveraged ETFs for which a jump in the benchmark index of the leverage ETF has occurred. Finally, we disregard jumps which have occurred after a certain time (given in row "Jumps Until"). Equipped with $r_{t}^{\text {incl. jump }}, r_{t}^{\text {next }}$, and the intraday return of the benchmark index, we reconstruct $\Gamma_{t}^{H P}$ and $\Omega_{t}^{L E T F}$ for each affected stock $j$. Subsequently, we run Equation 10 and Equation 12. The sample period is January 2012 - December 2019.

\begin{tabular}{lcccccc}
\hline & $(1)$ & $(2)$ & $(3)$ & $(4)$ & $(5)$ & $(6)$ \\
Dependent & $r_{t}^{\text {end }}$ & $r_{t}^{\text {end }}$ & $r_{t}^{\text {end }}$ & $r_{t}^{\text {end }}$ & $r_{t}^{\text {end }}$ & $r_{t}^{\text {end }}$ \\
\hline$\Gamma_{t}^{H P}$ & $-75.978^{* *}$ & -48.187 & -51.226 & -27.275 & $-38.879^{*}$ & $-42.076^{* *}$ \\
& $(-2.121)$ & $(-1.398)$ & $(-1.498)$ & $(-1.182)$ & $(-1.740)$ & $(-1.985)$ \\
$r^{\text {after jump }}$ & -0.104 & -0.230 & -0.250 & $-1.001^{* * *}$ & $-0.983^{* * *}$ & $-1.015^{* * *}$ \\
& $(-0.440)$ & $(-1.121)$ & $(-1.259)$ & $(-3.748)$ & $(-3.765)$ & $(-3.955)$ \\
\hline Observations & 173,131 & 287,164 & 331,109 & 166,421 & 272,356 & 314,137 \\
Entity FE & Yes & Yes & Yes & Yes & Yes & Yes \\
Time FE & Yes & Yes & Yes & Yes & Yes & Yes \\
SEs & {$[\mathrm{t} ; \mathrm{j}]$} & {$[\mathrm{t} ; \mathrm{j}]$} & {$[\mathrm{t} ; \mathrm{j}]$} & {$[\mathrm{t} ; \mathrm{j}]$} & {$[\mathrm{t} ; \mathrm{j}]$} & {$[\mathrm{t} ; \mathrm{j}]$} \\
Jumps Until & $12: 00$ & $14: 00$ & $15: 00$ & $12: 00$ & $14: 00$ & $15: 00$ \\
Market Cap & Small & Small & Small & Large & Large & Large \\
\hline
\end{tabular}




\section{Appendix OA7. Trading Strategy for Single Data Sets}

Table OA7.1: $\Gamma^{H P}$ and $\Omega^{L E T F}$ Trading Strategies on their respective Data

\section{Samples}

The table reports the economic value of timing the last half-hour market return using either $\Gamma^{H P}$ or $\Omega^{L E T F}$. The $\Gamma^{H P}$-strategy takes a long position in stock $j$ when the stock's $\Gamma_{j}^{H P}$ is in the upper decile and a short position when it is in the lower decile. The $\Omega^{L E T F}$-strategy takes a short position in stock $j$ when the stock's $\Omega_{j}^{L E T F}$ is in the upper decile and a long position when it is in the lower decile. Market ${ }^{\text {end }}$ denotes investing in all stocks from 15:30 to 16:00. We consider equally weighted (EW) and value weighted (VW) portfolios for all strategies, including Market ${ }^{\text {end }}$. For each strategy, we report the average return (Avg ret), standard deviation (Std dev), Sharpe ratio (Sharpe), skewness, kurtosis, and success rate (Success). The returns are annualized and in percentage. Newey and West (1987) robust t-statistics are in parentheses, and significance at the 1\%, $5 \%$, or $10 \%$ level is denoted by $* * *, * *$, or $*$, respectively. The sample periods are 2005-2020 and 2012-2019 for the $\Gamma^{H P}$-strategy and $\Omega^{L E T F_{-}}$-strategy, respectively.

\begin{tabular}{|c|c|c|c|c|c|c|}
\hline & Avg ret & Std dev & Sharpe & Skewness & Kurtosis & Success \\
\hline \multicolumn{7}{|c|}{ Panel A: $\eta\left(\Gamma^{H P}\right)$ (Equally Weighted) } \\
\hline$\eta\left(\Gamma^{H P}\right)$ & $6.23^{* * *}$ & 1.97 & 3.16 & 1.57 & 28.98 & 58.84 \\
\hline Market $^{\text {end }}$ & $2.84^{* *}$ & 6.09 & 0.47 & 0.55 & 24.37 & 53.22 \\
\hline \multicolumn{7}{|c|}{ Panel B: $\eta\left(\Gamma^{H P}\right)$ (Value Weighted) } \\
\hline$\eta\left(\Gamma^{H P}\right)$ & $5.94^{* * *}$ & 2.21 & 2.68 & 0.81 & 19.74 & 59.76 \\
\hline Market $^{\text {end }}$ & 0.45 & 5.89 & 0.08 & 0.32 & 28.75 & 51.29 \\
\hline \multicolumn{7}{|c|}{ Panel C: $\eta\left(\Omega^{L E T F}\right)$ (Equally Weighted) } \\
\hline$\eta\left(\Omega^{L E T F}\right)$ & $18.88^{* * *}$ & 3.23 & 5.85 & -0.14 & 7.69 & 67.72 \\
\hline Market $^{\text {end }}$ & 0.92 & 3.38 & 0.27 & -0.41 & 5.39 & 53.49 \\
\hline \multicolumn{7}{|c|}{ Panel D: $\eta\left(\Omega^{L E T F}\right)$ (Value Weighted) } \\
\hline$\eta\left(\Omega^{L E T F}\right)$ & $11.01^{* * *}$ & 2.72 & 4.05 & -0.18 & 9.81 & 61.15 \\
\hline Market $^{\text {end }}$ & -1.08 & 3.24 & -0.33 & -0.95 & 11.84 & 51.97 \\
\hline
\end{tabular}




\section{Appendix OA8. Risk-adjusted Trading Strategy Re- turns}

\section{Table OA8.1: Risk-adjusted Returns for $\Gamma^{H P}$ and $\Omega^{L E T F}$ Trading Strategies on their respective Data Samples}

The table reports the estimation results from regressing returns of strategies timing the last half-hour based on $\Gamma^{H P}$ and $\Omega^{L E T F}$ on the returns of all stocks from 15:30 to 16:00 (Market ${ }^{\text {end }}$ ), the equity market excess return (MKT), size (SMB), book-to-market (HML), profitability (RMW), investment (CMA), momentum (MOM), and an intermediary capital asset pricing factor (IC, proposed by He et al., 2017). The $\Gamma^{H P}$-strategy, $\eta\left(\Gamma^{H P}\right)$, takes a long (short) position in a stock when the stock's $\Gamma^{H P}$ is in the lowest (highest) decile. The $\Omega^{L E T F}$-strategy, $\eta\left(\Omega^{L E T F}\right)$, takes a long (short) position in a stock when the stock's $\Omega^{L E T F}$ is in the highest (lowest) decile. We consider equally weighted (EW) and value weighted (VW) portfolios. Newey and West (1987) robust t-statistics are in parentheses, and significance at the $1 \%, 5 \%$, or $10 \%$ level is denoted by $* * *$, **, or *, respectively. The sample periods are 2005-2020 and 2012-2019 for the $\Gamma^{H P}$-strategy and $\Omega^{L E T F}$-strategy, respectively.

\begin{tabular}{|c|c|c|c|c|c|c|c|c|c|c|c|}
\hline & Intercept & Market $^{\text {end }}$ & MKT & SMB & HML & RMW & CMA & $\mathrm{MOM}$ & IC & $\mathrm{R} 2$ & $\mathrm{R} 2 \mathrm{adj}$ \\
\hline \multicolumn{12}{|c|}{ Panel A: $\eta\left(\Gamma^{H P}\right)$ (Equally Weighted) } \\
\hline \multirow[t]{2}{*}{$\eta\left(\Gamma^{H P}\right)$} & $\begin{array}{c}6.19 \\
\left(9.54^{* * *}\right)\end{array}$ & $\begin{array}{c}0.01 \\
(1.24)\end{array}$ & & & & & & & & $0.20 \%$ & $0.17 \%$ \\
\hline & $\begin{array}{c}6.30 \\
\left(9.14^{* * *}\right)\end{array}$ & & $\begin{array}{c}0.33 \\
(0.35)\end{array}$ & $\begin{array}{c}-1.40 \\
(-0.86)\end{array}$ & $\begin{array}{c}3.23 \\
(1.18)\end{array}$ & $\begin{array}{c}3.49 \\
\left(1.76^{*}\right)\end{array}$ & $\begin{array}{c}-0.25 \\
(-0.07)\end{array}$ & $\begin{array}{c}1.37 \\
(1.47)\end{array}$ & $\begin{array}{c}0.19 \\
(0.22)\end{array}$ & $0.49 \%$ & $0.29 \%$ \\
\hline \multicolumn{12}{|c|}{ Panel B: $\eta\left(\Gamma^{H P}\right)$ (Value Weighted) } \\
\hline \multirow[t]{2}{*}{$\eta\left(\Gamma^{H P}\right)$} & $\begin{array}{c}5.94 \\
\left(9.18^{* * *}\right)\end{array}$ & $\begin{array}{l}-0.00 \\
(-0.15)\end{array}$ & & & & & & & & $0.01 \%$ & $-0.02 \%$ \\
\hline & $\begin{array}{c}5.91 \\
\left(8.65^{* * *}\right)\end{array}$ & & $\begin{array}{c}1.62 \\
(0.72)\end{array}$ & $\begin{array}{c}-0.42 \\
(-0.21)\end{array}$ & $\begin{array}{c}0.82 \\
(0.30)\end{array}$ & $\begin{array}{c}2.46 \\
(1.14)\end{array}$ & $\begin{array}{c}0.16 \\
(0.04)\end{array}$ & $\begin{array}{c}1.76 \\
\left(1.69^{*}\right)\end{array}$ & $\begin{array}{l}-1.09 \\
(-0.78)\end{array}$ & $0.59 \%$ & $0.39 \%$ \\
\hline \multicolumn{12}{|c|}{ Panel C: $\eta\left(\Omega^{L E T F}\right)$ (Equally Weighted) } \\
\hline \multirow[t]{2}{*}{$\overline{\eta\left(\Omega^{L E T F}\right)}$} & $\begin{array}{c}18.91 \\
\left(11.34^{* * *}\right)\end{array}$ & $\begin{array}{l}-0.03 \\
(-0.66)\end{array}$ & & & & & & & & $0.09 \%$ & $0.04 \%$ \\
\hline & $\begin{array}{c}20.13 \\
\left(11.56^{* * *}\right)\end{array}$ & & $\begin{array}{c}-5.44 \\
\left(-1.87^{*}\right)\end{array}$ & $\begin{array}{c}1.50 \\
(0.41)\end{array}$ & $\begin{array}{c}-0.83 \\
(-0.19)\end{array}$ & $\begin{array}{c}3.56 \\
(0.82)\end{array}$ & $\begin{array}{c}-2.14 \\
(-0.34)\end{array}$ & $\begin{array}{l}-1.25 \\
(-0.63)\end{array}$ & $\begin{array}{c}2.62 \\
(1.19)\end{array}$ & $0.48 \%$ & $0.05 \%$ \\
\hline \multicolumn{12}{|c|}{ Panel D: $\eta\left(\Omega^{L E T F}\right)$ (Value Weighted) } \\
\hline \multirow[t]{2}{*}{$\overline{\eta\left(\Omega^{L E T F}\right)}$} & $\begin{array}{c}11.01 \\
\left(8.17^{* * *}\right)\end{array}$ & $\begin{array}{l}-0.00 \\
(-0.04)\end{array}$ & & & & & & & & $0.00 \%$ & $-0.05 \%$ \\
\hline & $\begin{array}{c}12.34 \\
\left(8.51^{* * *}\right)\end{array}$ & & $\begin{array}{c}-1.92 \\
(-0.79)\end{array}$ & $\begin{array}{c}3.19 \\
(1.11)\end{array}$ & $\begin{array}{l}-0.16 \\
(-0.05)\end{array}$ & $\begin{array}{c}-0.29 \\
(-0.07)\end{array}$ & $\begin{array}{c}0.71 \\
(0.13)\end{array}$ & $\begin{array}{l}-2.43 \\
(-1.38)\end{array}$ & $\begin{array}{c}1.14 \\
(0.60)\end{array}$ & $0.40 \%$ & $-0.02 \%$ \\
\hline
\end{tabular}




\section{References}

He, Z., Kelly, B., Manela, A., 2017. Intermediary asset pricing: New evidence from many asset classes. Journal of Financial Economics 126, 1-35.

Moskowitz, T. J., Ooi, Y. H., Pedersen, L. H., 2012. Time series momentum. Journal of Financial Economics 104, 228 - 250, special Issue on Investor Sentiment. 